\title{
Natural ventilation assessment in typical open an semi-open urban environments under various wind directions
}

Article

Accepted Version

Hang, J., Luo, Z., Sandberg, M. and Jian, G. (2013) Natural ventilation assessment in typical open an semi-open urban environments under various wind directions. Building and Environment, 70. pp. 318-333. ISSN 0360-1323 doi: https://doi.org/10.1016/j.buildenv.2013.09.002 Available at https://centaur.reading.ac.uk/34361/

It is advisable to refer to the publisher's version if you intend to cite from the work. See Guidance on citing.

To link to this article DOI: http://dx.doi.org/10.1016/j.buildenv.2013.09.002

Publisher: Elsevier

All outputs in CentAUR are protected by Intellectual Property Rights law, including copyright law. Copyright and IPR is retained by the creators or other copyright holders. Terms and conditions for use of this material are defined in the End User Agreement.

www.reading.ac.uk/centaur 
Central Archive at the University of Reading

Reading's research outputs online 


\section{Accepted Manuscript}

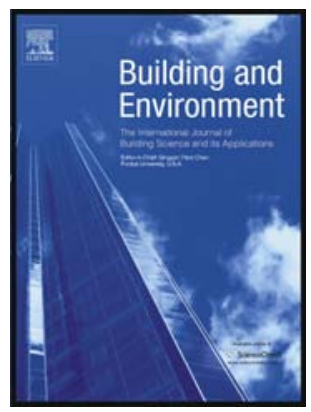

Natural ventilation assessment in typical open and semi-open urban environments under various wind directions

Jian Hang, Zhiwen Luo, Mats Sandberg, Jian Gong

PII: S0360-1323(13)00260-6

DOI: $\quad$ 10.1016/j.buildenv.2013.09.002

Reference: $\quad$ BAE 3509

To appear in: Building and Environment

Received Date: 20 June 2013

Revised Date: 2 September 2013

Accepted Date: 5 September 2013

Please cite this article as: Hang J, Luo Z, Sandberg M, Gong J, Natural ventilation assessment in typical open and semi-open urban environments under various wind directions, Building and Environment (2013), doi: 10.1016/j.buildenv.2013.09.002.

This is a PDF file of an unedited manuscript that has been accepted for publication. As a service to our customers we are providing this early version of the manuscript. The manuscript will undergo copyediting, typesetting, and review of the resulting proof before it is published in its final form. Please note that during the production process errors may be discovered which could affect the content, and all legal disclaimers that apply to the journal pertain. 
$>$ Semi-open street roofs protect pedestrians from strong sunshine and heavy rains. > But they may affect airflows and ventilation in urban canopy layers (UCL).> Age of air \& flow rates are analyzed under wind directions of $0^{\circ}, 15^{\circ}, 30^{\circ}, 45^{\circ}$. $>$ Walls fully or partly covering street roofs at $z=H$ get the worst UCL ventilation. $>$ Semi-open street roofs at $z=1.2 H, 1.1 H$ get good ventilation and are realistic designs. 
$1 \quad$ To be resubmitted to Building and Environment, September 2013

2 Natural ventilation assessment in typical open and semi-open urban

3 environments under various wind directions

4

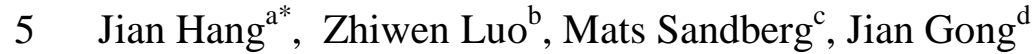

${ }^{a}$ Department of Atmospheric Sciences, School of Environmental Science and Engineering, Sun

8 Yat-Sen University, Guangzhou, Guangdong, P. R. China

$9{ }^{\mathrm{b}}$ School of Construction Management and Engineering, University of Reading, Reading, UK

$10{ }^{\mathrm{c}}$ Laboratory of Ventilation and Air Quality, University of Gävle, SE-80176 Gävle, Sweden

$11{ }^{\mathrm{d}}$ School of Civil Engineering and Architecture, Nanchang Hangkong University, Nanchang,

12 Jiangxi, 330063, P. R. China

14 *Corresponding author. Jian Hang

15 Tel: +86-20-84110375; fax: +86-20-84110375

16 E-mail address: hangj3@mail.sysu.edu.cn

\section{Abstract}

Semi-open street roofs protect pedestrians from intense sunshine and rains. Their effects on natural ventilation of urban canopy layers (UCL) are less understood. This paper investigates two

21 idealized urban models consisting of $4(2 \times 2)$ or $16(4 \times 4)$ buildings under a neutral atmospheric

22 condition with parallel $\left(0^{\circ}\right)$ or non-parallel $\left(15^{\circ}, 30^{\circ}, 45^{\circ}\right)$ approaching wind. The aspect ratio

23 (building height $(H) /$ street width $(W)$ ) is 1 and building width is $B=3 H$. Computational fluid

24 dynamic (CFD) simulations were first validated by experimental data, confirming that standard

$25 k-\varepsilon$ model predicted airflow velocity better than RNG $k-\varepsilon$ model, realizable $k-\varepsilon$ model and

26 Reynolds stress model. Three ventilation indices were numerically analyzed for ventilation assessment, including flow rates across street roofs and openings to show the mechanisms of air exchange, age of air to display how long external air reaches a place after entering UCL, and

29 purging flow rate to quantify the net UCL ventilation capacity induced by mean flows and 30 turbulence. 
Five semi-open roof types are studied: Walls being hung above street roofs (coverage ratio $\lambda_{\mathrm{a}}=100 \%$ ) at $z=1.5 \mathrm{H}, 1.2 \mathrm{H}, 1.1 \mathrm{H}$ ('Hung1.5H', 'Hung1.2H', 'Hung1.1H' types); Walls partly

33 covering street roofs $\left(\lambda_{\mathrm{a}}=80 \%\right)$ at $z=H$ ('Partly-covered' type); Walls fully covering street roofs

$34\left(\lambda_{\mathrm{a}}=100 \%\right)$ at $z=H$ ('Fully-covered' type).They basically obtain worse UCL ventilation than open

35 street roof type due to the decreased roof ventilation. 'Hung1.1H', 'Hung1.2H', 'Hung1.5H' types

36 are better designs than 'Fully-covered' and 'Partly-covered' types. Greater urban size contains

37 larger UCL volume and requires longer time to ventilate. The methodologies and ventilation

38 indices are confirmed effective to quantify UCL ventilation.

Key words: Semi-open street roof; natural ventilation; age of air; purging flow rate; CFD simulations; wind tunnel experiment

\section{Introduction}

pollutant and heat dilution. Good UCL ventilation has been known as one of the possible mitigation solutions to improve urban air environments[1-11], meanwhile ameliorate indoor air quality through building ventilation systems.

Complemented by wind tunnel/field experiments, computational fluid dynamics (CFD) simulations have been widely used to predict turbulent airflow, mass transports and energy budgets within, close to and above different UCLs [2,4-11, 17-26, 28-37], ranging from street canyons, street intersections, cavities and courtyards, up to structured building arrays and realistic urban areas. Good reviews on this topic can be found in the literatures [12-15]. For twodimensional (2D) street canyons [1, 15-19], street aspect ratio (building height/street width, $H / W$ ) is the first key parameter to affect the flow regimes and pollutant dispersion. For threedimensional (3D) urban canopy layers, total street length or urban size $[8,11,30]$, building packing density and frontal area density [8,10,20-23], ambient wind directions [23-24, 32, 37],

58 been widely investigated.

In addition to the widely studied urban models with open street roofs, semi-open street roof

60 is one of popular urban design elements existing in the realistic urban areas to protect pedestrians

61 from strong sunshine and reduce the inconveniences in rainy or snowy days. Such semi-open 
street roofs have been reported and investigated by experiments and CFD simulations in the

63 literatures [5-7], including a large naturally ventilated semi-open market building [5], a semi-

64 open shopping mall being located in Lisbon, Portugal [6], enclosed-arcade (or semi-open)

65 markets of Korea with eleven arcade-type designs (or semi-open street roof) [7]. Although the

66 requirements of design are different according to various climate conditions, sufficient natural

67 UCL ventilation has been considered as an important environment design factor for more healthy

68 semi-open outdoor environments [5-7]. Fig. 1 shows two other kinds of semi-open street roof

69 designs in the suburb of Guangzhou China, which are located in a subtropical region annually

70 characterized by intense solar radiation and precipitation. Fig. 1a shows walls being hung above

71 street roofs of a food court, and Fig. 1b displays walls partially covering street roofs of a retail

72 center. Each shop or restaurant has its own enclosed space with air conditioners inside for

73 cooling in summer (April to September) and with doors connected to the semi-open streets.

74 These semi-open outdoor environments are naturally ventilated to reduce energy consumption.

75 Such semi-open street roof designs are used to provide convenience for pedestrians, but they

76 possibly deteriorate UCL ventilation performance. This paper aims to quantitatively evaluate

77 these effects. Although thermal buoyancy force induced by temperature difference and

78 atmospheric stability also influence urban airflows and UCL ventilation [19, 28-29], this paper

79 takes the first step to consider a neutral atmospheric condition assuming that the ambient wind

80 velocity is sufficiently large and thermal effects are negligible.

81 In building ventilation, as reviewed by Chen [27], indoor ventilation indices have been

82 widely used to evaluate how external air enters a room and ventilates it. In recent years,

83 researchers have started to apply similar concepts to estimate UCL ventilation [2,4-11, 24, 28-32,

84 37], including ventilation flow rate and air change rate per hour $(\mathrm{ACH})$ [4, 6-7, 28-30], pollutant

85 exchange rate [31], pollutant retention time and purging flow rate [2,8,24], age of air and air

86 exchange efficiency [32], city breathability [10-11] etc. This paper emphasizes the quantitative

87 analysis of UCL ventilation induced by rural wind assuming that rural air is relatively clean.

88 Flow rates across street openings and street roofs are first analyzed to quantify the mechanisms

89 of air exchange [37], moreover the local mean age of air [32] is used to quantify how long the

90 external air can reach a place after it enters the UCL. Finally, the UCL purging flow rate $[2,8]$ is

91 also applied to estimate the net UCL ventilation capacity induced by both mean flows and

92 turbulent diffusions. 
Tracer gas techniques $[27,44]$ are usually used to measure indoor ventilation indices.

94 However for both open or semi-open outdoor spaces, ventilation indices such as age of air and

95 purging flow rate are difficult to be measured by tracer gas techniques, since outdoor

96 environment is not an enclosed space with more complicated openings than indoor, moreover

97 perfect mixing and uniform pollutant generation rate in UCLs are difficult to experimentally

98 control. Thus the literatures [5-11, 24, 28-32] usually use experimental data to validate the

99 reliability of CFD methods in predicting concentration and airflow field, then analyze outdoor

100 ventilation indices by using CFD simulations. This paper also utilizes similar methodologies.

\section{Methodologies}

\section{$103 \quad 2.1$ Turbulence modeling in CFD simulations}

Large eddy simulation (LES) models are known to perform better in predicting turbulent flows than the Reynolds-Averaged Navier-Stokes (RANS) approaches, but the applicability of LES models is more problematic due to its much longer computational time required than RANS approaches and some issues regarding the implementation of wall and inlet boundary conditions [33-34]. Considering that RANS turbulence models are more time-saving and provide reasonable results for mean flows and the spatial average flow properties [33], this paper adopted RANS turbulence models for evaluating UCL ventilation.

112 According to the literatures [35-36], the modified $k-\varepsilon$ models, for example RNG $k-\varepsilon$ model, are

113 able to correct the drawback of the standard $k-\varepsilon$ model that severely over-predicts turbulent

114 kinetic energy in separated flows around front corners of buildings, however, they fail to predict

115 the sizes of reattachment lengths behind buildings and under-predict the velocity in weak wind

116 regions. It is desirable to compare different RANS turbulence models in predicting urban

117 airflows and UCL ventilation to provide a sensitivity study, including standard $k-\mathcal{E}$ model, RNG

$118 k-\varepsilon$ model, realizable $k-\varepsilon$ model and Reynolds stress model (RSM).

\subsection{Experimental and CFD set-ups in the validation case}

121 This paper aims to study UCL ventilation in low-rise idealized and typical urban models

122 consisting of two-storey buildings (about $7 \mathrm{~m}$ tall). Wind tunnel data was first used to evaluate

123 the reliability of CFD methodologies. As shown in Fig. 2a, Hang et al. [37] performed some 
124 wind tunnel experiments to investigate the flow in a small-scale urban model with four square

125 building blocks (building height $H=0.069 \mathrm{~m}$, building width $B=3 H$ ) and two crossing streets

126 (street width $W=H$, urban size $L=7 H$ ). The approaching wind was parallel to the main street and

127 perpendicular to the secondary streets. The scale ratio between small-scale and full-scale models

128 is $1: 100$. Thus in full-scale real conditions $H=W \approx 7 \mathrm{~m}, B=3 H \approx 21 \mathrm{~m}, L \approx 49 \mathrm{~m}$. In small-scale

129 models the height of $1.5 \mathrm{~mm}(0.22 H)$ corresponds to the face level $(1.5 \mathrm{~m})$ in full-scale

130 conditions.

131 The measurements were performed in the closed-circuit type wind tunnel at the Laboratory

132 of Ventilation and Air Quality, University of Gävle, Sweden, with the working section of $11 \mathrm{~m}$

133 long, $3 \mathrm{~m}$ wide, $1.5 \mathrm{~m}$ tall. Thus the blockage ratio is about $0.6 \%$, which represents the percentage

134 of the small-scale urban model obstructing the test section area $(3 \mathrm{~m} \times 1.5 \mathrm{~m})$ of the wind tunnel.

135 The stream-wise, lateral and vertical directions are represented by $x, y, z$. Hotwire anemometer

136 was used to measure vertical profiles of velocity $\left(U_{m}(z)\right)$ and turbulence intensity $(I(z))$ in the

137 upstream free flow of wind tunnel (see Fig. 2b), horizontal profiles of velocity $\bar{u}(x)$ and

138 turbulence intensity $I(x)$ along the main street centerline (see Fig. 3b) at $z=0.11 H(7.5 \mathrm{~mm})$. The

139 sampling frequency was $100 \mathrm{~Hz}$. The measurement time was 30s for each point. It is worth

140 mentioning that, the hotwire is only sensitive to velocity components perpendicular to it (i.e. the

141 vertical velocity $\bar{w}$ and the stream-wise velocity $\bar{u}$ ). So data measured by the hotwire were

142 actually $\sqrt{\bar{u}^{2}+\bar{w}^{2}}$. Here the hotwire was only located where the span-wise $(y)$ velocity $\bar{v}$ was

143 zero, including in the upstream free flow and along the main street centerline, so the measured

144 data were actually the velocity magnitude $\left(U=\sqrt{\bar{u}^{2}+\bar{v}^{2}+\bar{w}^{2}}\right)$.

145 Because there were no roughness elements in wind tunnel experiments, a thin neutral

146 atmospheric boundary layer (ABL) and a sharp vertical profile of velocity was produced in the

147 upstream free flow (see Fig. 2b). We only used the measured profiles $\left(U_{m}(z)\right.$ and $\left.I(z)\right)$ in Fig. 2b

148 to provide boundary conditions at domain inlet in the CFD validation case. At domain inlet,

149 turbulent kinetic energy is defined as $k(z)=1.5\left(I U_{m}\right)^{2}$ and its dissipation rate is $\varepsilon(z)=C_{\mu}^{3 / 4} k^{3 / 2} / l$,

150 where $C_{\mu}=0.09$ and $l$ is the turbulent characteristic length scale. Note that, the maximum velocity

151 in the upstream free flow of wind tunnel experiments was $13.33 \mathrm{~m} / \mathrm{s}$, however in cases for

152 ventilation analysis, we used a realistic approaching wind (see Eq. (1a)) with a spatial mean

153 velocity of about $3.2 \mathrm{~m} / \mathrm{s}$, so in the validation case we actually utilized a smaller fitting velocity 
154 profile (maximum velocity is $3.24 \mathrm{~m} / \mathrm{s}$, see Fig. 2b) with the same thickness of ABL as that in 155 wind tunnel and the similar spatial mean velocity (about $3.2 \mathrm{~m} / \mathrm{s}$ ) as that in Eq. (1a). According to

156 Snyder [39], Reynolds-number independence can be satisfied if the Reynolds number is greater

157 than 4000, i.e. the main structure of turbulence can be almost entirely responsible for the bulk

158 transport of momentum and heat or mass transfer. If the velocity $z=H=0.069 \mathrm{~m}$ in the upstream

159 free flow (see Fig. 2b) is defined as the reference velocity $U_{\text {ref }} \approx 2.94 \mathrm{~m} / \mathrm{s}$, the reference Reynolds

160 number $\left(\operatorname{Re}_{H}=\rho U_{\mathrm{ref}} H / \mu \approx 13887\right)$ is much larger than 4000 , Thus the technique of using a smaller

161 inflow velocity (i.e. $3.24 \mathrm{~m} / \mathrm{s}$ ) can ensure Reynolds number independence.

162 The CFD code FLUENT 6.3 [38] was used to solve the steady-state isothermal turbulent

163 flows. For CFD simulations, we used the same small-scale urban geometries $(H=0.069 \mathrm{~m})$ as

164 those in wind tunnel experiments. Only half computational domain was used to reduce the

165 calculation time. Fig. 3a displays the computational domain and boundary conditions in the CFD

166 validation case. The computational domain is $14.5 H$ wide $(1 \mathrm{~m})$ in the lateral $(y)$ direction and

$16711 \mathrm{H}$ tall $(0.75 \mathrm{~m})$ in the vertical $(z)$ direction. Thus the blockage ratio is about $1.9 \%$ (less than

$1683 \%$ ) satisfying the requirement of the literature [40]. No-slip wall boundary condition was

169 utilized at wall surfaces, and zero normal gradient boundary condition was used at domain

170 outlet, domain roof, domain lateral boundary, domain symmetry boundary.

171 Fig. $3 b$ displays the grid arrangements in $x-y$ plane of the validation case. Finer grids are

172 produced within the UCL and near wall surfaces, building corners, street openings. The grid size

173 near the ground is $0.036 H(\mathrm{~d} z=2.5 \mathrm{~mm})$. There are 6 cells vertically from $z=0$ to the pedestrian

174 height $(z=20 \mathrm{~mm}=0.29 H)$. The grid size near building roofs at $z=H$ is $0.022 H(\mathrm{~d} z=1.5 \mathrm{~mm})$. The

175 horizontal grid size ( $\mathrm{d} x$ and $\mathrm{d} y$ ) near building surfaces varies from $0.022 H$ to $0.043 H$. The

176 maximum expansion ratio from building surfaces to the surrounding is 1.15 and the total

177 number of hexahedral cells is about 0.82 million.

178 In the CFD validation case, all CFD set-ups including computational domain size,

179 boundary conditions and grid arrangements fulfilled the major CFD guidelines recommended by

180 Tominaga et al. [40].

\subsection{CFD set-ups for flow modelling}

183 After the CFD validation case, more urban configurations with or without semi-open street 184 roofs and various ambient wind directions were investigated. To better illustrate idealized urban 
185

186

187

188

189

190

191

192

193

194

195

196

197

198

199

200

201

202

203

204

205

206

207

208

209

210

211

212

213

models, all test cases were defined as Case [number of rows-number of columns, wind direction, roof type]. 'Open' roof type denotes open street roofs; As shown in Fig. 4a-4c, four wind directions of $0^{\circ}, 15^{\circ}, 30^{\circ}, 45^{\circ}$ were included. So the name of validation case is Case [2-2, 0 , Open] with four buildings ( 2 rows, 2 columns), a parallel approaching wind $\left(0^{\circ}\right)$ and open street roof ('Open' roof type). As displayed in Fig. 4c, a bigger urban model with 16 buildings (4 columns, 4 rows, urban size $L=15 H \approx 105 \mathrm{~m}$ in full scale) was also investigated in CFD simulations. Besides the 'Open' roof type, Fig. 5 shows the other five types studied in CFD simulations. 'Fully-covered' roof type (see Fig. 5a) means walls entirely covering street roofs with a coverage ratio $\left(\lambda_{\mathrm{a}}\right)$ of $100 \%$ at $z=H$, and 'Partly-covered' roof type (see Fig. 5b) represents street roofs being partly covered $\left(\lambda_{\mathrm{a}}=80 \%\right)$ by walls at $z=H$. Roof types of 'Hung $1.5 \mathrm{H}$ ', 'Hung1.2H' and 'Hung1.1H' (see Fig. 5c) represent walls being hung above street roofs $\left(\lambda_{\mathrm{a}}=100 \%\right)$ at $z=1.5 H, 1.2 H$ and $1.1 H$, respectively. As summarized in Table 1 , total 48 test cases were numerically investigated.

For test cases with a parallel approaching wind $\left(0^{\circ}\right)$, the computational domain and boundary conditions were similar as the CFD validation case. A power-law velocity profile was applied at domain inlet with a power-law exponent of 0.16(see Eq. (1a)). As reported by Lien and Yee [41], it represents a neutral atmospheric boundary layer (ABL) with a depth of $1.8 \mathrm{~m}$ created in the wind tunnel by using spires and floor roughness with a roughness length of approximately $z_{0}=0.001 \mathrm{~m}$. In full-scale real conditions, it corresponds to a neutrally-stratified ABL with a surface roughness of $z_{0}=0.1 \mathrm{~m}$ [42] (i.e. a neutral ABL above open rural area with a regular cover of low crop and occasional large obstacles [43]) The spatial mean velocity at domain inlet calculated from Eq. (1a) approximately equals to that calculated from the inflow velocity profile of the CFD validation case (see Fig. 2b). The inlet profiles of turbulent kinetic energy and its dissipation rate were calculated by Eq. (1b)-(1c)) [30,41].

$$
\bar{u}(z)=U_{0}(z)=U_{H}(z / H)^{0.16}, \bar{v}(z)=\bar{w}(z)=0
$$

$$
k_{0}(z)=u_{*}^{2} / \sqrt{C_{\mu}}
$$

$$
\varepsilon_{0}(z)=C_{\mu}^{3 / 4} k_{0}(z)^{3 / 2} /\left(\kappa_{v} z\right)
$$

where the friction velocity $u_{*}=0.24 \mathrm{~ms}^{-1}, \kappa_{v}=0.41$ is von Karman's constant, $U_{H}=2.66 \mathrm{~ms}^{-1}$ is the reference velocity at $z=H=0.069 \mathrm{~m}$ of domain inlet. 
214 For test cases with a non-parallel approaching wind $\left(15^{\circ}, 30^{\circ}, 45^{\circ}\right)$, there are two domain 215 inlets and two domain outlets(see Fig. 4a). At domain inlets, the power-law velocity profiles

216 (stream-wise velocity $\bar{u}=U_{0}(z) \cos \theta$, span-wise velocity $\bar{v}=U_{0}(z) \sin \theta$ and vertical velocity

$217 \bar{w}(z)=0)$ and profiles of turbulent quantities in Eq. (1b)-(1c) were used to provide boundary

218 conditions. Zero normal gradient conditions were still used at two domain outlets and domain 219 roof.

220 Fig. $6 a$ and $6 b$ show two examples of the grid arrangements in test cases with four $(2 \times 2)$

221 buildings and semi-open street roofs. Note that, the thickness of hung walls to produce semi-

222 open street roofs was zero in CFD models. The grid arrangements were similar with those in the

223 CFD validation case except three points: The first is that the grids near semi-open street roofs

224 (i.e. at $z=1.1 H, 1.2 H, 1.5 H$ ) are also fine with a grid size of $\mathrm{d} z=0.014 H=1 \mathrm{~mm}$ (see Fig. 6b); The

225 second is that for test cases with 16 buildings the maximum expansion ratio of grid size from

226 wall surfaces to the surrounding is 1.2 which is less than 1.3 and satisfies the CFD guideline

227 [40]; The third is that the grid number in cases with ' Partly-covered' roof type (see Fig. 6a) is a

228 little more than the other roof types, because fine grids with grid size of $\mathrm{d} y=0.029 \mathrm{H}$ were also

229 generated near lateral boundaries of partly-covered street roofs. The maximum grid number is

230 about 3.5 million in Case [4-4,45, Partly-covered].

231 All transport equations were discretized by the second order upwind scheme to increase the

232 accuracy and reduce numerical diffusion. The SIMPLE scheme was used for the pressure and

233 velocity coupling. CFD simulations were run until all residuals became constant. Overall,

234 residual for the continuity equation was below $10^{-4}$, residuals for the velocity components and $k$

235 were below $10^{-7}$, residuals for pollutant concentration and $\varepsilon$ were below $0.5 \times 10^{-5}$ and $0.5 \times 10^{-4}$

236 respectively.

$238 \quad 2.4$ Ventilation assessment indices

$239 \quad$ 2.4.1 Age of air

240 The local mean age of air $\left(\tau_{p}\right)$ was originally defined in indoor ventilation and can be

241 measured by tracer gas techniques [44]. The local age of air in UCLs represents the mean time

242 required for the external young air to reach a point since it enters UCLs. If the age of air in rural

243 areas is zero, the greater age of air in UCLs represents a greater probability to be polluted. The 
244 UCL age of air depicts how rural air is supplied and distributed within UCLs. Hang et al. [32]

245 first introduced the homogeneous emission method [44] to numerically predict age of air in UCLs.

247 The governing equations of time-averaged pollutant concentration $\left(\bar{c}, \mathrm{~kg} / \mathrm{m}^{3}\right)$ and the age of 248 air $\left(\tau_{p}, \mathrm{~s}\right)$ are displayed as below:

$\bar{u}_{j} \frac{\partial \tau_{p}}{\partial x_{j}}-\frac{\partial}{\partial x_{k}}\left(K_{c} \frac{\partial \tau_{p}}{\partial x_{k}}\right)=1$

$$
\bar{u}_{j} \frac{\partial \bar{c}}{\partial x_{j}}-\frac{\partial}{\partial x_{j}}\left(K_{c} \frac{\partial \bar{c}}{\partial x_{j}}\right)=S_{c}
$$

where $\bar{u}_{j}$ is the velocity components $(\bar{u}, \bar{v}, \bar{w})$ in the stream-wise $(x)$, span-wise $(y)$ and vertical $(z)$ directions, $K_{c}=v_{t} / S_{c t}$ is the turbulent eddy diffusivity of pollutants, $v_{t}$ is the kinematic eddy viscosity, $S_{c t}$ is the turbulent Schimdt number $\left(S_{c t}=0.7\right)[8,10,20,45] . S_{c}$ is the 254 pollutant source term $\left(\mathrm{kgm}^{-3} \mathrm{~s}^{-1}\right)$.

255 In the homogeneous emission method[44], a relation between these two variables was mathematically derived. If a homogenous pollutant release rate $\left(S_{c}, \mathrm{kgm}^{-3} \mathrm{~s}^{-1}\right)$ is defined in the entire UCL, the age of air $\left(\tau_{p}, \mathrm{~s}\right)$ can be calculated:

$$
\tau_{p}=\bar{c} / S_{c}
$$

Eq. (4) illustrates a relationship that, with a uniform pollutant source in the entire UCL, higher pollutant concentration at a point represents that it takes the external clean air a longer 261 time to arrive.

Fig.6c shows an example of defining uniform pollutant source in the entire UCL. In this paper, the pollutant emission rate was small $\left(S_{c}=10^{-7} \mathrm{~kg} \mathrm{~m}^{-3} \mathrm{~s}^{-1}\right)$ to ensure the source release producing little disturbance to the flow field. The inflow concentration at domain inlet was defined zero, and the zero normal flux condition was used at wall surfaces. At all other boundaries zero normal gradient condition was utilized.

Because the age of air in small-scale urban models is small (scale ratio 1:100), the age of air was normalized in Eq. (5a). To compare the age of air in the entire UCLs, this paper also analyzed the normalized spatial mean age of air $\left(<\tau_{p}{ }^{*}>\right)$ in Eq. (5b)

$$
\tau_{p}^{*}=\tau_{p} \times 100
$$




$$
<\tau_{p}^{*}>=\int_{V o l} \tau_{p}^{*} d x d y d z / V o l
$$

272 where $\mathrm{Vol}$ is the entire UCL volume.

\subsubsection{Ventilation flow rates and UCL purging flow rates}

Both mean flows and turbulent diffusions are significant factors for UCL ventilation [37] and pollutant removal [8]. The purging flow rate represents the net flow rate induced by both mean flows and turbulent diffusions for a volume to be purged out by wind through it. It has been used to quantify the ventilation in UCLs [2] and at the pedestrian levels [8].

This paper mainly emphasizes the purging flow rate for the entire UCL. If a passive contaminant source is generated within the entire UCL (see Fig. 6c) with a uniform emission rate (here $\left.S_{c}=10^{-7} \mathrm{kgm}^{-3} \mathrm{~s}^{-1}\right)$, the UCL purging flow rate $\left(P F R, \mathrm{~m}^{3} / \mathrm{s}\right)$ is calculated in Eq. (6).

$$
P F R=\frac{S_{c} \times V o l}{\langle\bar{c}\rangle}=\frac{S_{c} \times V o l}{\int_{V o l} \bar{c} d x d y d z / V o l}
$$

Here $\langle\bar{c}\rangle$ is the spatially-averaged concentration in the entire UCL volume $(\mathrm{Vol})$. It is worth mentioning that PFR is independent of pollutant sources, and illustrates the net UCL ventilation capacity due to both mean flows and turbulent diffusion.

Because PFR is small for small-scale urban models (scale ratio 1:100), PFR is normalized by the reference flow rate $\left(Q_{\infty}\right)$.

$$
P^{*} R^{*}=\frac{S_{c} \times V o l}{<\bar{c}>Q_{\infty}}=\frac{P F R}{Q_{\infty}}
$$

$$
Q_{\infty}=H \times \int_{0}^{H} U_{0}(z) d z
$$

290 where $Q_{\infty}=0.01093 \mathrm{~m}^{3} / \mathrm{s}$ is the flow rate far upstream through the same area with a windward 291 street opening (area $A=H \times H), U_{0}(z)$ is defined in Eq. (1a).

Fig. 4b-4c show the definition of street openings in test cases with $4(2 \times 2)$ and $16(4 \times 4)$ 293 buildings. To quantify the ventilation pattern, all flow rates entering and leaving UCL volumes 294 were normalized by the reference flow rate $\left(Q_{\infty}\right)$, including $Q^{*}$ due to mean flows (see Eq. (9)) 295 and $Q^{*}$ roof $($ turb) due to turbulence fluctuations across street roofs [37] (see Eq. (10)): 


$$
Q^{*}=\int_{A} \vec{V} \bullet \vec{n} d A / Q_{\infty}
$$

$$
Q^{*}{ }_{\text {roof }}(t u r b)= \pm \int 0.5 \sigma_{w} d A / Q_{\infty}
$$

298 where in Eq.(9), $\vec{V}$ is velocity vector, $\vec{n}$ is the normal direction of street openings or street roofs, $A$ is surface area; In Eq.(10), $\sigma_{w}=\sqrt{\overline{w^{\prime} w^{\prime}}}=\sqrt{2 k / 3}$ is the fluctuation velocity on street roofs based on the approximation of isotropic turbulence ( $k$ is the turbulent kinetic energy).

Due to the flow balance by mean flows, the total flow rate leaving $\operatorname{UCL}\left(Q_{\text {out }}\right)$ through UCL boundaries equals to that entering $\operatorname{UCL}\left(Q_{\text {in }}\right)$. They are named as the total flow rates by mean flows $Q_{T}$ and are normalized by the reference flow rate $Q_{\infty}$.

$$
Q_{T}^{*}=Q_{\text {in }}{ }^{*}=Q_{\text {out }} *
$$

By applying the above concepts, this paper quantifies the effects of semi-open street roofs and various wind directions on the age distribution, the ventilation pattern and the entire UCL ventilation capacity.

\section{Results and discussions}

\subsection{Evaluation and validation of CFD results}

Fig. 7 shows the validation of CFD results by using the measured horizontal profiles of velocity and turbulent intensity along street centerline at $z=0.11 \mathrm{H}$ in Case [2-2.0, Open]. $x / H=0$

314 inflow velocity at domain inlet at the same height $(z=0.11 H)$. In comparison to wind tunnel data,

315 the standard $k-\varepsilon$ model and realizable $k-\varepsilon$ model predicted the velocity profile better than RNG $k$ -

$316 \varepsilon$ model and RSM model. More importantly the standard $k-\varepsilon$ model performed the best in

317 predicting airflow velocity in the downstream region of the main street. This finding agrees with

318 the literature [35-36] that non-standard $k-\varepsilon$ models perform better in predicting separate flows

319 but do worse in predicting airflow velocity in weak wind regions. All RANS turbulence models

320 can only predict the shape of turbulence intensity profile, thus $Q^{*}$ roof $($ turb) calculated by CFD

321 simulations were only used to provide a reference study and the relative values of $Q^{*}$ roof $($ turb)

322 among different test cases were emphasized. Since the better prediction of mean flows within 
$323 \mathrm{UCL}$ and along the streets is more important, this paper hereby regards the standard $k-\mathcal{E}$ model as the default turbulence model in the following CFD simulations.

325 For the validation case (medium grid, 0.8 million), a finer grid arrangement with the minimum grid size of $0.014 \mathrm{H}$ and grid number of 1.3 million was used to perform a grid independence study. As displayed in Fig. 7c, numerical results were not sensitive to the grid refinement, indicating present grid arrangements in Fig. 3b were sufficiently fine.

\subsection{Ventilation assessment in cases with four buildings}

In this subsection, the effects of semi-open street roofs and various wind directions in test cases with four buildings and two crossing streets (i.e. Case [2-2, wind direction, roof type], see

333 Table 1) were investigated.

\subsubsection{Effect of semi-open street roofs in four example test cases}

Fig. 8a displays three-dimensional (3D) streamline in four test cases (only half domain, $0^{\circ}$ ), i.e. Case [2-2, 0, Open], Case [2-2, 0, Hung1.2H], Case [2-2, 0,Partly-covered], Case [2-2, 0,Fully-covered]. Channel flows are found in the main streets parallel to the approaching wind and 3D helical flows exist in the secondary streets. These channel and helical flows produce air exchange and turbulent diffusion through street openings and street roofs. Different semi-open street roofs may produce various flow pattern and ventilation capacity but this effect cannot be

342 clearly displayed by only 3D streamlines in Fig. 8a. To quantify this effect, Fig. 8b shows the normalized age of air $\left(\tau_{p}{ }^{*}=\tau_{p} \times 100\right)$ in $z=0.22 H$ (i.e. $1.5 \mathrm{~m}$ in full scale) and normalized flow

344 rates $\left(Q^{*}\right)$ in these four test cases. Positive values denote air entering UCLs and negative ones

345 represent air leaving UCLs. $\tau_{p} *$ along the main street (Street 1 and Street 3 ) is relatively small

346 (i.e. air is relatively young) because $Q^{*}$ through $\mathrm{O} 1$ and $\mathrm{O} 3$ are always large $\left(Q^{*}(\mathrm{O} 1)=1.048\right.$ to

$3470.848 ; Q^{*}(\mathrm{O} 3)=-0.551$ to -0.813$)$. In the secondary streets (Street 2 and Street 4$), Q^{*}$ through O2

348 (O4) are small (only 0.086 to -0.019). Thus the roof ventilations are more significant to the

349 secondary streets. For example, in Case [2-2, 0, Open], $\tau_{p} *$ in Street 2 (or Street 4) is similar

350 with that in Street 3 because the flow rates across street roofs are comparable to those across O1

351 and $\mathrm{O} 3$, including the upward and downward flow rates due to mean flows $\left(Q^{*}\right.$ roof $($ out $)=-0.825$

352 and $Q^{*}$ roof (in) $=0.148$ ), and the effective flow rate induced by turbulence fluctuations 
$353\left(Q^{*}\right.$ roof $($ turb $\left.)=1.211\right)$. For types of 'Hung $1.2 \mathrm{H}^{\prime}$ and 'Partly-covered', roof ventilation capacity 354 significantly decreases, including $Q^{*}$ roof $($ out $)=-0.825$ to -0.424 and $-0.306, Q^{*}$ roof $($ in $)=0.148$ to

3550.116 and $0.008, Q^{*}$ roof $($ turb $)=1.211$ to 1.059 and 0.258 . Moreover $Q^{*}$ across $\mathrm{O} 1$ decreases a little 356 (1.048 to 0.999 and 0.950 ) due to the displacement by semi-open street roofs, and $Q^{*}$ across O3 357 increases a little (-0.551 to -0.684 and -0.685$)$. These results show that semi-open street roofs not 358 only pose additional flow resistances and therefore reduce the ventilation by vertical mean flows 359 and turbulence across street roofs, but also influence the inflow rates and redistribution of 360 airflows along the streets within UCL, especially driving more air across Street 3 (O3). Thus in contrast to Case [2-2, 0, Open], models with semi-open street roofs obtain much greater $\tau_{p} *$ and older air in the secondary streets due to the weakened roof ventilation. An extreme example is 363 'Fully-covered' type, in which the flow rates across street roofs are zero, and $\tau_{p} *$ in the secondary street (125 to 225 ) is much greater than that in the main street (0-45). The UCL spatial mean age of air $\left\langle\tau_{p}^{*}>\right.$ with 'Open' and 'Hung1.2H' types are 24.3 and 37.7, which is much smaller than $\left\langle\tau_{p}{ }^{*}\right\rangle$ with 'Partly-covered' and 'Fully-covered' types (54.9 and 90.4), confirming that the 'Hung1.2H' type provide better overall UCL ventilation than 'Partly-covered' and 'Fullycovered' types.

\subsubsection{Effect of ambient wind directions in four example test cases}

Fig. 9 displays 3D streamline, $\tau_{p} *$ and $Q^{*}$ in Case [2-2, 0, Hung1.5H], Case [2-2, 15,

372 Hung 1.5H], Case [2-2, 30, Hung1.5H] and Case [2-2, 45, Hung1.5H]. The flow patterns are 373 obviously different and flow rates are redistributed. With a parallel approaching wind, air enters 374 UCL through O1, O2 and O4, then leaves through O3. Moreover 3D helical flows mainly exist 375 in Street 2 and Street 4 where air is relatively old. With non-parallel approaching wind, air enters 376 UCLs across $\mathrm{O} 1$ and $\mathrm{O} 2$, then leaves through $\mathrm{O} 3$ and $\mathrm{O} 4$; Recirculation flows exist in all four 377 streets and $\tau_{p} *$ is relatively large in the downstream streets (Street 3 and Street 4) and in 378 recirculation regions. If wind directions change from $0^{\circ}$ to $15^{\circ}, 30^{\circ}, 45^{\circ}$, both roof ventilation and 379 overall UCL ventilation are improved including $Q^{*}$ roof (out) varies from $-0.547\left(0^{\circ}\right)$ to $-0.939\left(15^{\circ}\right)$, $380-0.919\left(30^{\circ}\right)$ and $-0.730\left(45^{\circ}\right), Q^{*}$ roof $($ in $)$ changes from $0.106\left(0^{\circ}\right)$ to $0.586\left(15^{\circ}\right), 1.092\left(30^{\circ}\right)$ and $\left.3811.041\left(45^{\circ}\right)\right)$, and $\left\langle\tau_{p}{ }^{*}\right\rangle$ decreases from $29.6\left(0^{\circ}\right)$ to $22.6\left(15^{\circ}\right), 18.9\left(30^{\circ}\right)$ and $18.5\left(45^{\circ}\right)$.

382 These results confirm that $30^{\circ}$ and $45^{\circ}$ produce better $\mathrm{UCL}$ ventilation than $0^{\circ}$ and $15^{\circ}$. 
As discussed and reported by the literature [2, 8-11, 18-20, 24, 31-32, 45],turbulent Schimdt numbers $\left(S_{c t}\right)$ may influence numerical results of pollutant dispersion. As displayed in Table 2, the effects of different $S_{c t}$ and turbulence models are studied in Case [2-2, 0, Open] to quantify the sensitivity of turbulence models and $S_{c t}$ on UCL ventilation: $S_{c t}=1.0,0.7$ and 0.4 are used in standard $k$ - $\varepsilon$ model, $S_{c l}=0.7$ in RNG $k-\varepsilon$ model, and $S_{c t}=0.7$ in Realizable $k-\varepsilon$ model. With the same standard $k-\mathcal{E}$ model and $S_{c t}$ of $1.0,0.7$ or $0.4,\left\langle\tau_{p}{ }^{*}>\right.$ in the entire UCL are 26.4, 24.3 and 21.2, respectively, showing that smaller $S_{c t}$ may enhance pollutant dispersion by turbulent diffusion and slightly reduce the age of air. With the same $S_{c t}$ of 0.7 , realizable $k-\varepsilon$ model and RNG $k-\varepsilon$ model obtain different flow rates through $\mathrm{O} 3$ and street roofs which result in a little greater $\left\langle\tau_{p}{ }^{*}\right\rangle$ (27.2 and 28.2) than that by standard $k$ - $\varepsilon$ model (24.3). Especially $Q^{*}$ across O3 explained by the fact that RNG $k-\varepsilon$ model significantly over-predicts $Q^{*}$ roof (out) $(-1.127)$ than the other two (-0.825 and -0.844). To be consistent, standard $k-\varepsilon$ model with $S_{c t}$ of 0.7 was selected as the default settings in CFD simulations.

\subsubsection{Overall ventilation assessment in cases with four $(2 \times 2)$ buildings}

To quantify the effect of semi-open street roofs on UCL ventilation flow rates, Fig. 10 shows $Q^{*}$ through $\mathrm{O} 1-\mathrm{O} 4$ and $Q^{*}$ roof (out), $Q^{*}$ roof (in), $Q^{*}$ roof (turb) in all test cases with 4 buildings and wind directions of $0^{\circ}$ to $45^{\circ}$. Roof types change from 'Open', 'Hung 1.5H', 'Hung1.2H', 402 'Hung1.1H', to 'Partly-covered' and 'Fully-covered' (reading figure from left to right). Roof 403 ventilations for 'Fully-covered' type are all zero. For wind directions of $0^{\circ}$ and $15^{\circ}$ (see Fig.10a404 10b), roof type variations result in a slightly decreasing flow rates across $\mathrm{O} 1$ and an increasing 405 flow rates across O3. More importantly, the flow rates across street roofs are all significantly 406 weakened, including $Q^{*}$ roof (out) from $-0.825\left(0^{\circ}\right)$ and $-1.156\left(15^{\circ}\right)$ to $0, Q^{*}$ roof (in) from $0.148\left(0^{\circ}\right)$ 407 and $0.619\left(15^{\circ}\right)$ to 0 , and $Q^{*}$ roof (turb) from $1.211\left(0^{\circ}\right)$ and $1.315\left(15^{\circ}\right)$ to 0 . Moreover, $Q^{*}$ across $408 \mathrm{O} 2$ and $\mathrm{O} 4$ are relatively small for wind direction of $0^{\circ}$ (see Fig. 10a), but they become 409 considerably large for wind direction of $15^{\circ}$ (see Fig. 10b). For wind directions of $30^{\circ}$ and $45^{\circ}$ 410 (see Fig.10c-10d), similar findings exist due to such roof type variations that all roof ventilation 411 indices decrease quickly and $Q^{*}$ across street openings decrease a little. 
To quantify the reduction of UCL ventilation as roof types varying from 'Open' type to

413 'Fully-covered' type, the normalized ventilation ratio $(N V R)$ is defined as the value of ventilation 414 indices in a case divided by those with 'open street roofs' and the same wind direction. Thus for 415 cases with open street roofs, $N V R=1$, and $Q^{*}$ across street roofs for 'Fully-covered' roof type are 416 all zero $(N V R=0)$. Fig. 11displays $Q^{*}$ roof (in) and $Q^{*}$ roof (out), $Q^{*}$ roof (turb), total normalized flow 417 rates by mean flows $\left(Q_{T}^{*}\right)$, normalized UCL purging flow rate $\left(P F R^{*}\right),\left\langle\tau_{p}{ }^{*}\right\rangle$ in the entire

$418 \mathrm{UCL}$, and their NVR values for all 24 cases with 4 buildings. With the same roof type, wind 419 direction of $30^{\circ}$ and $45^{\circ}$ obtain greater $Q^{*}$ roof (in) and $Q^{*}$ roof (turb), larger $Q_{T}^{*}$ and $P F R^{*}$, smaller $420<\tau_{p}^{*}>$, showing that $30^{\circ}$ and $45^{\circ}$ produce better UCL ventilation than $0^{\circ}$ and $15^{\circ}$. In addition,

421 Fig.11a-11b also confirm that, all roof ventilation indices decrease as roof type varies from 422 'Open' to 'Partly-covered', and NVR for 'Partly-covered' type are as small as 5.6\% to 34\% for $423 Q_{\text {roof }}$ (in), $18.0 \%-37.1 \%$ for $Q^{*}$ roof (out), and $21.3 \%-22.6 \%$ for $Q^{*}$ roof (turb) respectively. Fig. 424 11c-11d displays that overall UCL ventilation basically decreases from 'Open' type to 'Fully425 covered' type, indicated by the fact as below: the $N V R$ of $Q_{T}^{*}$ are $87 \%-99 \%$ for 'Hung $1.5 \mathrm{H}$ ' type, $42681 \%-92 \%$ for 'Hung1.2H' type, 67\%-78\% for 'Hung1.1H' type, 57\%-72\% for 'Partly-covered' 427 type and 41\%-62\% for 'Fully-covered' type; the NVR of PFR* are from 82\%-110\%, 64\%-110\%, $42852 \%-104 \%$ to $44 \%-87 \%$ and $27 \%-64 \%$, and the $N V R$ of $<\tau_{p}{ }^{*}>$ are from $90 \%-122 \%, 91 \%-$ $429155 \%, 96 \%-190 \%$ to $115 \%-226 \%$ and 156-373\%. Overall, Fig. 11d-11e confirm that roof types 430 of 'Hung1.5H', 'Hung1.2H' and 'Hung 1.1H' may produce relatively considerable UCL ventilation 431 in contrast to 'Open' type (i.e. $N V R$ are $52 \%-110 \%$ for $P F R^{*}$ and $91 \%-190 \%$ for $<\tau_{p}^{*}>$ ).

432 Considering 'Hung1.1H' and 'Hung1.2H' types are more realistic, they are proposed as better 433 semi-open street roof configurations. Meanwhile, Fig. 11d-11e also verify that, if roof types 434 change from 'Open" to 'Fully-covered', overall UCL ventilation with $0^{\circ}$ wind direction may 435 decrease much more significantly (NVR are $100 \%$ to $27 \%$ for $P F R^{*}$, and $100 \%$ to $372 \%$ for $436<\tau_{p}{ }^{*}>$ ) than the other wind directions, because the secondary streets with $0^{\circ}$ wind direction and 437 semi-open street roofs tend to be poorly ventilated.

\subsection{Ventilation assessment in test cases with sixteen buildings}

What happen if urban size enlarges? To quantify this effect, test cases with 16 buildings are 441 investigated, as summarized in Table 1. Fig. 12 displays normalized age of air in four test cases, 
442 i.e. Case [4-4, 0, Hung1.2H], Case [4-4, 15, Hung1.2H], Case [4-4, 30, Hung1.2H], Case [4-4, 45, 443 Hung $1.2 \mathrm{H}]$. The ventilation patterns are similar with those consisting of 4 buildings. For wind 444 direction of $0^{\circ}$, air mainly enters UCL across windward street openings of O1a, O1b, O1c, and 445 leaves UCL through leeward openings of O3a, O3b, O3c. For wind directions of $15^{\circ}, 30^{\circ}$, and $44645^{\circ}$, air enters UCL through O1a to O1c and O2a to O2c, then leaves UCL across O2a to O2c 447 and $\mathrm{O} 4 \mathrm{a}$ to $\mathrm{O} 4 \mathrm{c}$. Age of air is relatively large and air is old in recirculation regions and 448 downstream regions.

449 UCL ventilation indices and their normalized ventilation ratios $(N V R)$ in all 24 test cases 450 with 16 buildings are quantitatively analyzed, including $Q^{*}$ roof (in) and $Q^{*}$ roof (out) in Fig. 13a, $451 Q^{*}$ roof (turb) in Fig. 13b, $Q_{T}{ }^{*}$ in Fig. 13c, $P F R^{*}$ in Fig. 13d and $\left\langle\tau_{p}^{*}>\right.$ in the entire UCL in Fig.

452 13e. It is found that UCL ventilation indices basically become a little better if wind directions 453 change from $0^{\circ}$ and $15^{\circ}$ to $30^{\circ}$ and $45^{\circ}$. More importantly, roof type variations from 'Open' to 454 'Fully-covered' produce a large decreasing rate of overall UCL ventilation and obtain 455 macroscopically older air, which can be represented by the below data. For roof ventilation 456 indices(see Fig. 13a-13b), NVR for 'Fully-covered' type are all zero, and those for 'Partly457 covered' type are $11 \%-23 \%$ for $Q^{*}$ roof (in), $28 \%-39 \%$ for $Q^{*}$ roof (out), and $16 \%-22 \%$ for $Q^{*}$ roof 458 (turb). For overall UCL ventilation, $N V R$ of $Q_{T}{ }^{*}$ (see Fig. 13c) are $81 \%-96 \%$ for 'Hung1.5H' type, $45978 \%-87 \%$ for 'Hung1.2H' type, 65\%-86\% for 'Hung1.1H' type, 52\%-61\% for 'Partly-covered' 460 type and 28\%-50\% for 'Fully-covered' type, and $N V R$ of $P F R^{*}$ (see Fig. 13d) for the above roof 461 types are 84\%-90\%, 76\%-87\%, 65\%-86\%,52\%-68\%, and 36\%-45\% respectively, moreover NVR 462 of $\left\langle\tau_{p}{ }^{*}\right\rangle$ increase from $111 \%-120 \%, 115 \%-131 \%, 116 \%-154 \%$ to $148 \%-192 \%, 223 \%-279 \%$

463 (i.e. air becomes older). Results also confirm that, 'Hung1.5H', 'Hung1.2H' and 'Hung1.1H' types 464 produce a little smaller but comparable UCL ventilation in contrast to 'Open' type. Thus for cases 465 with 16 buildings, the roof types of 'Hung $1.2 \mathrm{H}$ ' and 'Hung1.1H' are better choices considering 466 they are more realistic designs.

\subsection{Effect of urban size on UCL ventilation}

To quantify how overall UCL ventilations change if building number or urban size increases, Fig. 13b-13e also compares $Q^{*}$ roof (turb), $Q_{T}^{*}, P F R^{*}$ and $\left\langle\tau_{p}{ }^{*}>\right.$ between urban 
472 (turb), $Q_{T}{ }^{*}$ and $P F R^{*}$ in the bigger model are found several times (about 3.2-4.7 for $Q^{*}$ roof, $1.2-$

4732.6 for $Q_{T^{*}}, 0.8-3.5$ for $P F R^{*}$ ) larger than those in the smaller model. Larger urban model

474 obtains greater ventilation capacity because their total area of street openings and street roofs are

4752 and 5.2 times greater than the smaller one. However it does not represent larger urban model

476 can produces better overall UCL ventilation. It can be confirmed by Fig. 13e that $\left\langle\tau_{p} *\right\rangle$ in the

477 bigger model is about 1.4 to 3.5 times as great as that in the smaller model, showing that the

478 bigger model obtains macroscopically older air. It is because the bigger model has a UCL

479 volume of 5.2 times larger than that in the smaller model and requires longer time for wind to

480 flow through.

\subsection{Discussions and Future outlooks}

Further investigations are still required before formulating a practical guidelines for these semi-open street roof designs, such as the effect of the surrounding building height, the effect of atmospheric thermal stratification (not neutral) and buoyancy force due to solar shading, the analysis of rain-cover and shading capability etc. This paper is one of the first attempts to quantify and address a relationship between semi-open street roof configurations and UCL ventilation indices. The methodologies and techniques utilized in this paper are promising, and possibly provide a valid tool to investigate UCL ventilation in other types of idealized or realistic urban configurations.

\section{Conclusions}

The arrangements of semi-open street roofs in urban space are effective to protect

494 pedestrians from strong sunshine and heavy rains or snows. Their effects on urban canopy layer

495 (UCL) ventilation are still not fully understood. This paper numerically quantified how five types

496 of semi-open street roofs influence isothermal turbulent airflows and UCL ventilation

497 performance under a neutral atmospheric condition with various ambient wind directions $\left(0^{\circ}, 15^{\circ}\right.$,

$\left.49830^{\circ}, 45^{\circ}\right)$. Two small-scale idealized urban models were investigated consisting of $4(2 \times 2)$ or 16

499 (4×4) buildings with uniform building height of $H=0.069 \mathrm{~m}$, and street aspect ratio of $H / W=1$,

500 corresponding to full-scale urban models of about $7 \mathrm{~m}$ tall, $49 \mathrm{~m}$ and $105 \mathrm{~m}$ long as the scale ratio

501 is 1:100. In contrast to 'Open' roof type (open street roof), five kinds of semi-open street roofs

502 were included: Walls are hung above open street roofs (coverage ratio $\lambda_{\mathrm{a}}=100 \%$ ) at $z=1.1 \mathrm{H}, 1.2 \mathrm{H}$, 
$1.5 H$, i.e. types of 'Hung1.1H', 'Hung $1.2 \mathrm{H}$ ', 'Hung1.5H'; Walls partly cover street roofs at $z=H$

$504\left(\lambda_{\mathrm{a}}=80 \%\right)$, i.e. 'Partly-covered' type; Walls are set up to cover the entire street roof at $z=H$

$505\left(\lambda_{\mathrm{a}}=100 \%\right)$, i.e. 'Fully-covered' type. The age of air and its spatial mean value, flow rates across

506 street openings and street roofs, the UCL purging flow rate were numerically analyzed to

507 quantify UCL ventilation.

$508 \quad$ Results show that the prediction of airflow velocity by using standard $k$ - $\varepsilon$ model agreed

509 better with wind tunnel data than other three RANS turbulence models. Semi-open street roofs

510 significantly influence UCL ventilation patterns and redistribute flow rates across street openings

511 and street roofs. As roof types vary from 'Open' to 'Hung1.5H', 'Hung1.2H', 'Hung1.1H' then to

512 'Partly-covered' and 'Fully-covered', both roof ventilation and overall UCL ventilation

513 performance are basically weakened. The net UCL ventilation is the worst for the 'Fully-covered'

514 type, followed by the 'Partly-covered' type. The roof types of 'Hung 1.2H' and 'Hung $1.1 \mathrm{H}$ ' are

515 proposed because they produce comparable UCL ventilation, meanwhile are more realistic roof

516 designs. Oblique ambient wind directions of $30^{\circ}$ and $45^{\circ}$ obtain better UCL ventilation than $15^{\circ}$

517 and $0^{\circ}$. If the building number increases from $4(2 \times 2)$ to $16(4 \times 4)$, air in the entire UCL becomes

518 macroscopically older because the greater UCL volume requires longer time for rural wind to

519 flow through.

\section{Acknowledgements}

522 This study was financially supported by the National Natural Science Foundation of China 523 (No. 51108102) and Guangdong Natural Science Foundation (Code S2011040004149). The two 524 anonymous reviewers who provided constructive suggestions and comments are also gratefully 525 acknowledged.

\section{Nomenclature}

$528 \quad A \quad$ area of a surface $\left(\mathrm{m}^{2}\right)$

$529 \quad B, H, L, W \quad$ building width, building height, total length, street width

$530 \bar{c},\langle\bar{c}\rangle \quad$ time-averaged pollutant concentration $\left(\mathrm{kgm}^{-3}\right)$ and its spatial mean value

$531 \quad K_{c}, v_{t} \quad$ turbulent eddy diffusivity of pollutant and momentum $K_{c}=v_{t} / S_{c t}$

$532 k, \varepsilon \quad$ turbulent kinetic energy and its dissipation rate 
$533 \vec{n} \quad$ normal direction of street openings or canopy roofs

$534 \quad$ NVR normalized ventilation ratio in contrast to models with 'open' street roofs

$535 P F R, P F R^{*} \quad$ purging flow rate and its normalized value $\left(P F R^{*}=P F R / Q_{\infty}\right)$

$536 \quad Q^{*} \quad$ normalized flow rate through street openings or street roofs

$537 Q_{\text {in }} *, Q_{\text {out }} *$ normalized total inflow and outflow rate for entire UCL

$538 Q_{T}^{*} \quad$ total ventilation flow rate by mean flows $\left(\mathrm{m}^{3} \mathrm{~s}^{-1}\right)$

$539 Q_{\infty} \quad$ reference flow rate in upstream free flow to normalize flow rates

$540 Q^{*}$ roof (turb) normalized effective flow rate across street roofs by turbulence

$541 Q_{\text {roof }}^{*}$ (in) normalized inflow rate across street roofs by downward flows

$542 Q_{\text {roof }}^{*}$ (out) normalized outflow rate across street roofs by upward outflows

$543 \quad S_{c} \quad$ pollutant release rate

$544 S_{c t} \quad$ turbulent Schmidt number

$545 \sigma_{w} \quad$ fluctuation velocity on street roofs

$546 \tau_{p}, \tau_{p}^{*} \quad$ age of air (s) and its normalized value

$547<\tau_{p}^{*}>\quad$ normalized spatial mean age of air

$548 U_{\mathrm{m}}, I_{\mathrm{m}} \quad$ velocity, turbulence intensity measured in upstream free flow

$549 \quad U_{0}(z) \quad$ velocity profiles used at CFD domain inlet for ventilation cases

$550 \quad U_{H} \quad$ reference velocity $(2.66 \mathrm{~m} / \mathrm{s})$ at $z=H$

$551 \quad \bar{u}_{j}, x_{j} \quad$ velocity and coordinate components

$552 \vec{V} \quad$ velocity vector

$553 \mathrm{Vol} \quad$ control volume

$554 x, y, z \quad$ stream-wise, span-wise, vertical directions

\section{References}

557 [1] Oke TR. Street design and urban canopy layer climate. Energ Build 1988; 11(1-3): 103-113.

558 [2] Bady M, Kato S, Huang H. Towards the application of indoor ventilation efficiency indices

559 to evaluate the air quality of urban areas. Build Environ 2008; 43(12): 1991-2004. 
560 [3] Deng Q, He G, Lu C, Liu W. Urban ventilation - a new concept and lumped model. Int J 561 Vent 2012; 11: 131-140.

562 [4] Yang, XY, Li YG, Yang LN. Predicting and understanding temporal 3D exterior surface 563 temperature distribution in an ideal courtyard. Build Environ 2012; 57:38-48.

564 [5] Kato S, Murakami S, Takahashi T, Gyobu T. Chained analysis of wind tunnel test and CFD on cross ventilation of large-scale market building. J Wind Eng Ind Aerodyn 1997; 67566 68: 573-587.

567 [6] da Graça GC, Martins NR, Horta CS. Thermal and airflow simulation of a naturally 568 ventilated shopping mall. Energ Build 2012; 50: 177-188.

569 [7] Kim T, Kim K, Kim BS. A wind tunnel experiment and CFD analysis on airflow 570 performance of enclosed-arcade markets in Korea. Build Environ 2010; 45: 1329-1338.

571 [8] Hang J, Li Y, Sandberg M, Buccolieri R, Di Sabatino S. The influence of building height 572 variability on pollutant dispersion and pedestrian ventilation in idealized high-rise urban areas. 573 Build Environ 2012; 56: 346-360.

574 [9] Hu T, Yoshie R. Indices to evaluate ventilation efficiency in newly-built urban area at 575 pedestrian level. J Wind Eng Ind Aerodyn 2013; 112: 39-51.

576 [10]Buccolieri R, Sandberg M, Di Sabatino S. City breathability and its link to pollutant 577 concentration distribution within urban-like geometries. Atmos Environ 2010; 44(15): 18945781903.

579 [11]Hang J, Li Y, Buccolieri R, Sandberg M, Di Sabatino S. On the contribution of mean flow 580 and turbulence to city breathability: the case of long streets with tall buildings. Sci Total Environ 581 2012; 416: 363-373.

582 [12]Britter RE, Hanna SR. Flow and dispersion in urban areas. Annu Rev Fluid Mech 2003; 583 35:469-496.

584 [13] Arnfield AJ. Two decades of urban climate research: a review of turbulence, exchanges of 585 energy and water, and the urban heat island. Int J Climato 2003; 23:1-26.

586 [14] Grimmond CSB, Blackett M, Best MJ, Barlow J, Baik JJ, Belcher SE et al. The 587 International Urban Energy Balance Models Comparison Project: First Results from Phase 1. J 588 Appl Meteorol Clim 2010; 49: 1268-1292.

589 [15] Li XX, Liu CH, Leung DYC, Lam KM. Recent progress in CFD modelling of wind field 590 and pollutant transport in street canyons. Atmos Environ 2006; 40(29): 5640-5658. 
591 [16] Meroney RN, Pavegeau M, Rafailidis S, Schatzmann M. Study of line source characteristics 592 for 2-D physical modelling of pollutant dispersion in street canyons. J Wind Eng Ind Aerodyn 593 1996; 62(1):37-56.

594 [17] Li XX, Liu CH, Leung DYC. Numerical investigation of pollutant transport characteristics 595 inside deep urban street canyons. Atmos Environ 2009; 43(15): 2410-2418.

596 [18] Salim SM, Cheah SC, Chan A. Numerical simulation of dispersion in urban street canyons 597 with avenue-like tree plantings: Comparison between RANS and LES. Build Environ 2011; 598 46(9): 1735-1746.

599 [19] Cai XM. Effects of differential wall heating in street canyons on dispersion and ventilation 600 characteristics of a passive scalar. Atmos Environ 2012; 51: 268-277.

601 [20] Di Sabatino S, Buccolieri R, Pulvirenti B, Bitter R. Simulations of pollutant dispersion 602 within idealised urban-type geometries with CFD and integral models. Atmos Environ 2007; 603 41(37):8316-8329.

604 [21] Kanda M. Large-eddy simulations on the effects of surface geometry of building arrays on 605 turbulent organized structures. Boundary-layer meteorol 2006; 18(1): 151-168.

606 [22] Zaki SA, Hagishima A, Tanimoto J, Ikegaya N. Aerodynamic Parameters of Urban 607 Building Arrays with Random Geometries. Boundary-Layer Meteorol 2011; 138:99-120. 608 [23] Abd Razak A, Hagishima A, Ikegaya N, Tanimoto J. Analysis of airflow over building 609 arrays for assessment of urban wind environment. Build Environ 2013; 59:56-65.

610 [24] Yim SHL, Fung JCH, Lau AKH, Kot SC. Air ventilation impacts of the "wall effect" 611 resulting from the alignment of high-rise buildings. Atmos Environ 2009; 43(32): 4982-4994.

612 [25] Hagishima A, Tanimoto J, Nagayama K, Meno S. Aerodynamic parameters of regular 613 arrays of rectangular blocks with various geometries. Boundary-Layer Meteorol 2009; 614 132(2):315-337.

615 [26] Gu ZL, Zhang YW, Cheng Y, Lee SC. Effect of uneven building layout on air flow and 616 pollutant dispersion in non-uniform street canyons. Build Environ 2011; 46(12): 2657-2665.

617 [27] Chen Q. Ventilation performance prediction for buildings: a method overview and recent 618 applications. Build Environ 2009; 44:848-858.

619 [28] Luo ZW, Li YG. Passive urban ventilation by combined buoyancy-driven slope flow and 620 wall flow: Parametric CFD studies on idealized city models. Atmos Environ 2011; 45(32):59466215956. 
622 [29] Yang LN, Li YG. Thermal conditions and ventilation in an ideal city model of Hong Kong.

623 Energ Buildings 2011; 43(5): 1139-1148.

624 [30]Hang J, Li YG. Wind conditions in idealized building clusters--macroscopic simulations by a 625 porous turbulence model. Boundary-Layer Meteorol 2010; 136(1): 129-159.

626 [31]Liu CH, Cheng WC, Leung TCY, Leung DYC. On the mechanism of air pollutant re-

627 entrainment in two-dimensional idealized street canyons. Atmos Environ 2011; 45(27) : 47636284769.

629 [32] Hang J, Sandberg M, Li YG. Age of air and air exchange efficiency in idealized city models. 630 Build Environ 2009; 44(8):1714-1723.

631 [33]Santiago JL, Dejoan A, Martilli A, Martin F, Pinelli A. Comparison between Large-Eddy

632 Simulation and Reynolds-Averaged Navier-Stokes computations for the MUST field

633 experiment. Part I: study of the flow for an incident wind directed perpendicularly to the front

634 array of containers. Boundary-Layer Meteorol 135; 2010:109-132.

635 [34] Salim SM, Buccolieri R, Chan A, Di Sabatino S. Numerical simulation of atmospheric

636 pollutant dispersion in an urban street canyon: Comparison between RANS and LES. J Wind

637 Eng Ind Aerodyn 2011; 99(2-3): 103-113.

638 [35] Yoshie R, Mochida A, Tominaga Y, Kataoka H, Harimoto K, Nozu T, Shirasawa T.

639 Cooperative project for CFD prediction of pedestrian wind environment in the Architectural

640 Institute of Japan. J Wind Eng Ind Aerodyn 2007; 95:1551-1578.

641 [36] Mochida A, Lun IYF. Prediction of wind environment and thermal comfort at pedestrian

642 level in urban area. J Wind Eng Ind Aerodyn 2008; 96(10-11): 1498-1527.

643 [37]Hang J, Sandberg M, Li Y. Effect of urban morphology on wind condition in idealized city 644 models. Atmos Environ 2009; 43(4): 869-878.

645 [38] FLUENT V6.3. User's Manual.2006. http://www.fluent.com.

646 [39] Snyder WH. Similarity criteria for the application of fluid models to the study of air 647 pollution meteorology. Boundary-Layer Meteorol 1972; 3:113-134.

648 [40] Tominaga Y, Mochida A, Yoshie R, Kataoka H, Nozu T, Yoshikawa M, Shirasawa T. AIJ 649 guidelines for practical applications of CFD to pedestrian wind environment around buildings. $J$

650 Wind Eng Ind Aerodyn 2008; 96(10-11):1749-1761. 
651 [41] Lien FS, Yee E. Numerical modelling of the turbulent flow developing within and over a 3-

652 D building array, part I: A high-resolution Reynolds-averaged Navier-Stokes approach.

653 Boundary-layer Meteorol 2004; 112(3): 427-466.

654 [42] Irwin JS. A theoretical variation of the wind profile power-law exponent as a function of 655 surface roughness and stability. Atmos Environ 1979; 13(1):191-194.

656 [43]WMO Guide to Meteorological Instruments and Methods of Observation WMO-No. 8, page $657 \quad$ I.5-12

658 [44]Etheridge D, Sandberg M. Building Ventilation: Theory and Measurement. John Wiley \& 659 Sons, Chichester. 1996, p.573-633.

660 [45] Tominaga Y, Stathopoulos T. Turbulent Schmidt numbers for CFD analysis with various 661 types of flow field. Atmos Environ 2007; 41(37):8091-8099.

\section{Figure list}

664 Fig. 1. Two urban configurations of semi-open street roof design: (a) Walls being hung above 665 street roofs of food court, (b) Walls being partly covered at street roof height $(z=H)$ of retail 666 center.

668 Fig. 2. Model descriptions of experimental model: (a) The idealized urban model with 4 669 buildings and open street roof, (b) Vertical profiles of velocity and turbulence intensity in the 670 upstream free flow of wind tunnel experiment.

672 Fig. 3. (a) Computational domain for cases with a parallel approaching wind $\left(0^{\circ}\right)$ and half domain 673 size, (b) Grid arrangements in $x-y$ plane in the validation case.

675 Fig. 4. (a) Computational domain with oblique wind direction and full domain size. Model 676 descriptions of urban models with (b) 4 (2×2) buildings and (c) 16 (4×4) buildings.

678 Fig. 5. (a)'Fully-covered' roof type: walls fully cover street roofs at $z=H$ (b) 'Partly-covered' roof 679 type: walls partly cover street roofs at $z=H$, (c) Types of 'Hung1.5H', 'Hung1.2H', 'Hung1.1H': 680 walls are hung above street roofs at $z=1.1 \mathrm{H}, 1.2 \mathrm{H}, 15 \mathrm{H}$. 
682 Fig. 6. Two examples of grid arrangements for urban geometries with 4 buildings: (a) in $x-y$

683 plane, (b) in $x$ - $z$ plane. (c)Definition of uniform pollutant source in UCL volume.

684

685 Fig. 7. Validation profiles of (a) velocity and (b) turbulence intensity along the street centerline 686 at $z=0.11 \mathrm{H}$ by using different turbulence models. (c) Horizontal profiles of velocity for a grid 687 independence study.

689 Fig. 8. (a) 3D streamline, (b) $\tau_{p} *$ in $z=0.22 H$ and $Q^{*}$ in Case [2-2, 0, Open], Case [2-2, 0,

690 Hung1.2H], Case [2-2, 0, Partly-covered], Case [2-2, 0, Fully-covered].

692 Fig. 9. (a) 3D streamline, (b) $\tau_{p}^{*}$ and $Q^{*}$ in Case [2-2, 0, Hung1.5H], Case [2-2, 15, Hung1.5H], 693 Case $\left[2-2,30\right.$, Hung1.5H], Case [2-2, 45, Hung1.5H]. Note that in Fig. 9b, negative values of $Q^{*}$ 694 by mean flows denote air leaving UCL and positive ones represent air entering UCL.

696 Fig. 10. $Q^{*}$ in urban models with 4 buildings and wind directions of (a) $0^{\circ}$, (b) $15^{\circ}$, (c) $30^{\circ}$, 697 (d) $45^{\circ}$.

698

699 Fig. 11. Ventilation indices and their $N V R$ for test cases with 4 buildings: (a) $Q^{*}$ roof (in) and $700 Q_{\text {roof }}^{*}$ (out), (b) $Q_{\text {roof }}$ (turb), (c) $Q_{T}^{*}$, (d) $P F R^{*}$, (e) $<\tau_{p}^{*}>$.

702 Fig. 12. $\tau_{p} *$ in $z=0.22 H$ in (a) Case [4-4, 0, Hung1.2H], (b) Case [4-4, 15, Hung1.2H], (c) Case $703 \quad[4-4,30$, Hung1.2H], (d) Case [4-4, 45, Hung1.2H].

705 Fig. 13. Ventilation indices and their $N V R$ : (a) $Q^{*}$ roof (in) and $Q^{*}$ roof (out) in 24 test cases with 70616 buildings, In all 48 test cases: (b) $Q^{*}$ roof (turb), (c) $Q_{T^{*}}$, (d) $P F R^{*}$, (e) $<\tau_{p}^{*}>$. 
Table 1 Model descriptions of 48 test cases.

\begin{tabular}{|c|c|c|c|}
\hline \multicolumn{2}{|c|}{2 rows, 2 columns $(2 \times 2)$} & \multicolumn{2}{|c|}{4 rows, 4 columns $(4 \times 4)$} \\
\hline Case name* & $\begin{array}{l}\text { Ambient wind } \\
\text { direction } \theta^{\circ}\end{array}$ & Case name & $\begin{array}{l}\text { Ambient wind } \\
\text { direction } \theta^{\circ}\end{array}$ \\
\hline$[2-2,0$, Open] & \multirow{6}{*}{$0^{\circ}$} & {$[4-4,0$, Open $]$} & \multirow{6}{*}{ - } \\
\hline$[2-2,0$, Hung1.5H] & & {$[4-4,0$, Hung $1.5 \mathrm{H}]$} & \\
\hline$[2-2,0$, Hung1.2H] & & {$[4-4,0$, Hung $1.2 \mathrm{H}]$} & \\
\hline$[2-2,0$, Hung1.1H] & & {$[4-4,0$, Hung $1.1 \mathrm{H}]$} & \\
\hline$[2-2,0$, Partly-covered] & & [4-4, 0,Partly-covered] & \\
\hline$[2-2,0$, Fully-covered $]$ & & [4-4, 0, Fully-covered] & \\
\hline & & & 2 \\
\hline$[2-2,15$, Open $]$ & \multirow{6}{*}{$15^{\circ}$} & {$[4-4,15$, Open $]$} & \multirow{6}{*}{$15^{\mathrm{o}}$} \\
\hline$[2-2,15$, Hung $1.5 \mathrm{H}]$ & & {$[4-4,15$, Hung $1.5 \mathrm{H}]$} & \\
\hline$[2-2,15$, Hung $1.2 \mathrm{H}]$ & & {$[4-4,15$, Hung $1.2 \mathrm{H}]$} & \\
\hline$[2-2,15$, Hung $1.1 \mathrm{H}]$ & & {$[4-4,15$, Hung $1.1 \mathrm{H}]$} & \\
\hline$[2-2,15$, Partly-covered $]$ & & {$[4-4,15$, Partly-covered $]$} & \\
\hline$[2-2,15$, Fully-covered $]$ & & {$[4-4,15$, Fully-covered $]$} & \\
\hline & & $\mathrm{B}$ & \\
\hline$[2-2,30$, Open] & \multirow{6}{*}{$30^{\circ}$} & {$[4-4,30$, Open $]$} & \multirow{6}{*}{$30^{\circ}$} \\
\hline$[2-2,30$, Hung $1.5 \mathrm{H}]$ & & {$[4-4,30$, Hung $1.5 \mathrm{H}]$} & \\
\hline$[2-2,30$, Hung $1.2 \mathrm{H}]$ & & {$[4-4,30$, Hung $1.2 \mathrm{H}]$} & \\
\hline$[2-2,30$, Hung $1.1 \mathrm{H}]$ & & {$[4-4,30$, Hung $1.1 \mathrm{H}]$} & \\
\hline [2-2, 30,Partly-covered] & & {$[4-4,30$, Partly-covered $]$} & \\
\hline \multirow[t]{2}{*}[2-2,30,\text{Fully-covered}]{} & & {$[4-4,30$, Fully-covered $]$} & \\
\hline & & $y$ & \\
\hline$[2-2,45$, Open] & \multirow{6}{*}{$45^{\circ}$} & {$[4-4,45$, Open $]$} & \multirow{6}{*}{$45^{\circ}$} \\
\hline$[2-2,45$, Hung $1.5 \mathrm{H}]$ & & {$[4-4,45$, Hung $1.5 \mathrm{H}]$} & \\
\hline$[2-2,45$, Hung $1.2 \mathrm{H}]$ & & {$[4-4,45$, Hung $1.2 \mathrm{H}]$} & \\
\hline$[2-2,45$, Hung $1.1 \mathrm{H}]$ & & {$[4-4,45$, Hung $1.1 \mathrm{H}]$} & \\
\hline$[2-2,45$, Partly-covered $]$ & & {$[4-4,45$, Partly-covered $]$} & \\
\hline$[2-2,45$, Fully-covered $]$ & & {$[4-4,45$, Fully-covered $]$} & \\
\hline
\end{tabular}

*Case name is defined as [row number-column number, wind direction $\left(\theta^{\circ}\right)$, roof type]. Open' denotes open street roofs; 'Fully-covered' and 'Partly-covered' means solid walls 'fully or 'partly cover' street roofs at $z=H$. 'Hung $1.5 \mathrm{H}$, Hung1.2H and Hung1.1H' represent solid walls are 'Hung' above street roofs at $z=1.5 \mathrm{H}, 1.2 \mathrm{H}$ and $1.1 \mathrm{H}$.

Table 2 Effect of turbulence models and turbulent Schimdt number $(S c t)$ on $\left\langle\tau_{p}{ }^{*}\right\rangle, P F R^{*}$ and $Q_{T}^{*}$ in the entire UCL, $Q_{\text {roof }}(\text { turb })^{*}$ and $Q^{*}$ across O3 in Case [2-2, 0, Open].

\begin{tabular}{|l|l|l|l|l|l|l|l|l|}
\hline $\begin{array}{l}\text { Turbulence } \\
\text { models }\end{array}$ & Sct & $\left\langle\tau_{p}^{*}\right\rangle$ & $P F R^{*}$ & $Q_{T}^{*}$ & $Q_{\text {roof }}^{*}$ (out) & $Q_{\text {roof }}^{* \text { (in) }}$ & $Q_{\text {roof }}^{*}$ (turb) & $Q^{*}(\mathrm{O} 3)$ \\
\hline \multirow{3}{*}{ Standard $k-\varepsilon$} & 0.4 & 21.2 & 1.847 & & & & & \\
\cline { 2 - 10 } & 0.7 & 24.3 & 1.609 & 1.376 & -0.825 & 0.148 & 1.211 & -0.551 \\
\cline { 2 - 10 } & 1.0 & 26.4 & 1.482 & & & & & -0.536 \\
\hline Realizable $k-\mathcal{E}$ & 0.7 & 27.2 & 1.439 & 1.401 & -0.844 & 0.145 & 1.066 & -0.274 \\
\hline RNG $k-\varepsilon$ & 0.7 & 28.8 & 1.358 & 1.378 & -1.127 & 0.181 & 0.919 & \\
\hline
\end{tabular}

*Negative values denote air leaving UCL and positive ones represent air entering it. 

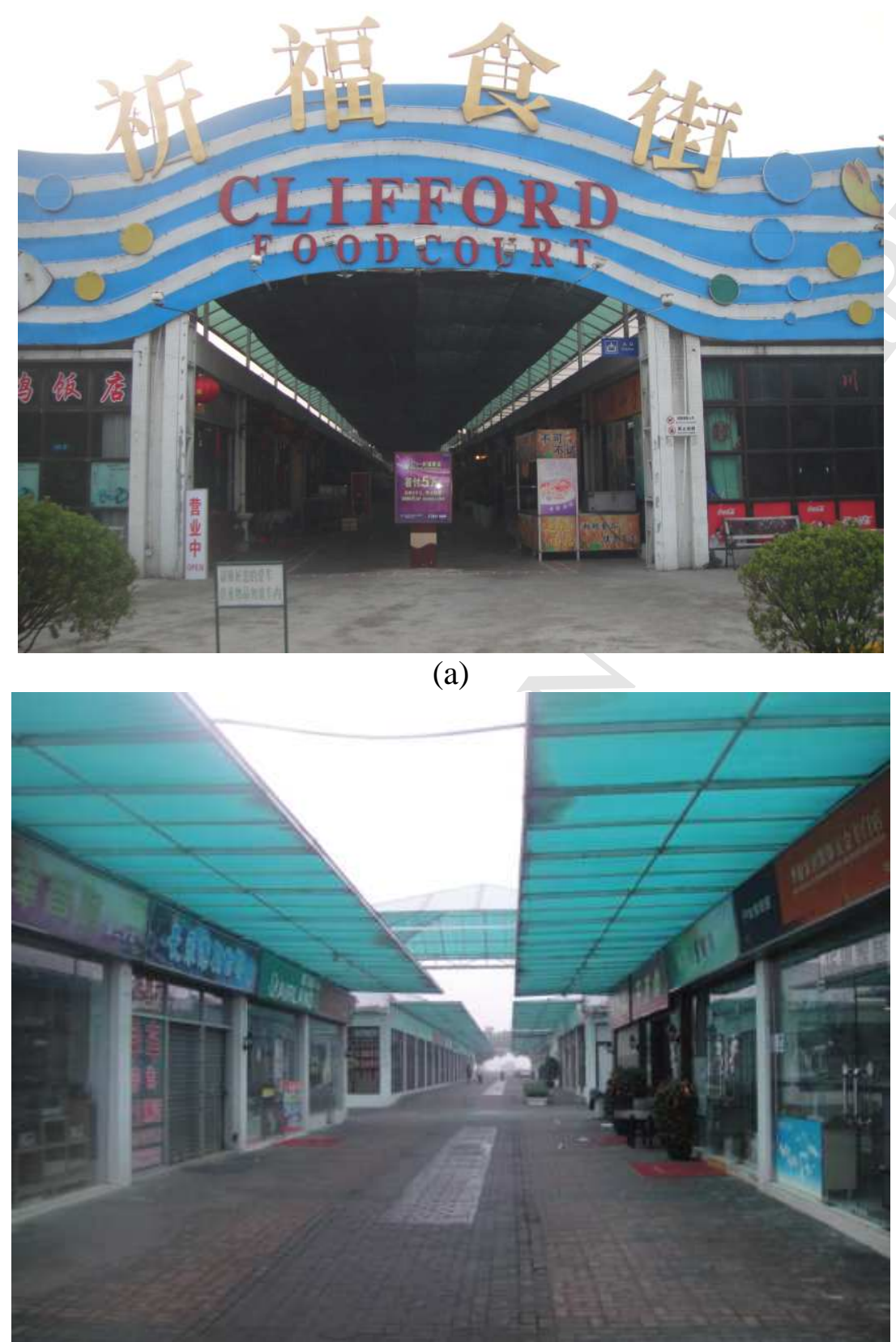

(b)

Fig. 1. Hang et al. 


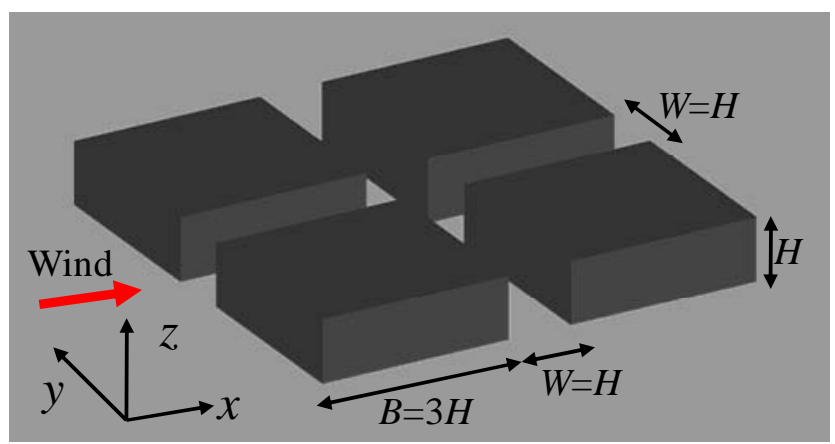

(a)
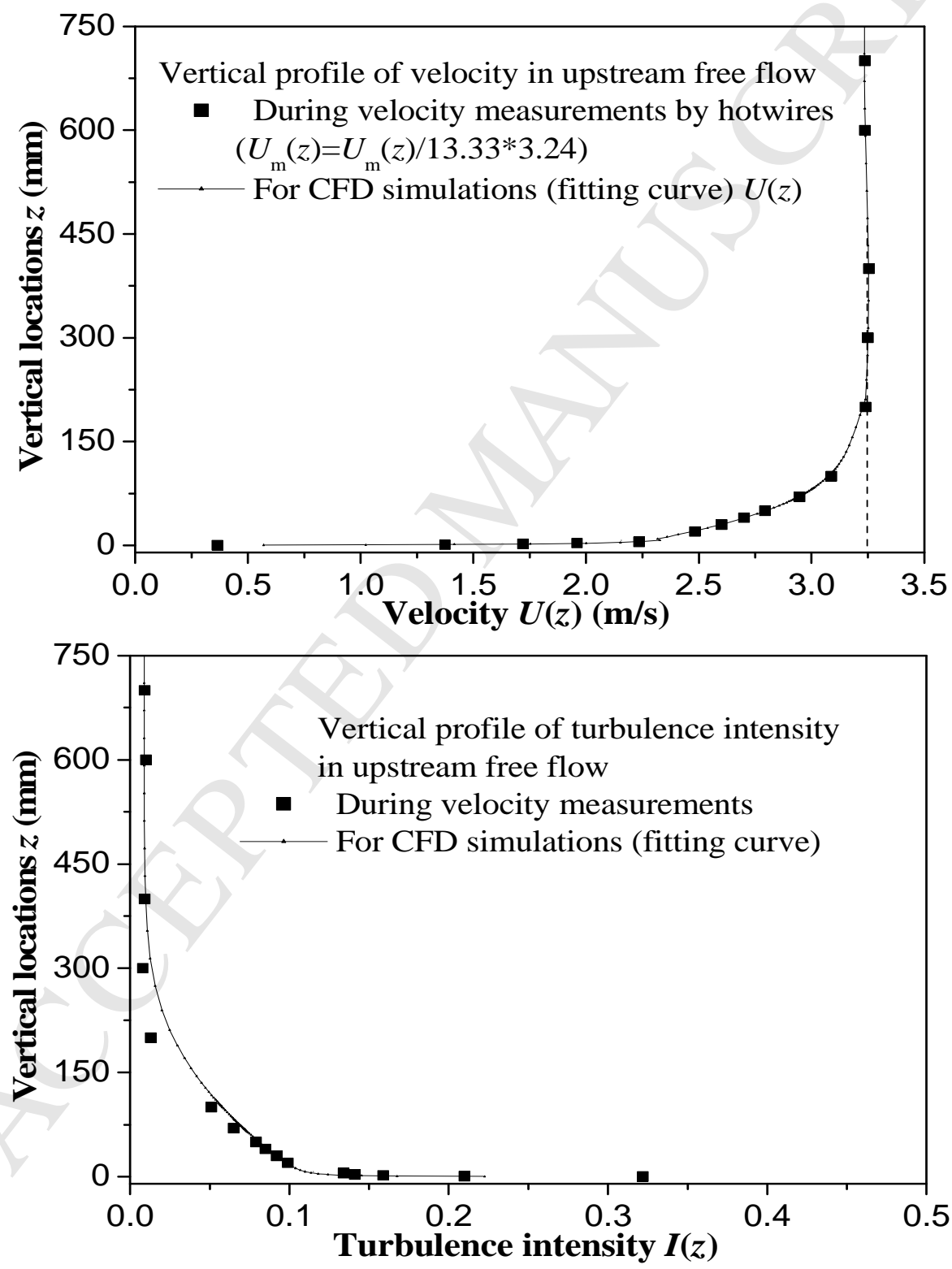

Fig. 2. Hang et al.

(b) 

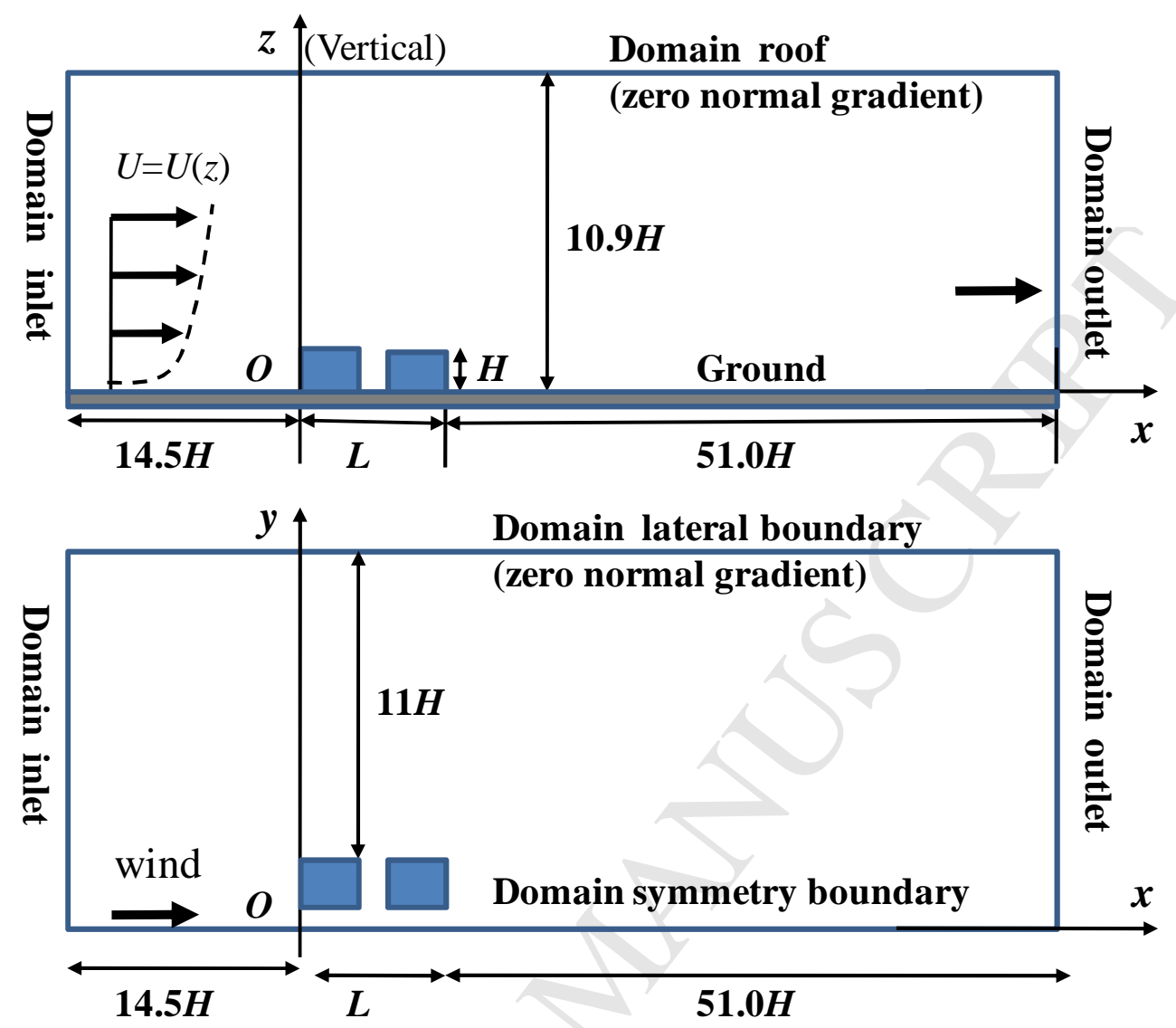

(a)

Horizontal profiles along main street centerline at $z=0.11 \mathrm{H}$ measured by hotwires

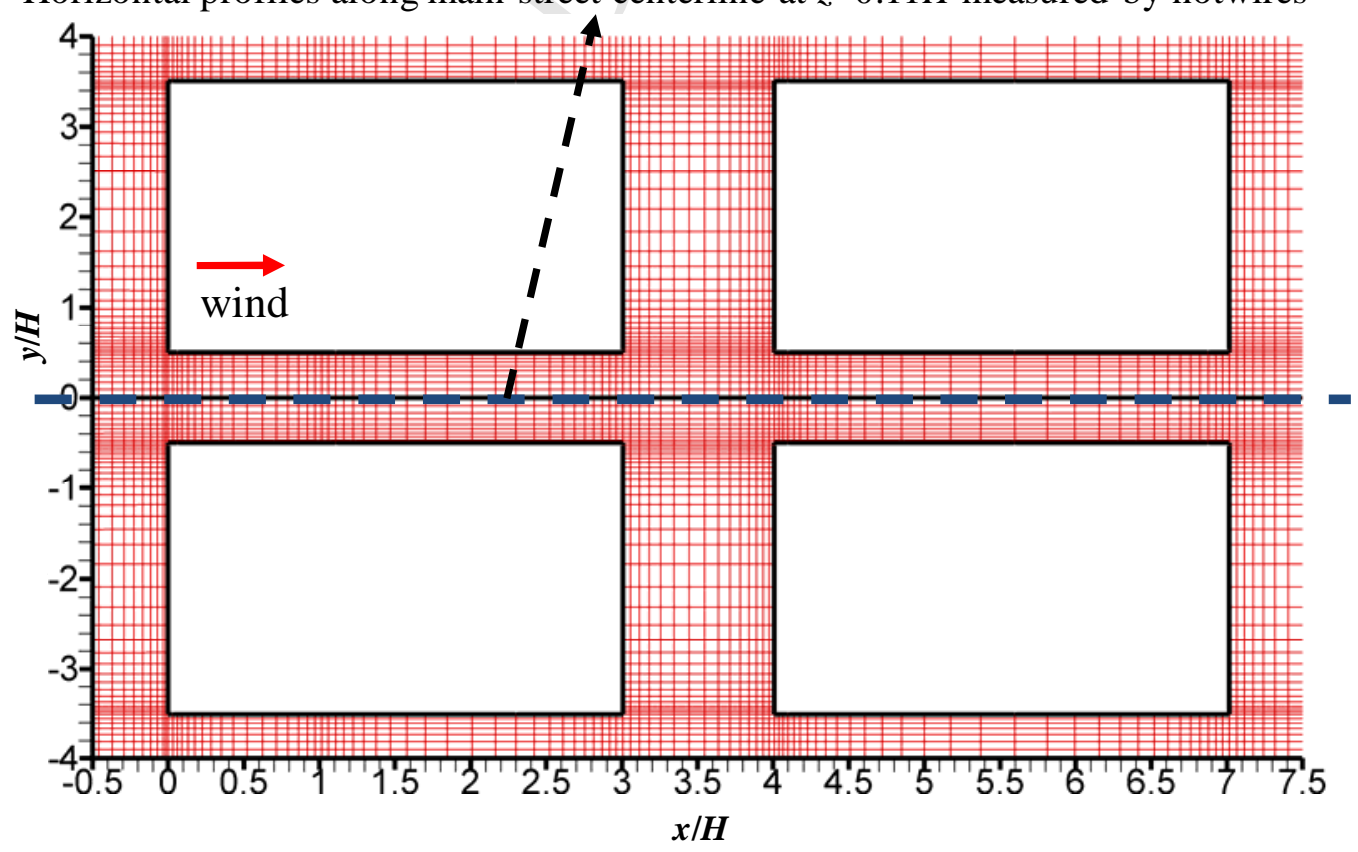

(b)

Fig. 3 Hang et al. 

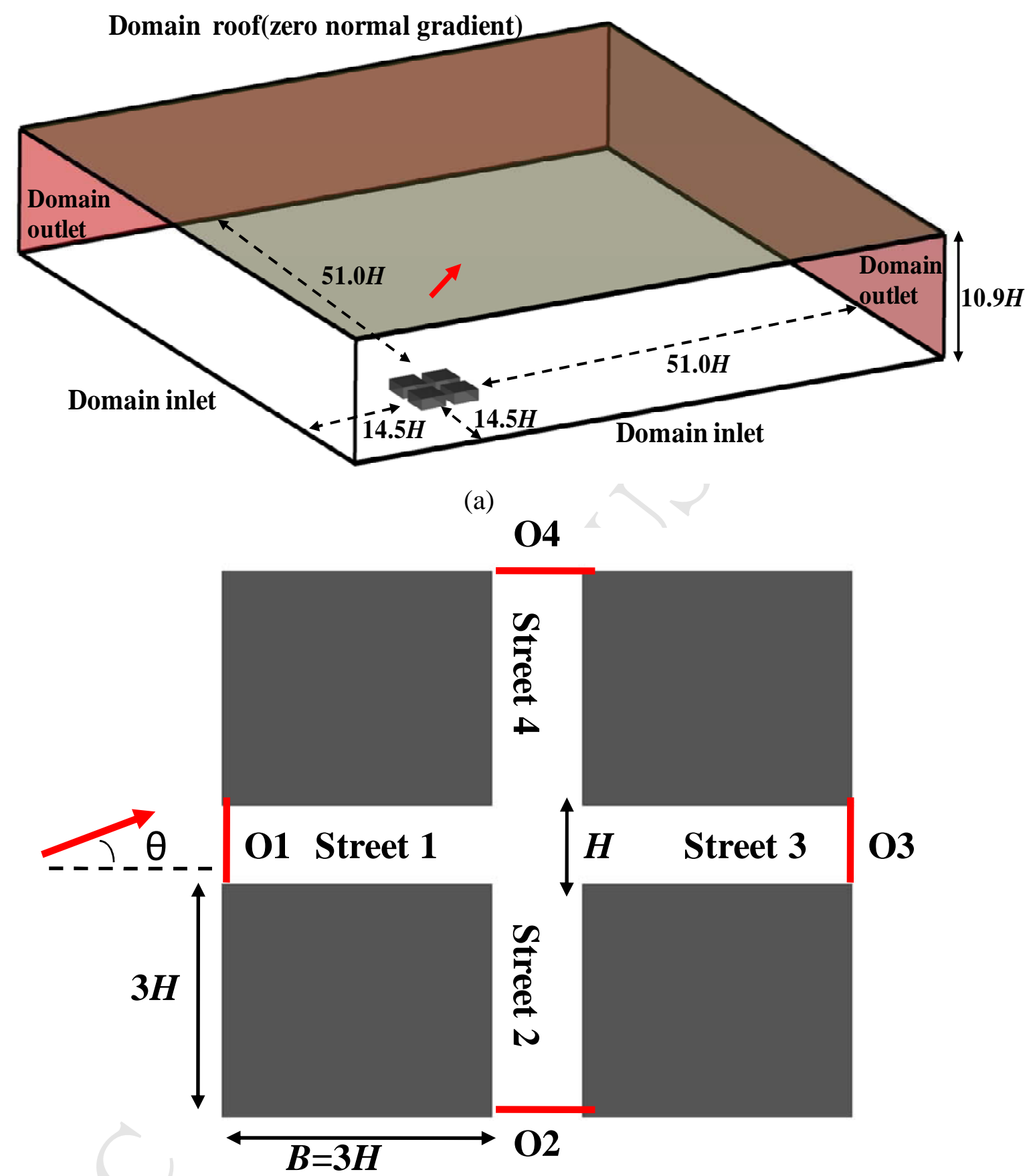

(b) 


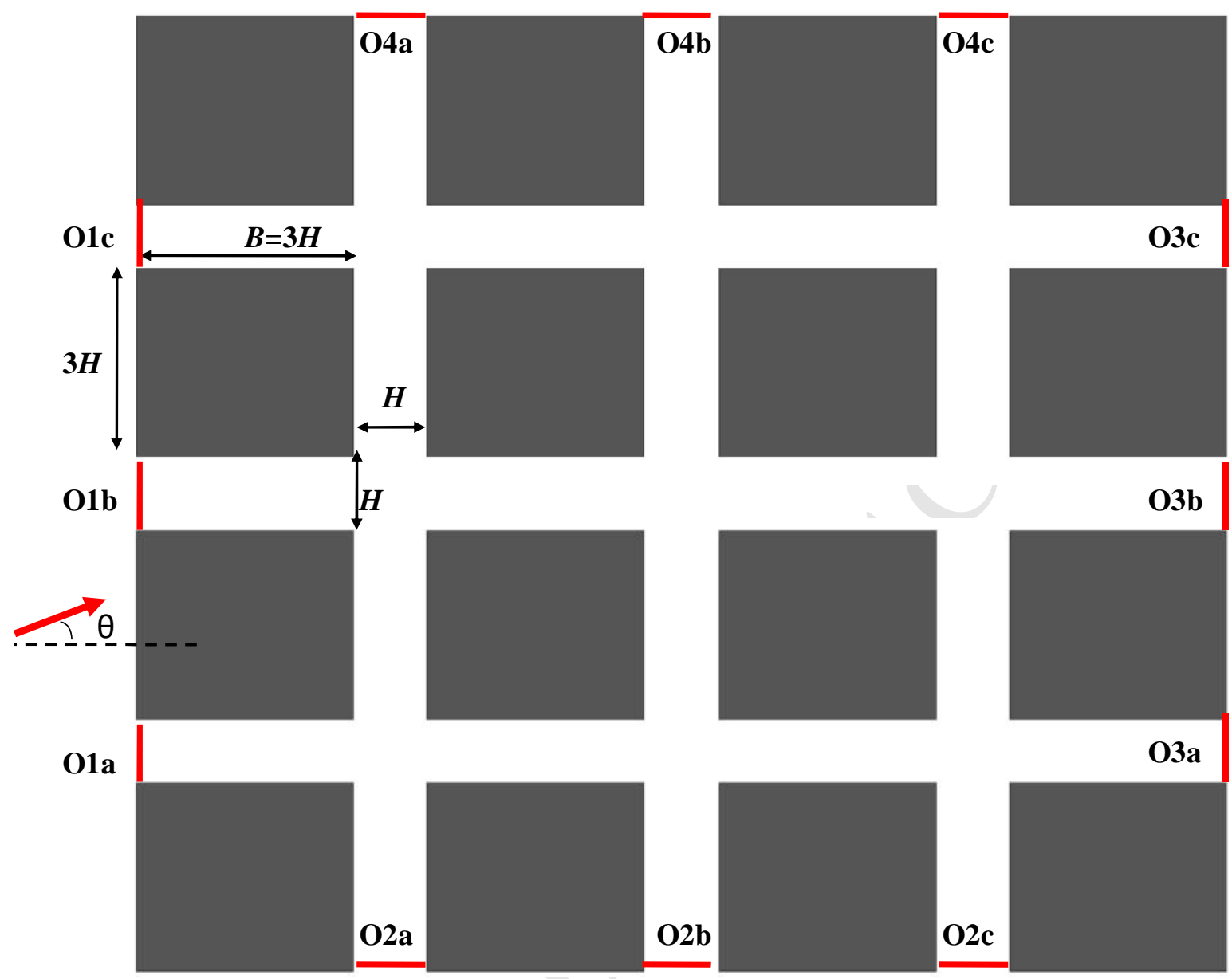

(c)

Fig. 4. Hang et al. 


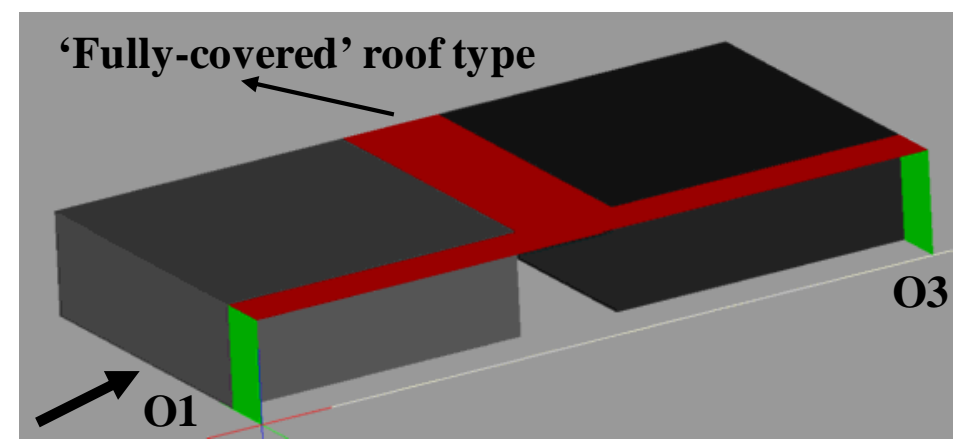

(a) Enclosed street roof
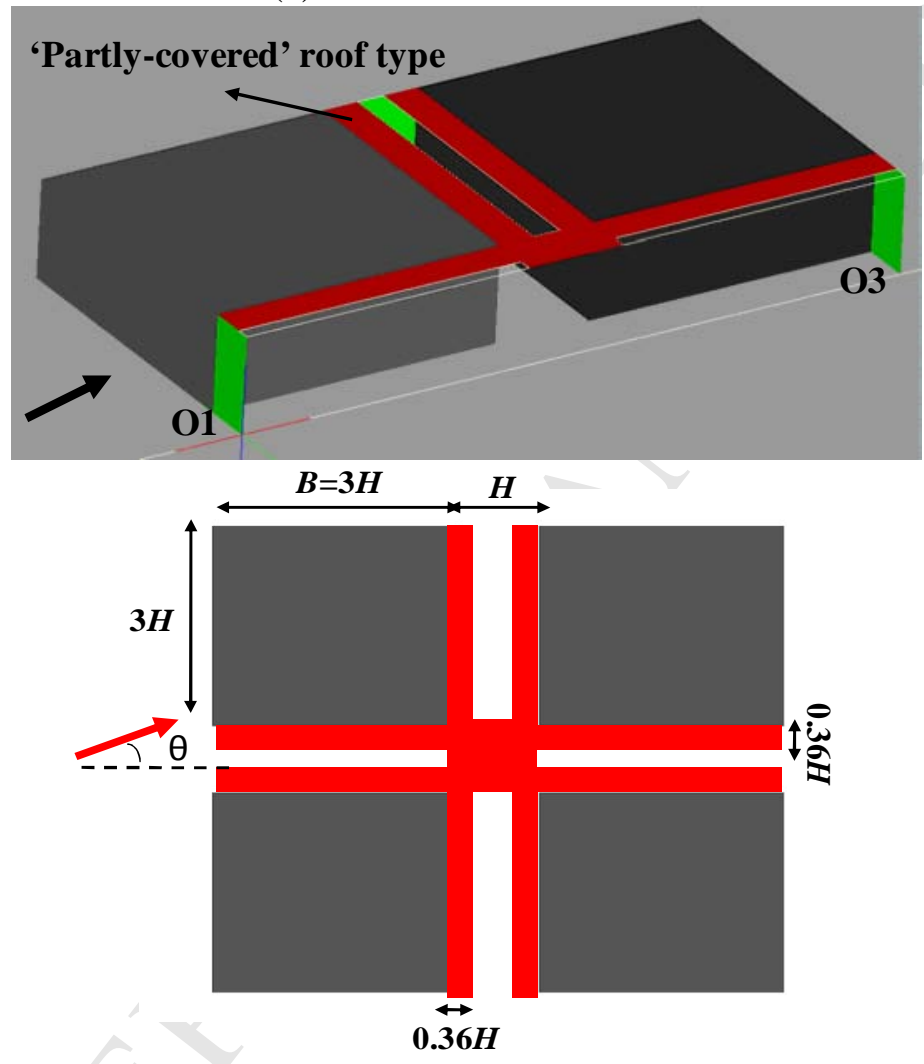

(b)

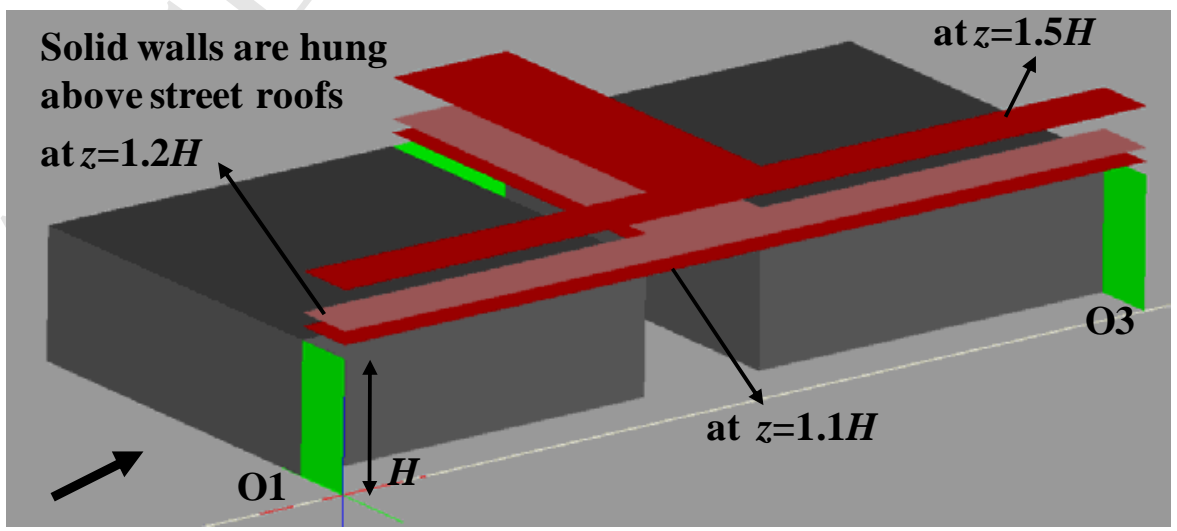

(c)

Fig. 5. Hang et al. 


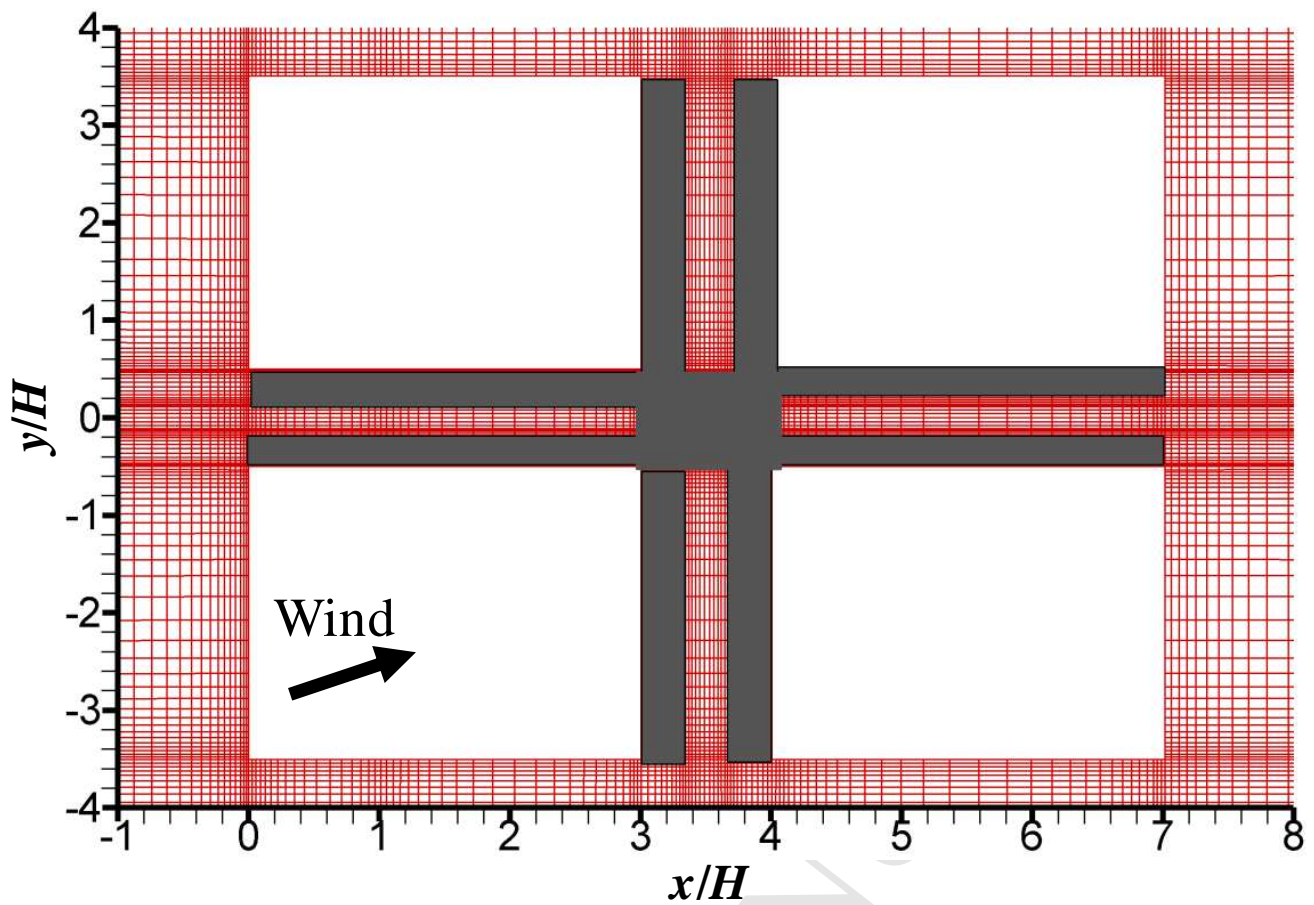

(a)

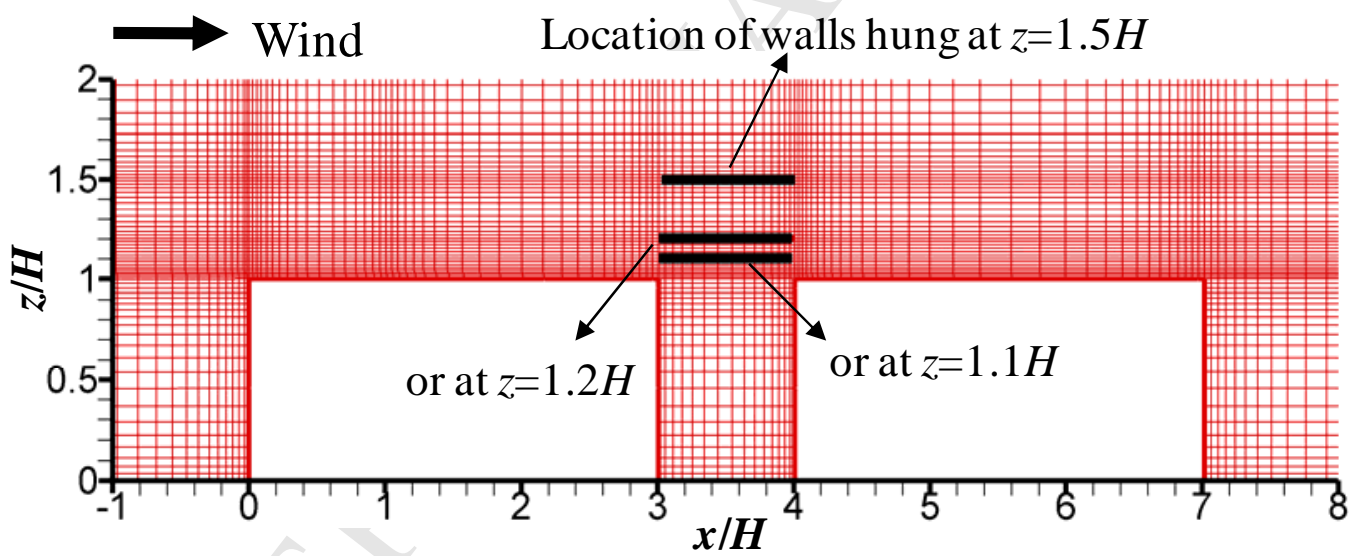

(b)

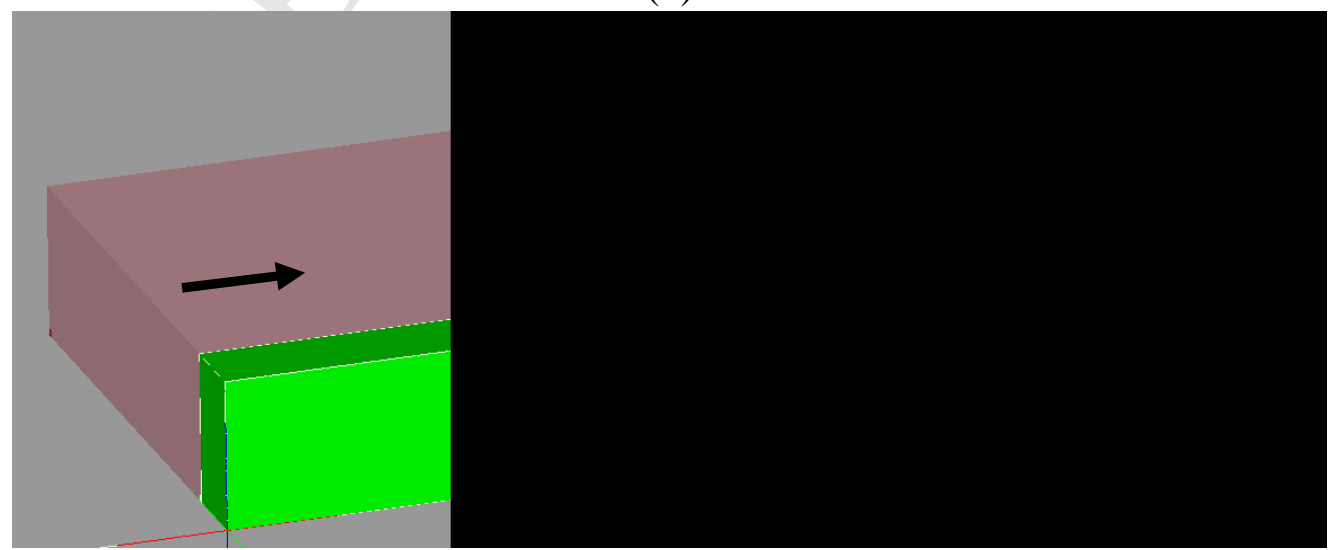

(c)

Fig.6. Hang et al. 


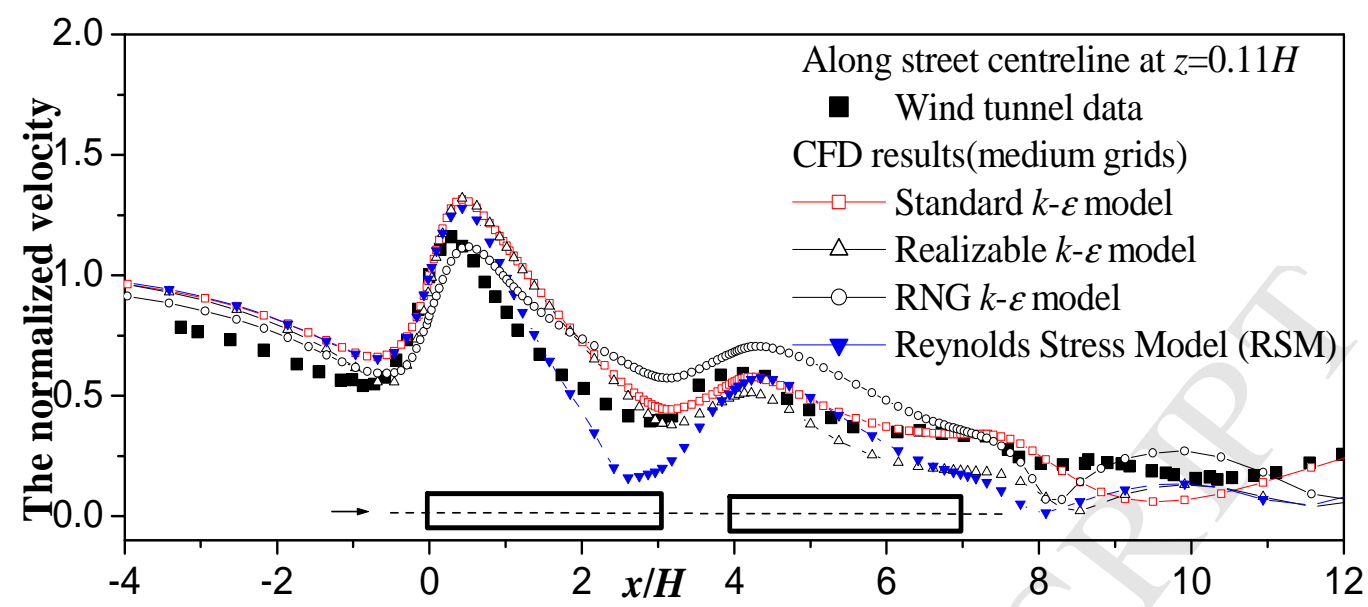

(a)

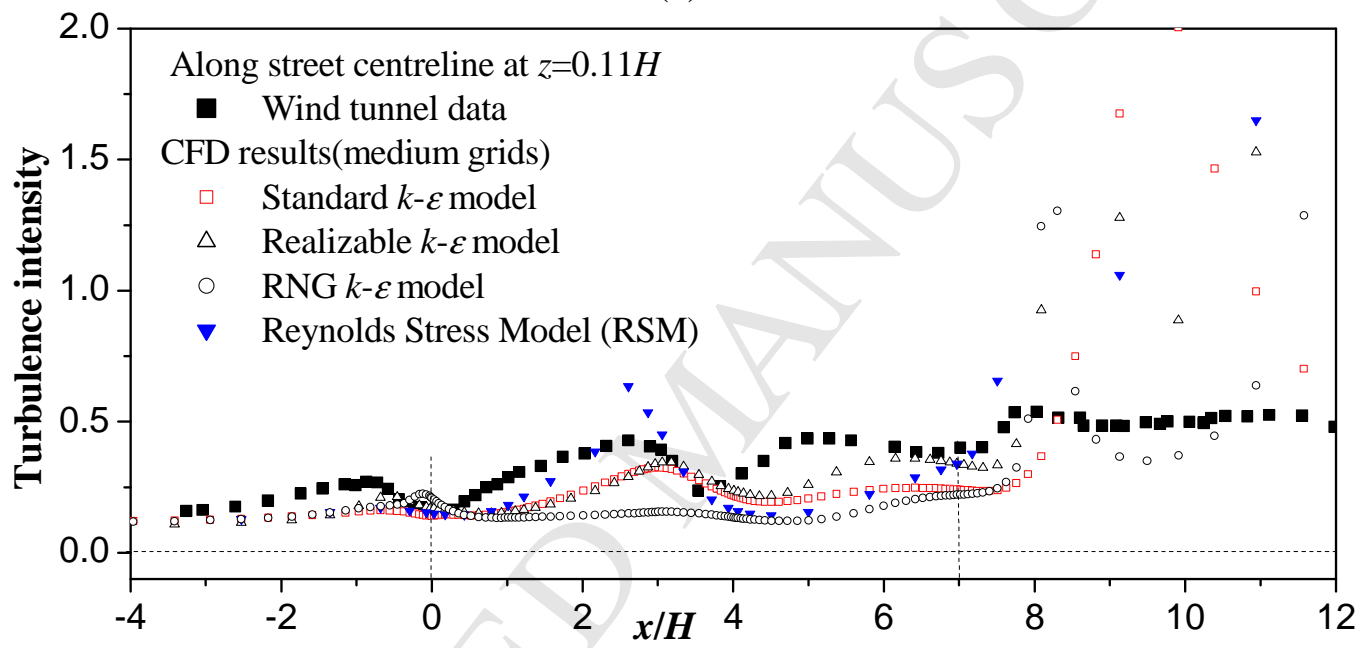

(b)

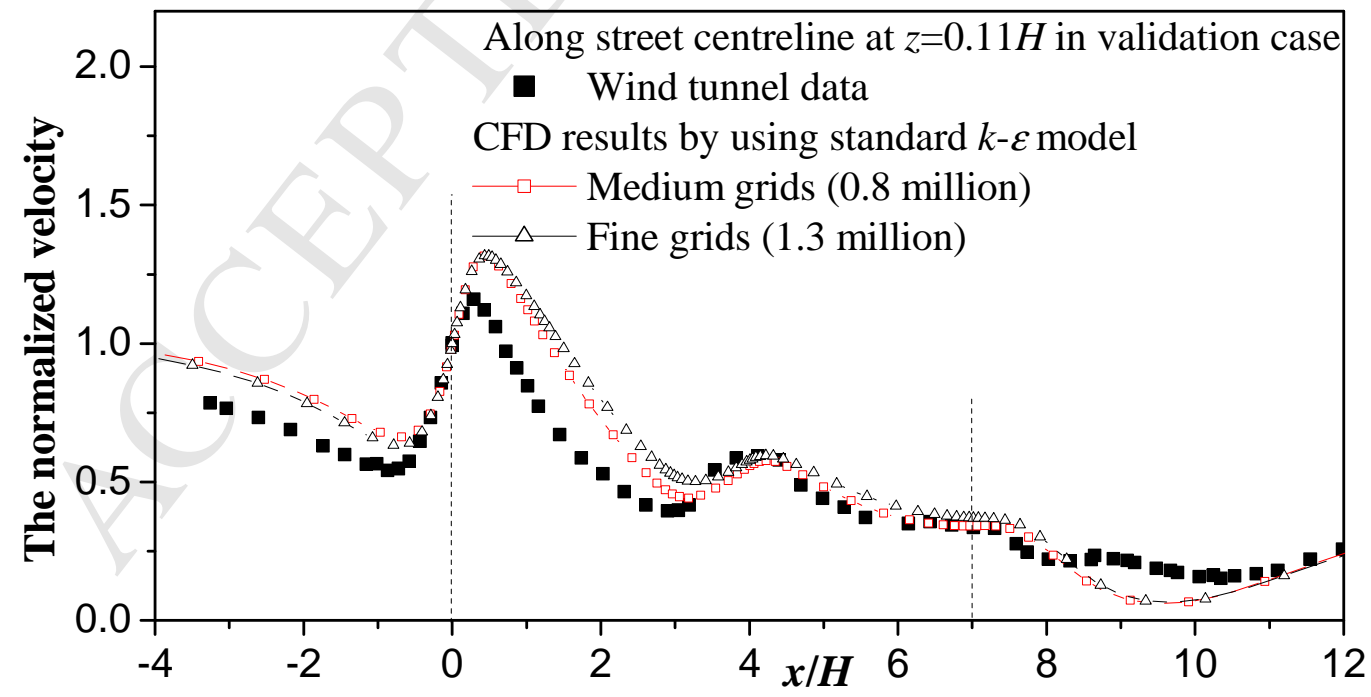

(c)

Fig. 7. Hang et al. 

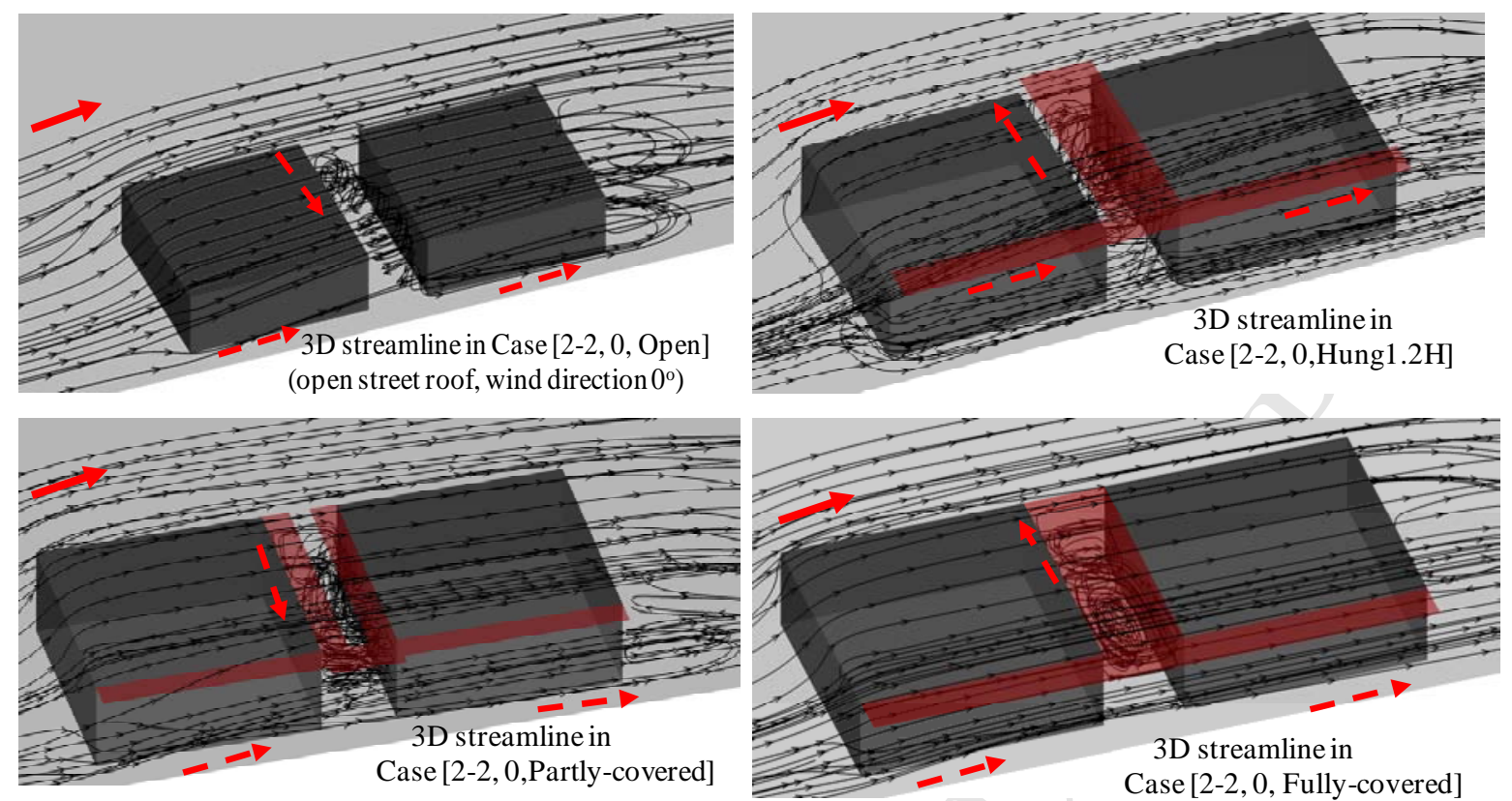

(a)

Normalized age of air $\left(\tau_{p}^{*}=\tau_{p} \times 100 \mathrm{~s}\right)$ in $z=0.22 \mathrm{H}$
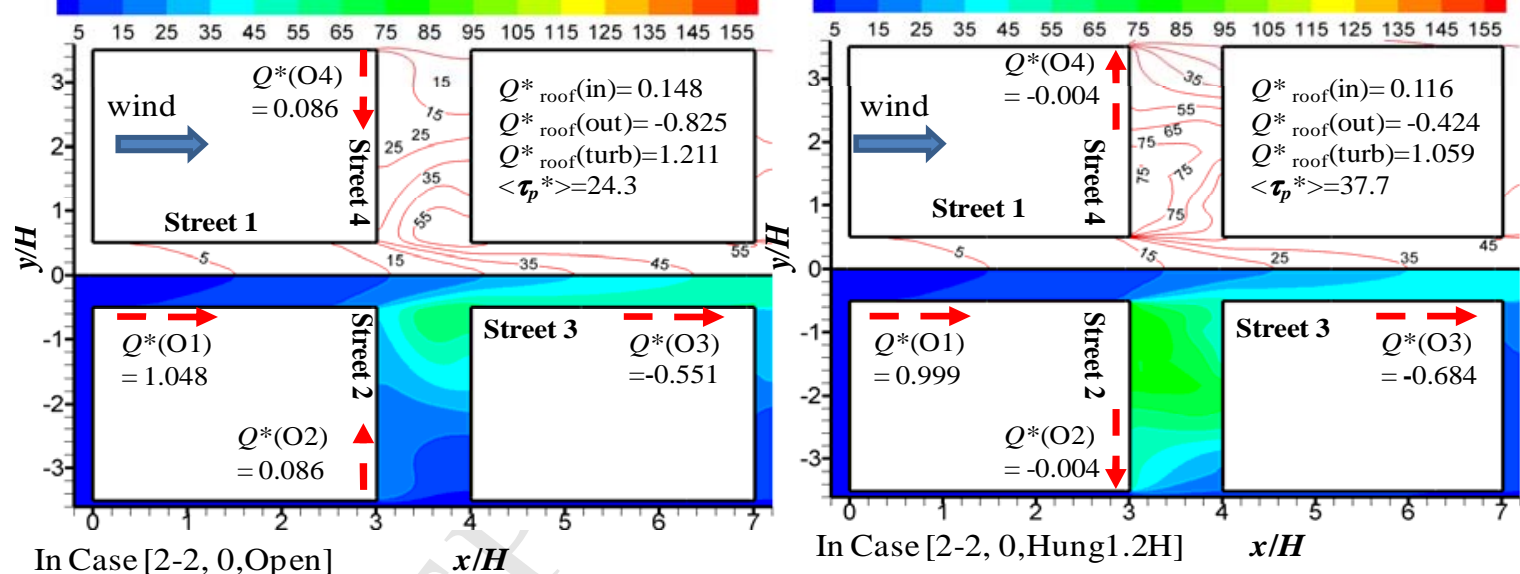

In Case [2-2, 0,Open]

In Case [2-2, 0,Hung1.2H] $\quad \boldsymbol{x} / \boldsymbol{H}$

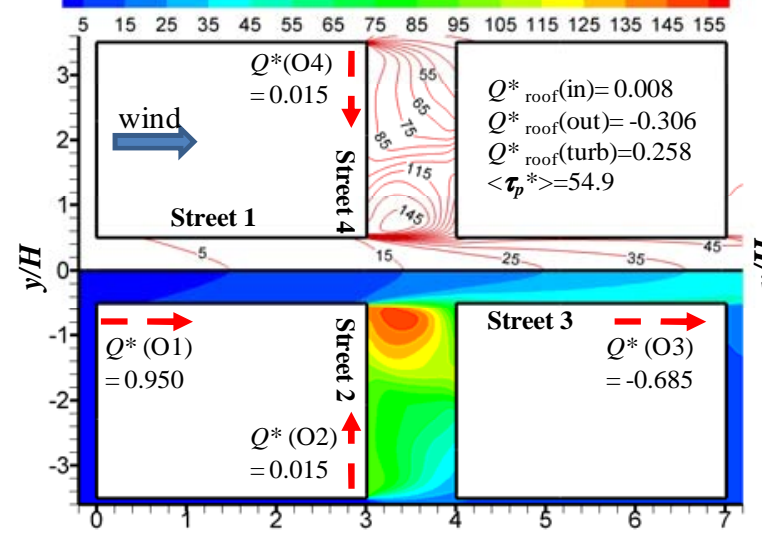

In Case [2-2, 0, Partly-covered] $\boldsymbol{x} / \boldsymbol{H}$

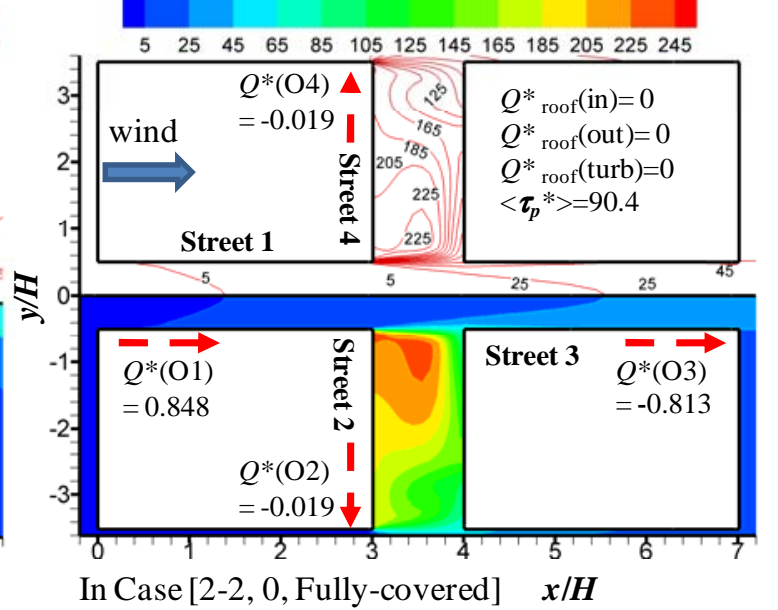

(b)

Fig. 8 Hang et al. 

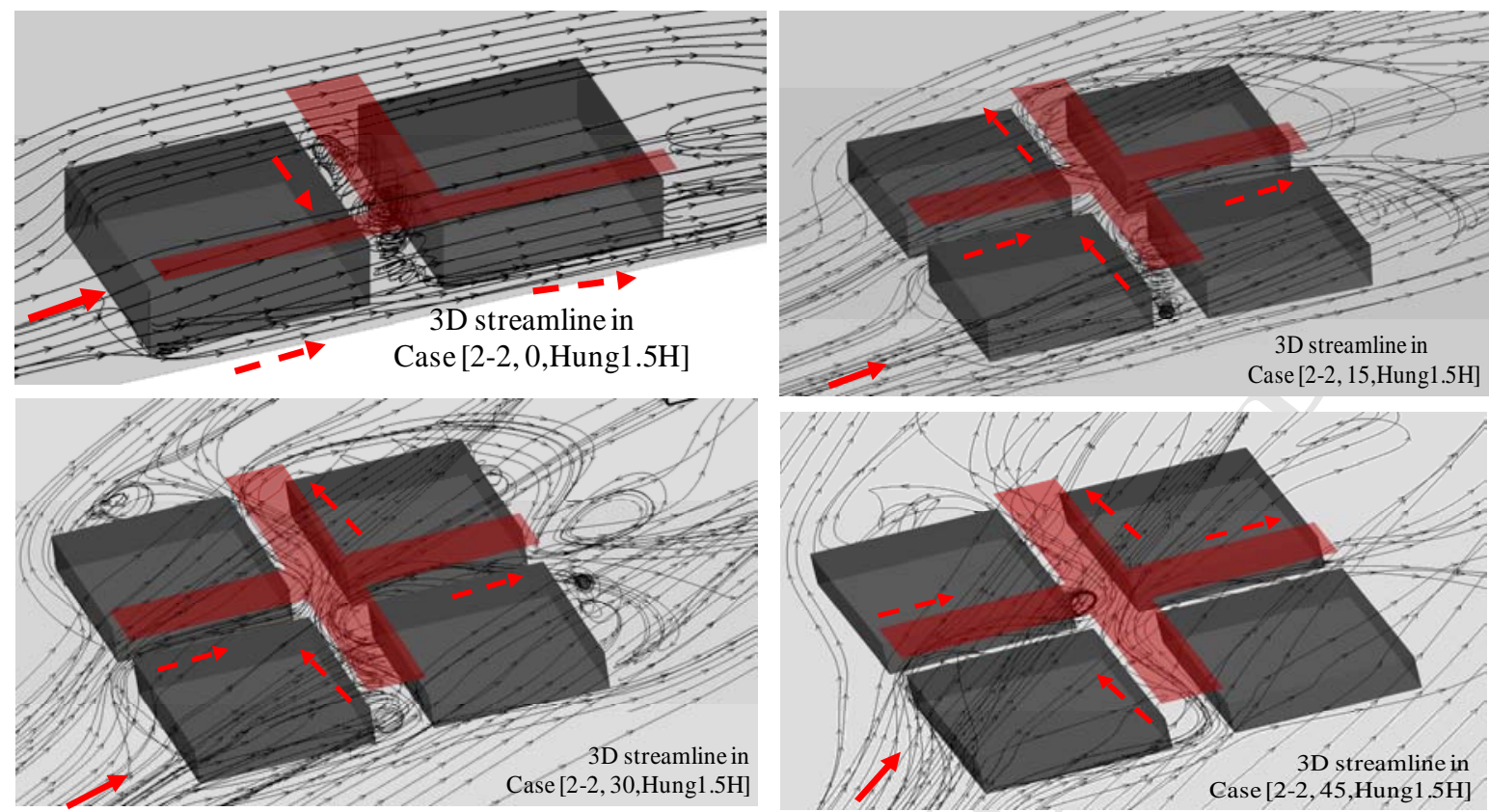

(a)

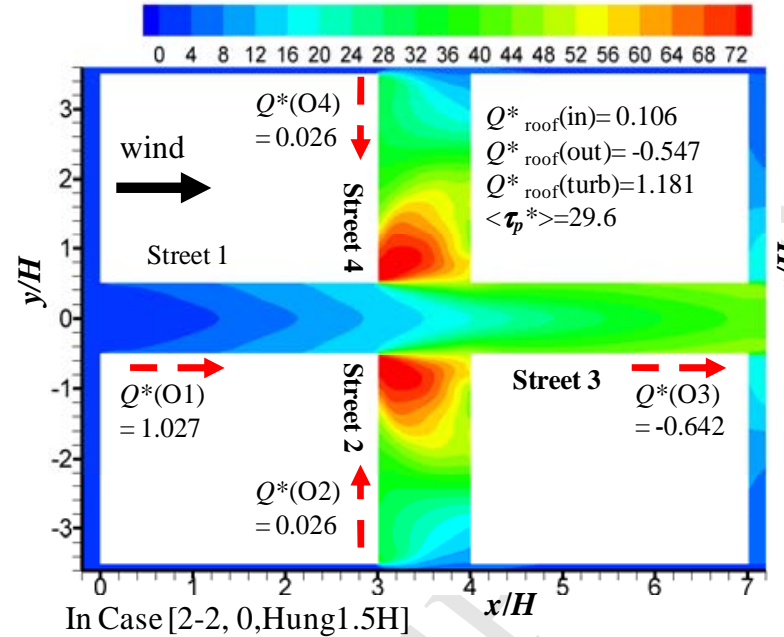

Normalized age of air $\left(\tau_{p}{ }^{*}=\tau_{p} \times 100 \mathrm{~s}\right)$ in $z=0.22 \mathrm{H}$
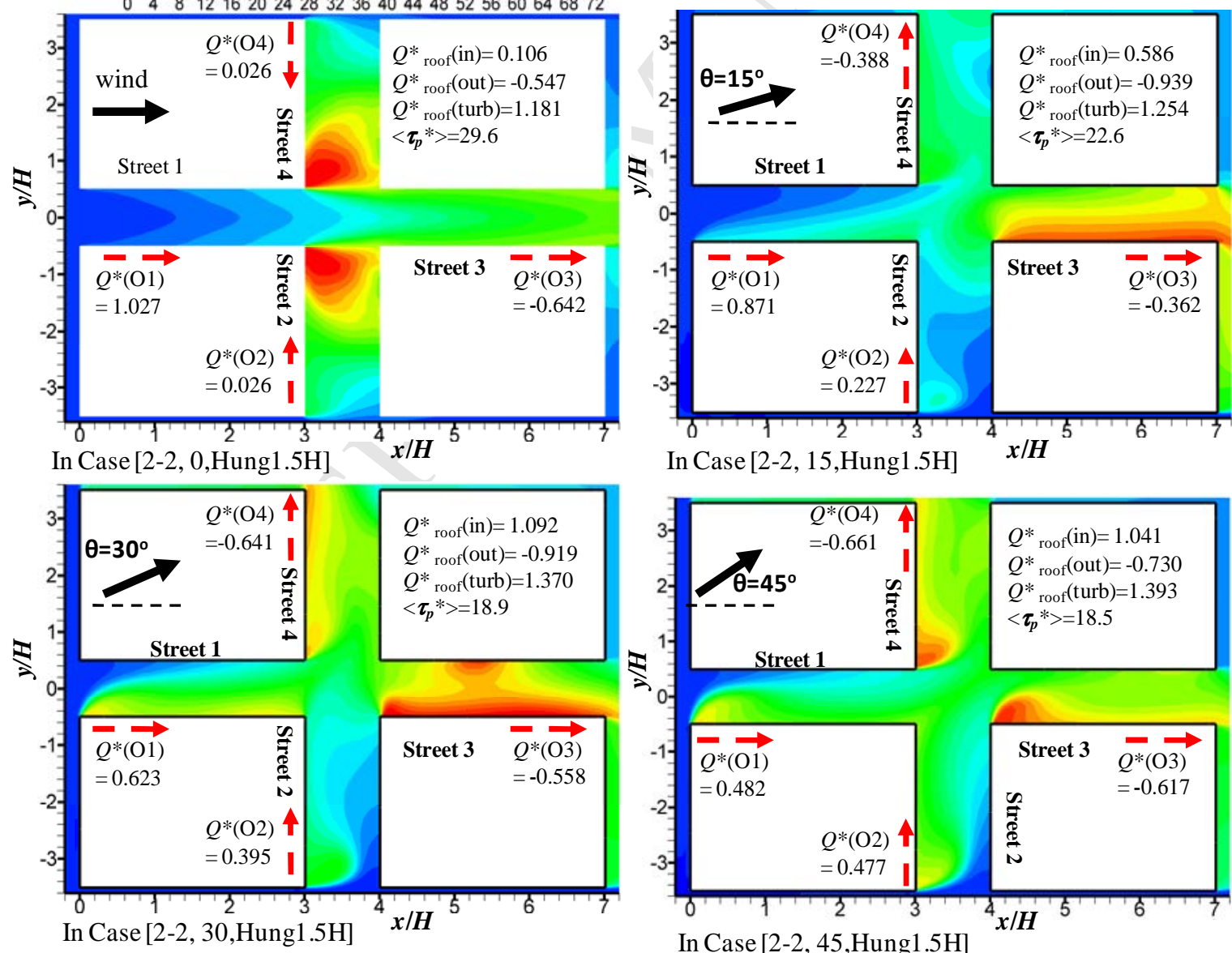

(b)

Fig. 9 Hang et al. 


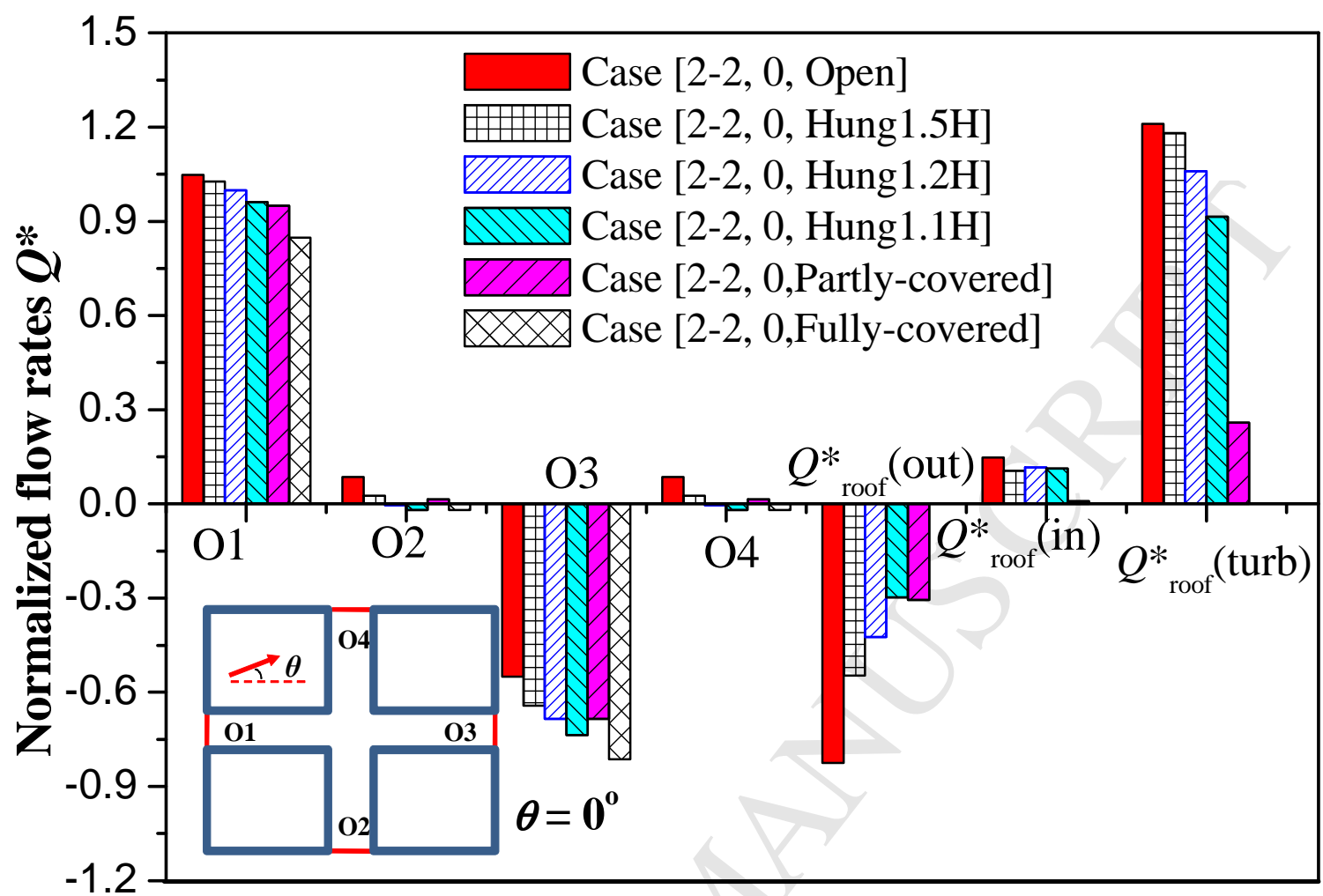

(a)

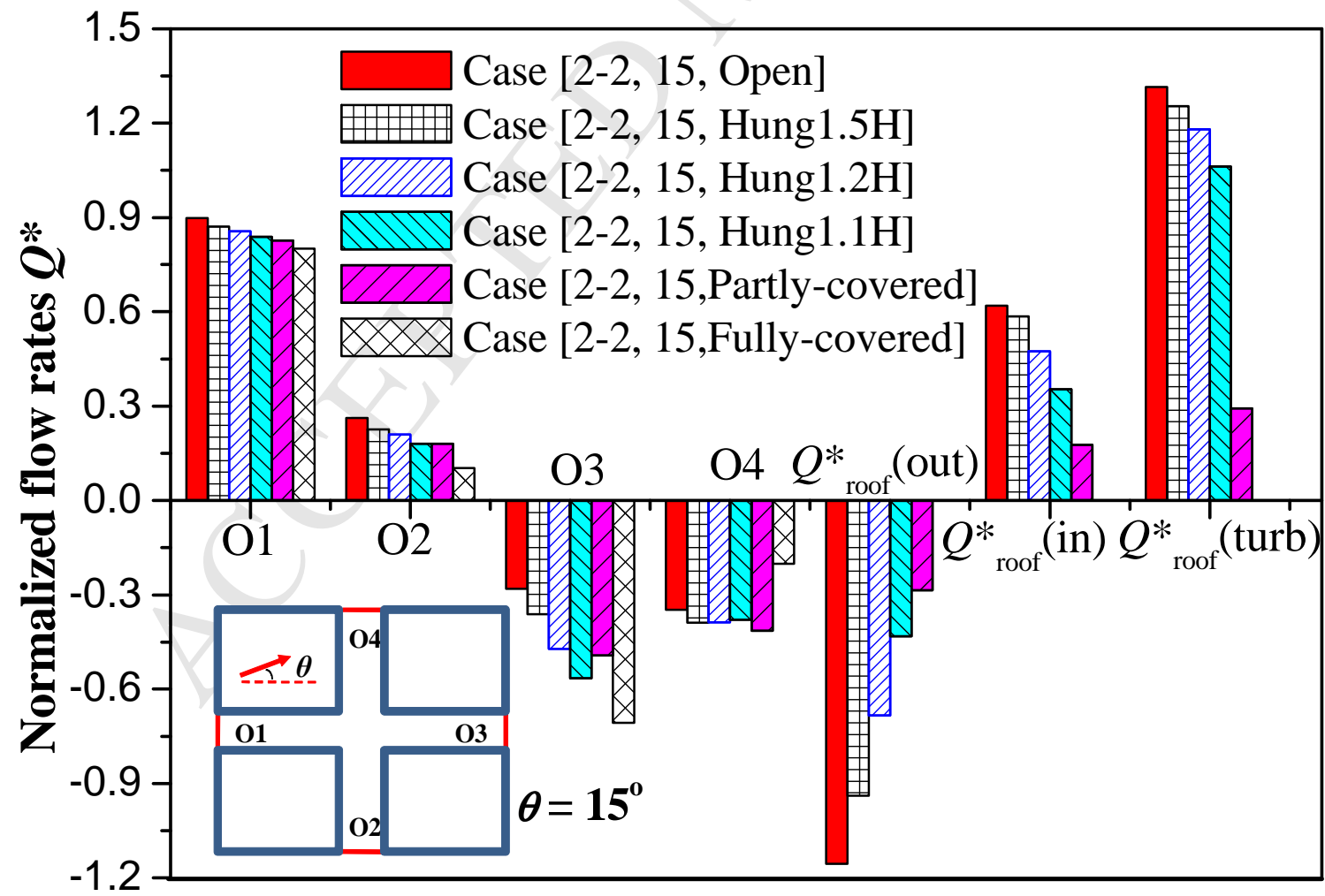

(b) 


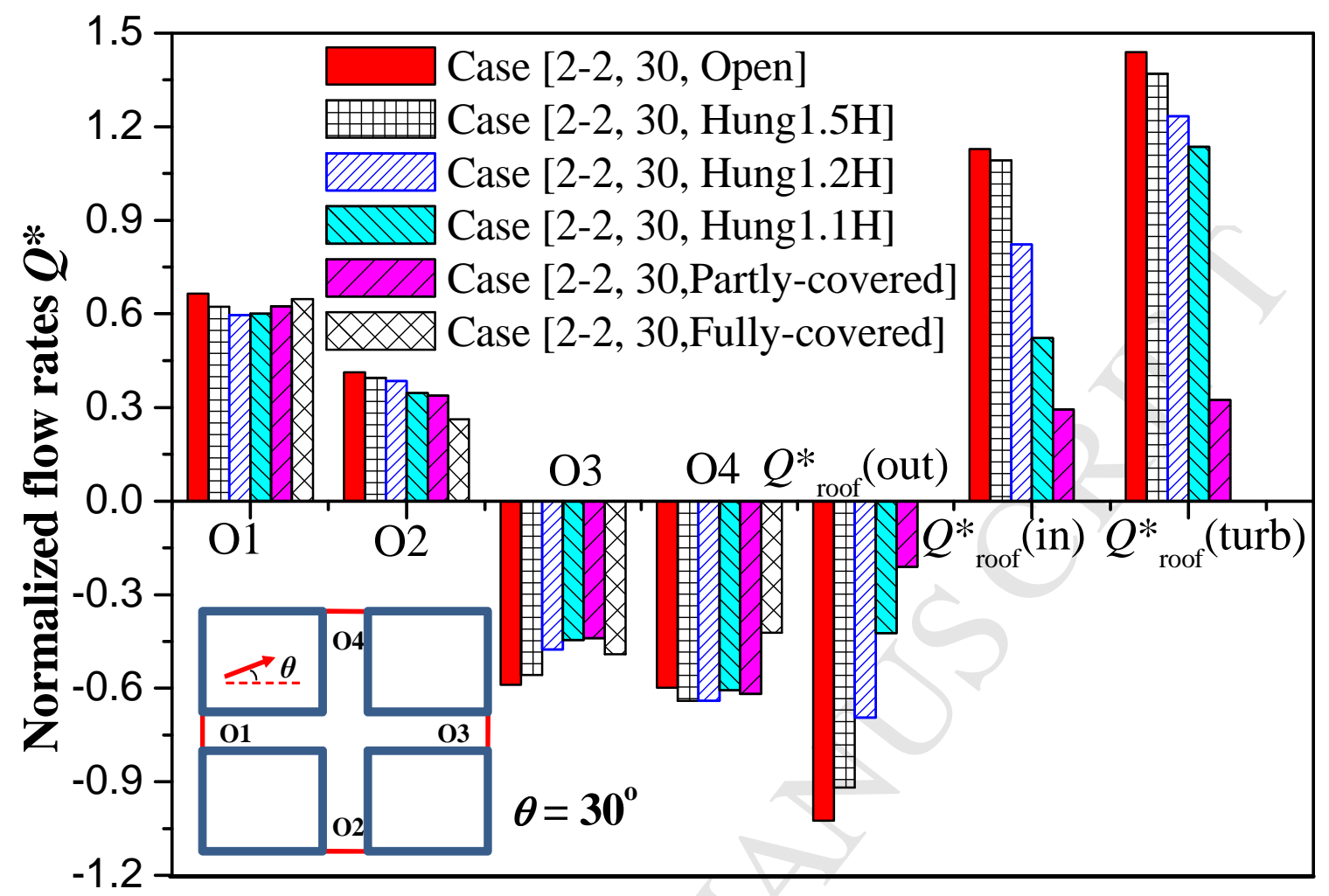

(c)

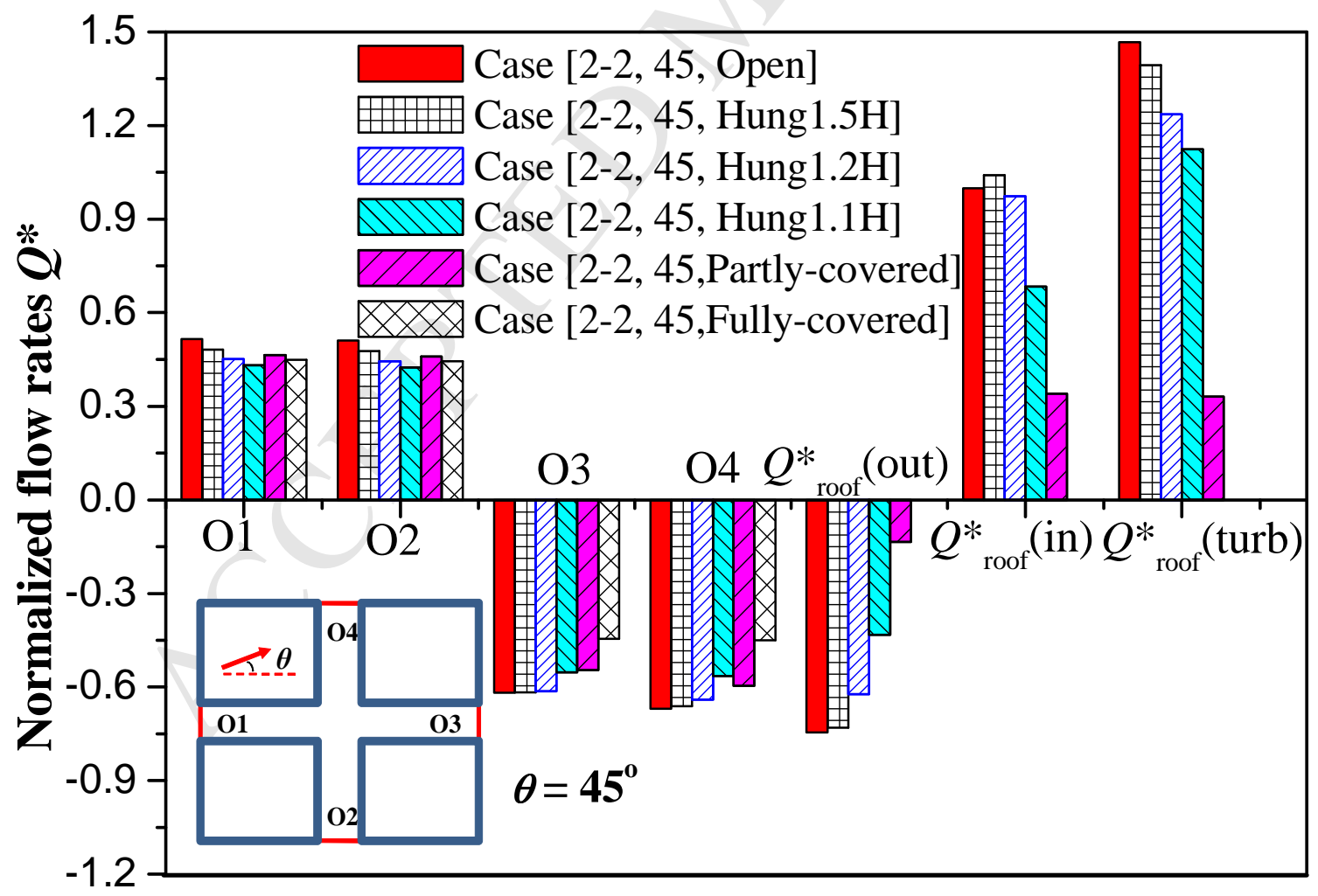

(d)

Fig.10 . Hang et al. 

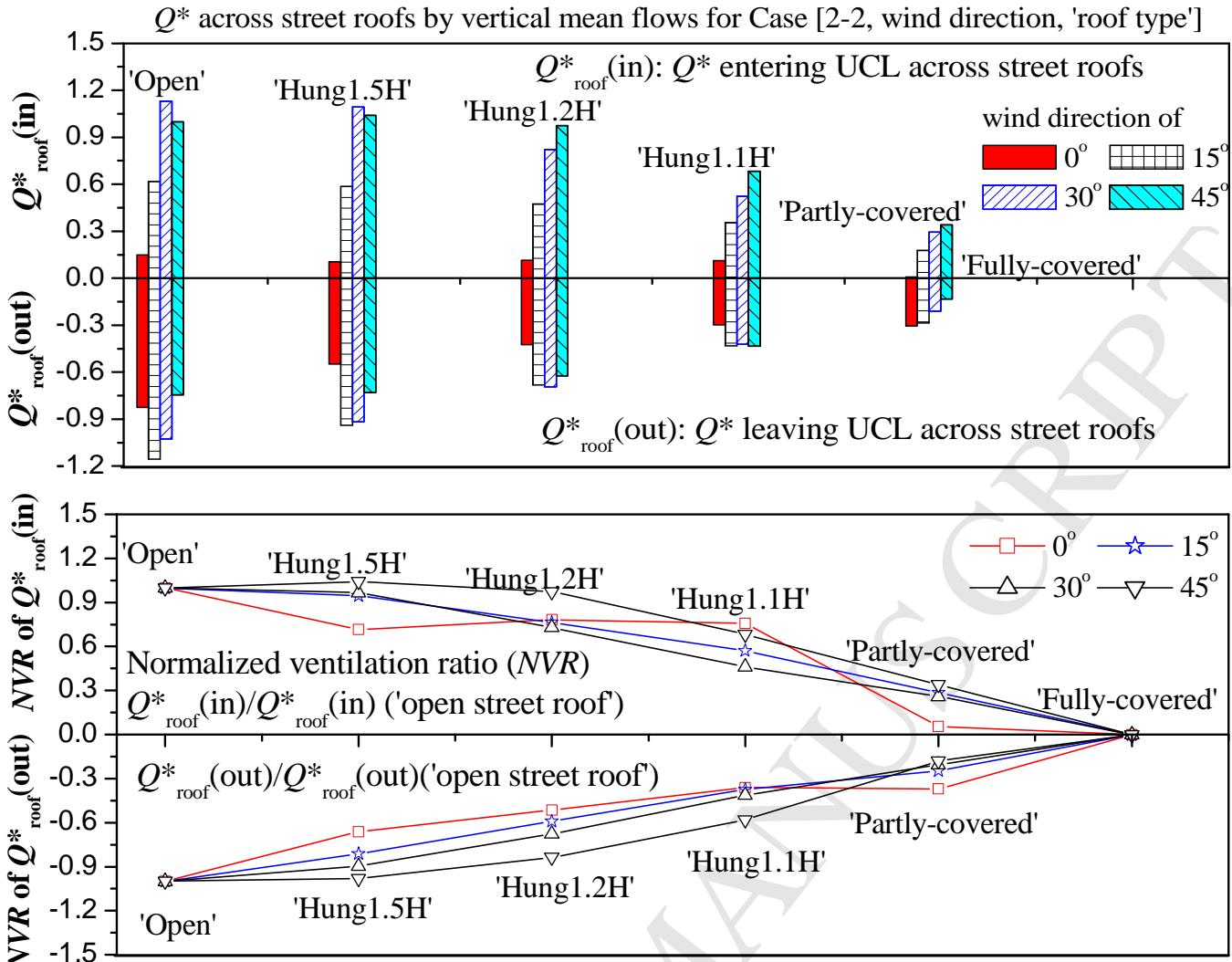

(a)
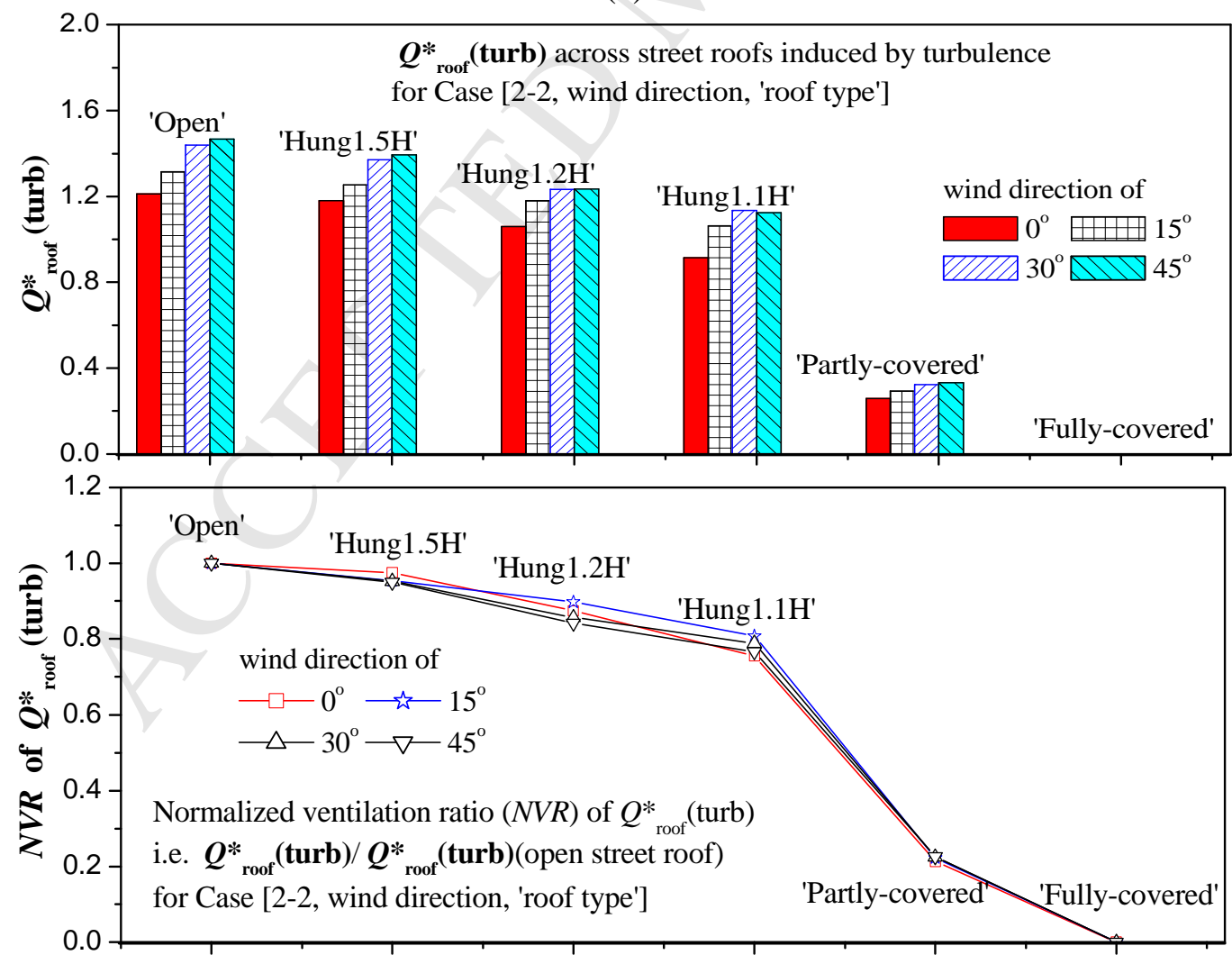

(b) 

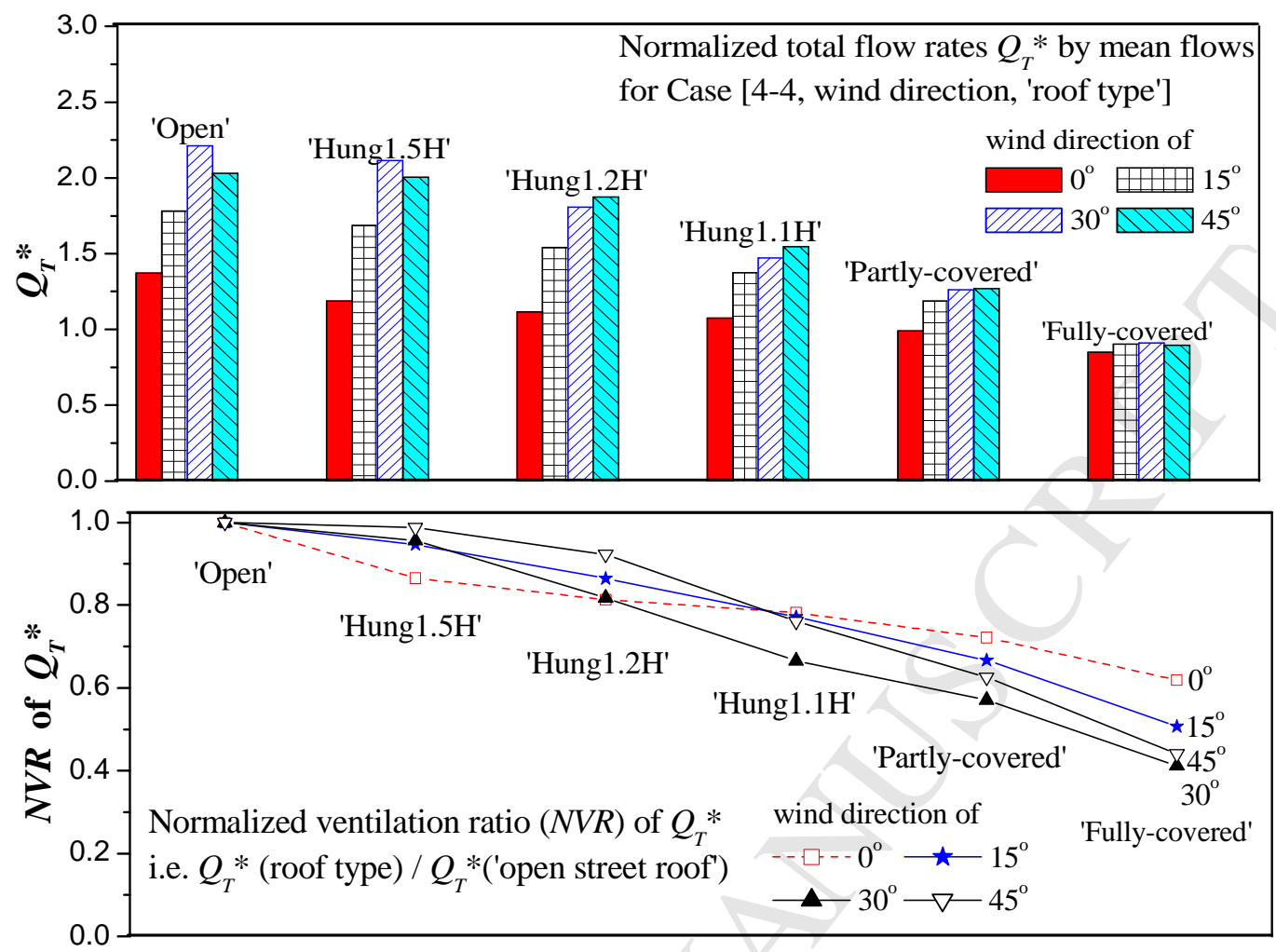

(c)
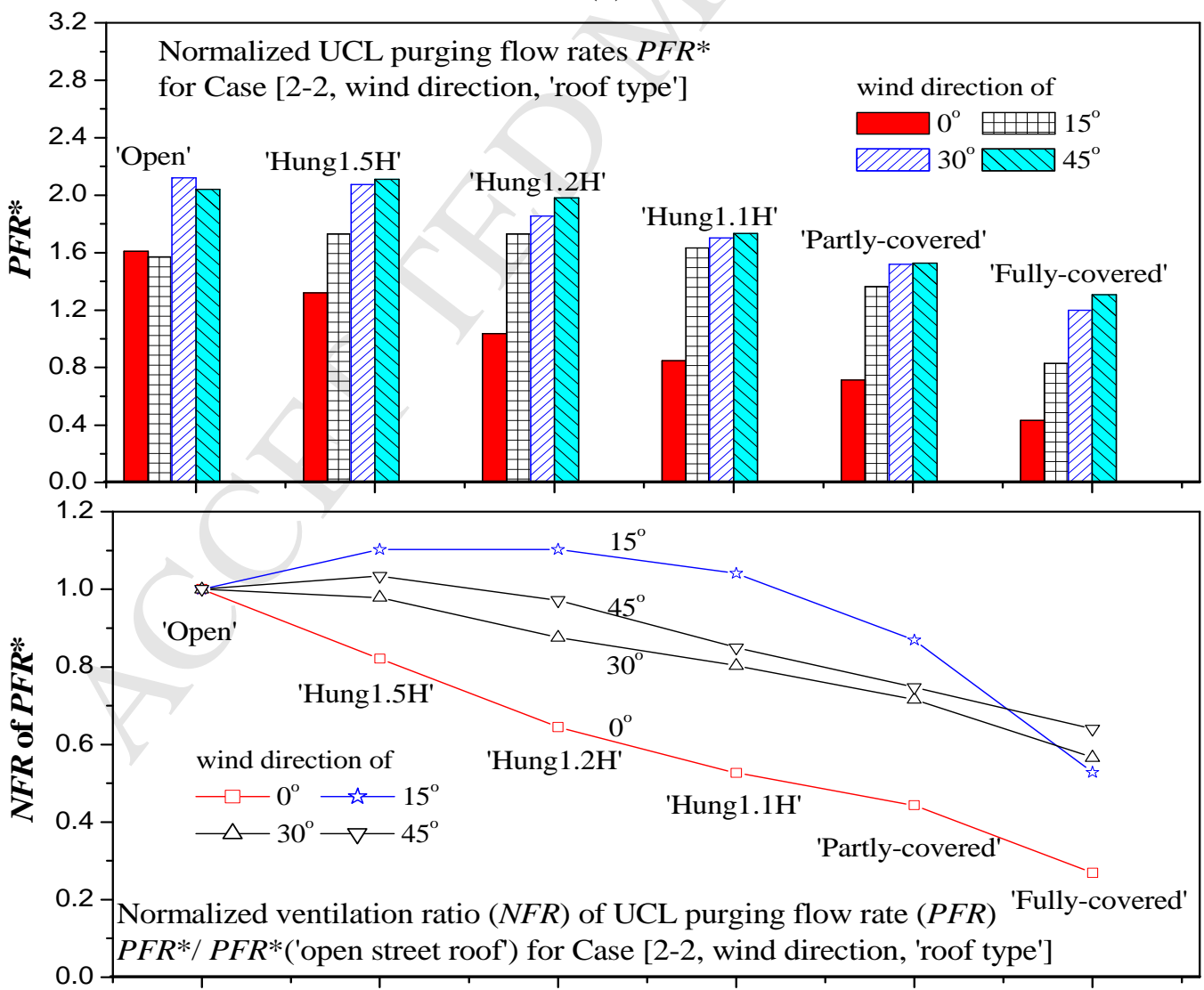

(d) 

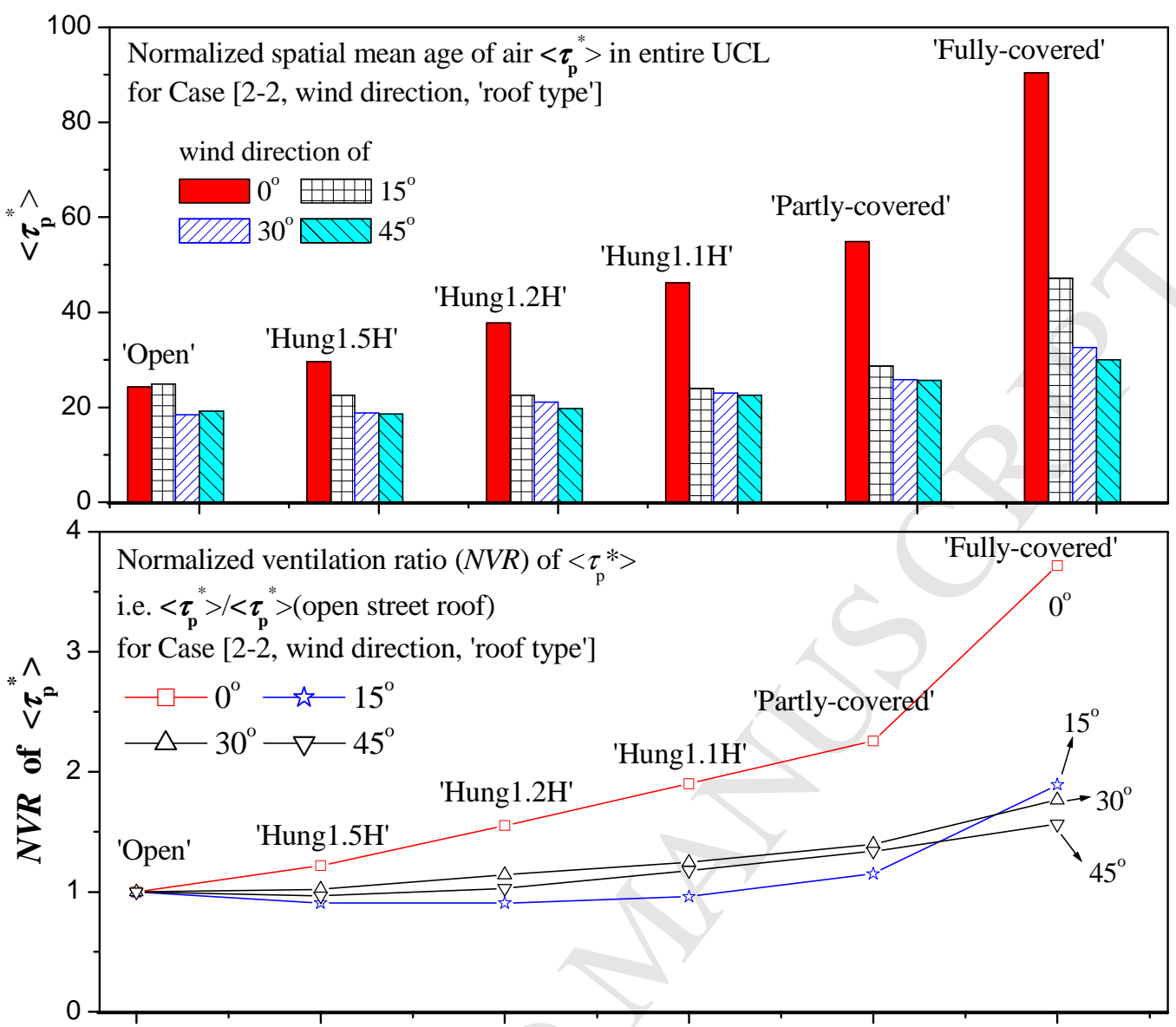

(e)

Fig. 11. Hang et al. 
Normalized age of air $\left(\tau_{p}^{*}=\tau_{p} \times 100 \mathrm{~s}\right)$ in $z=0.22 \mathrm{H}$

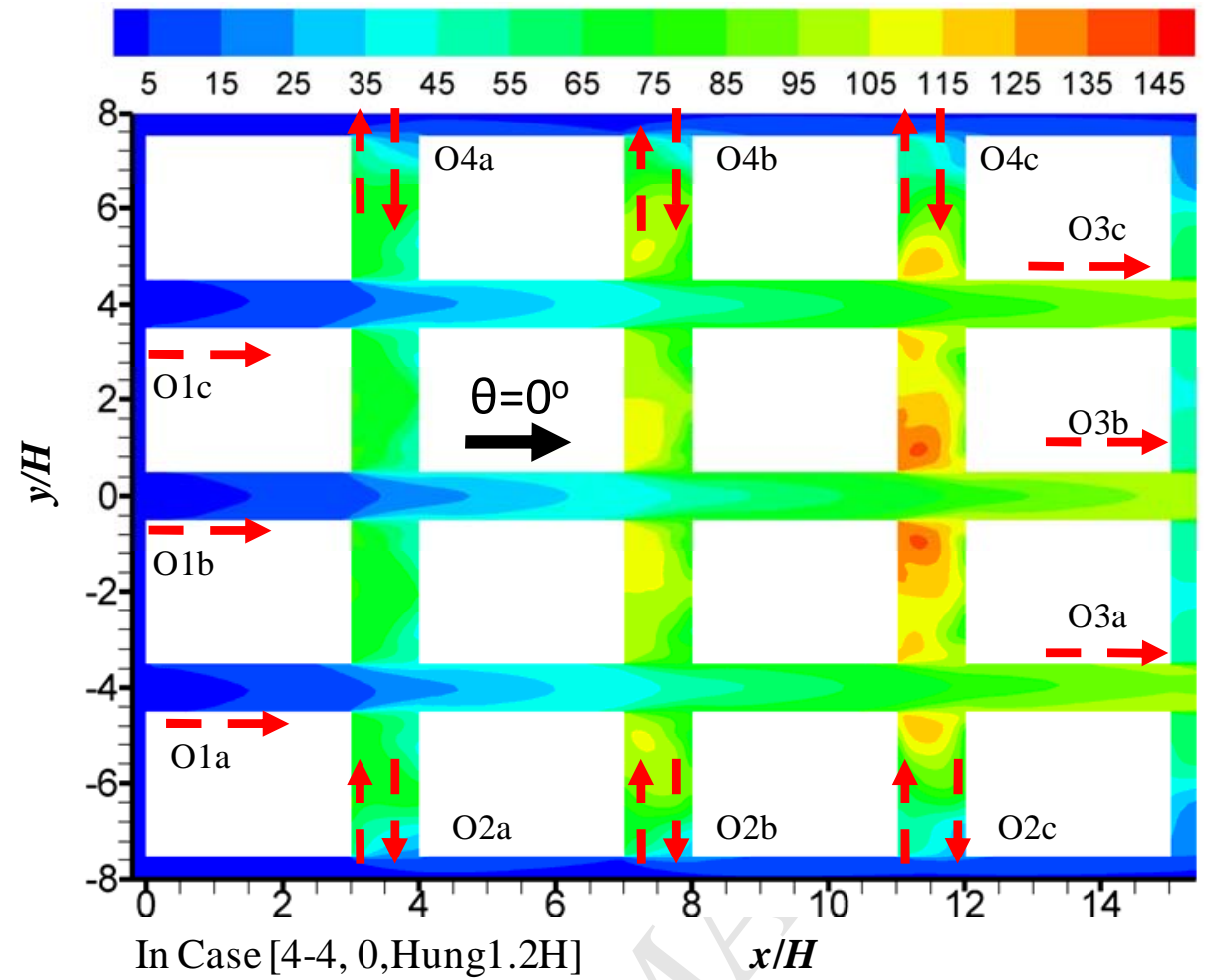

(a)

Normalized age of air $\left(\tau_{p}^{*}=\tau_{p} \times 100 \mathrm{~s}\right)$ in $z=0.22 \mathrm{H}$

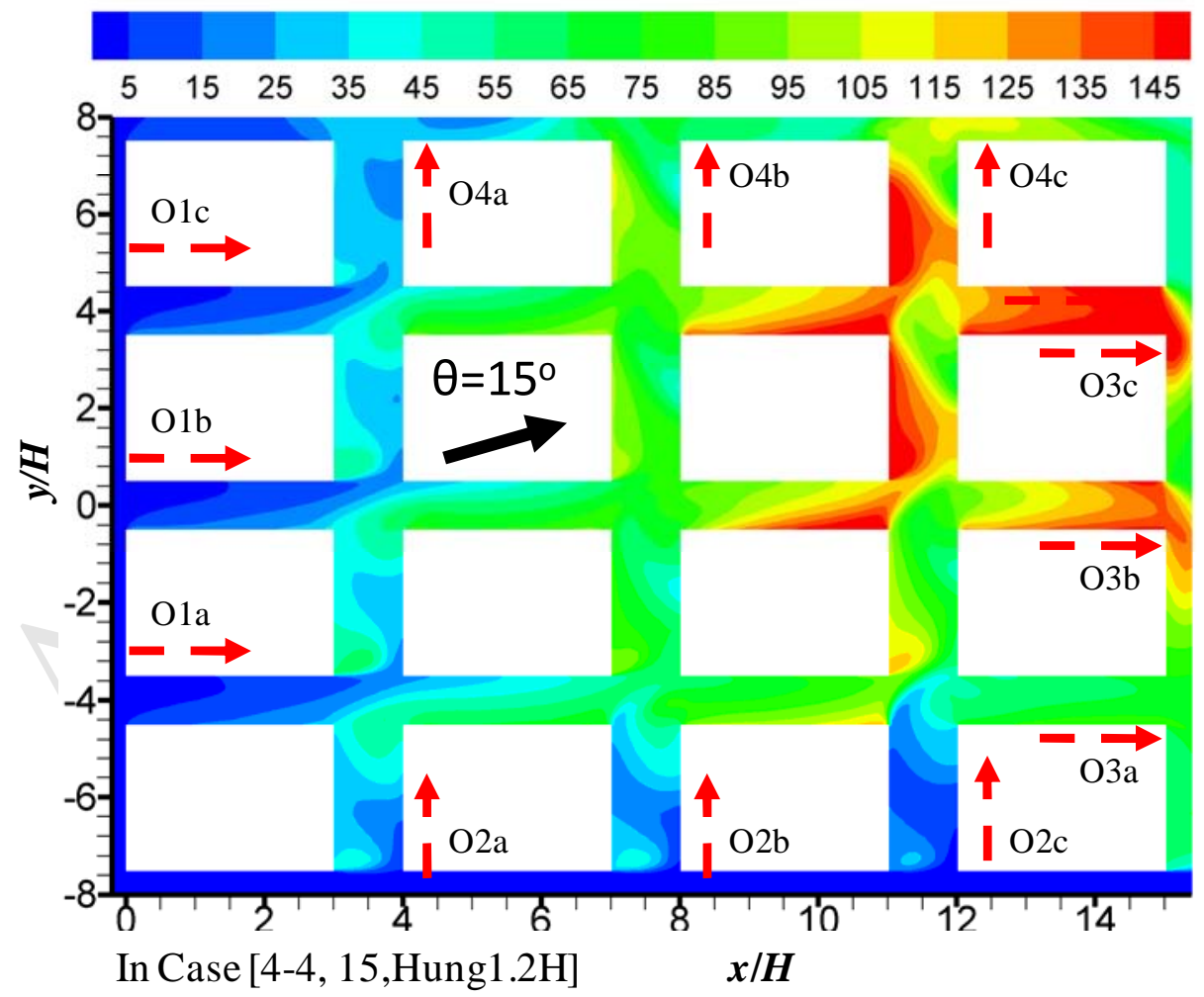

(b) 
Normalized age of air $\left(\tau_{p}^{*}=\tau_{p} \times 100 \mathrm{~s}\right)$ in $z=0.22 \mathrm{H}$

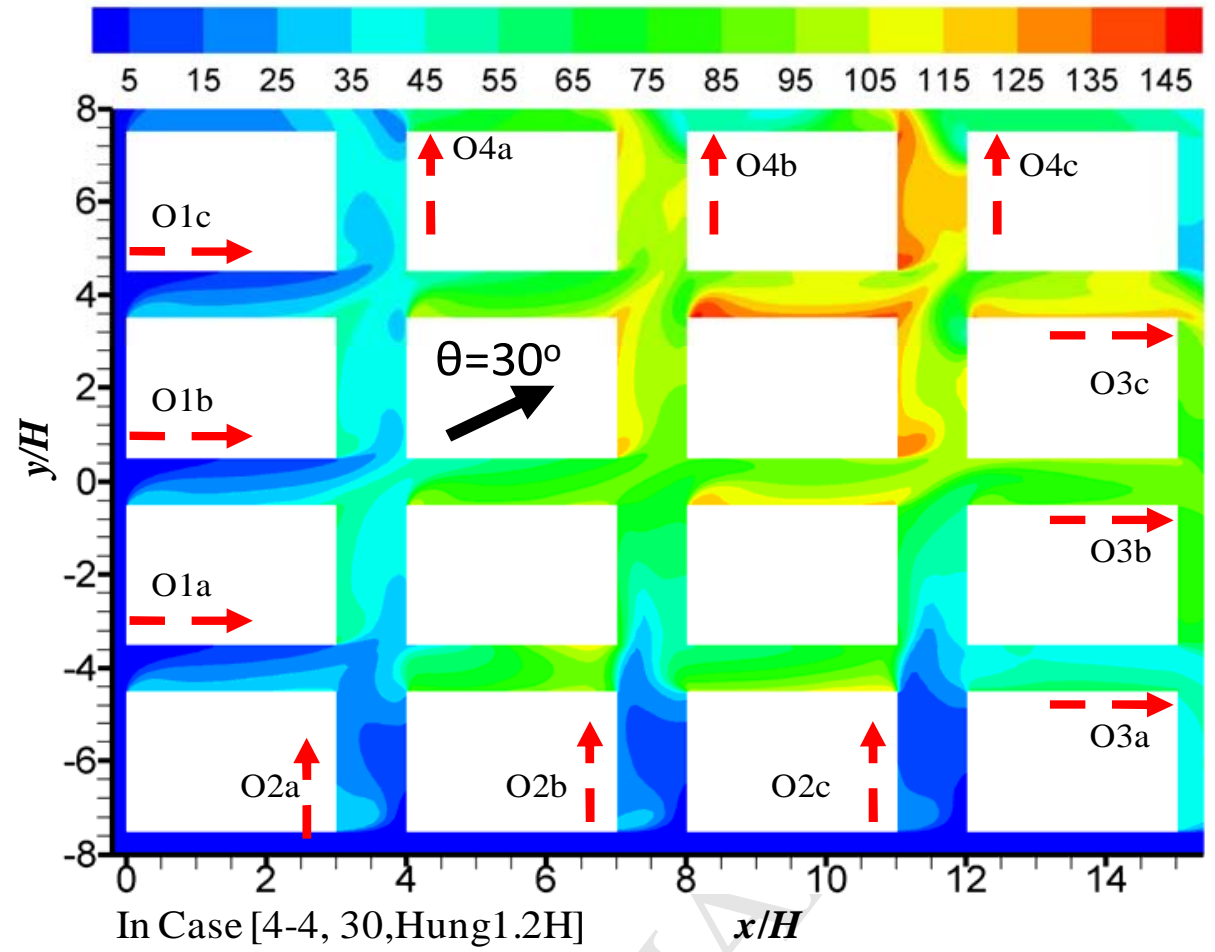

(c)

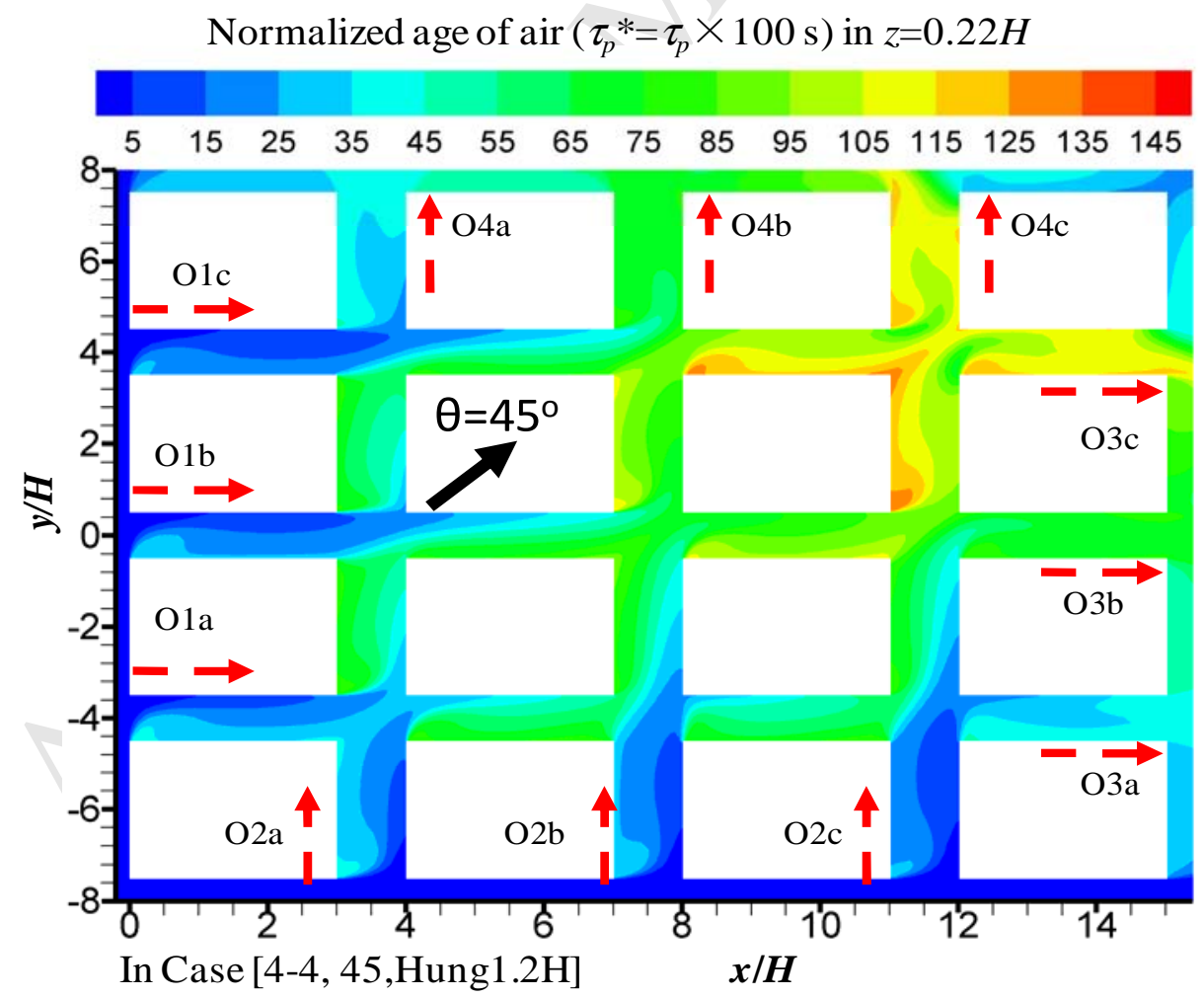

(d)

Fig. 12. Hang et al. 

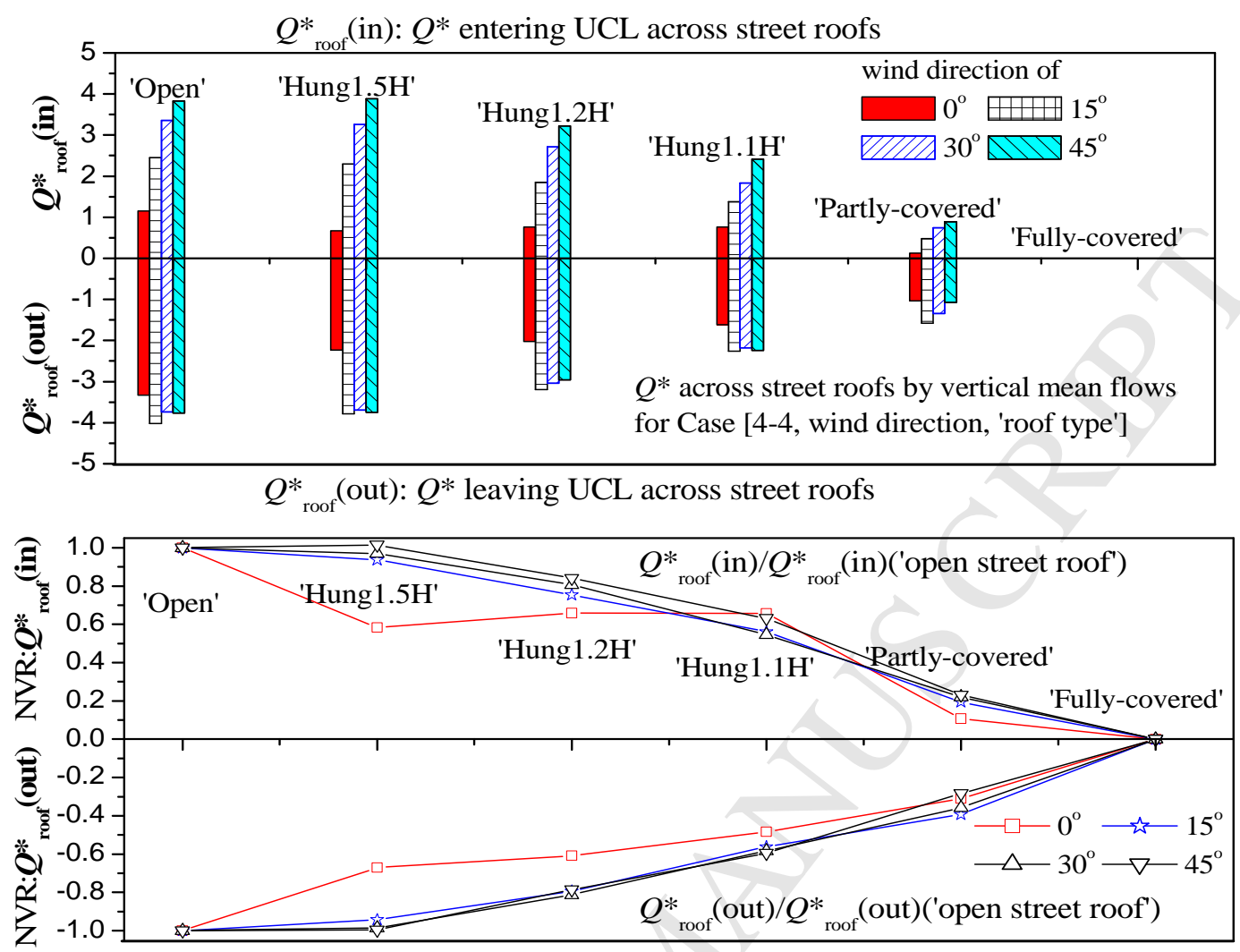

(a)

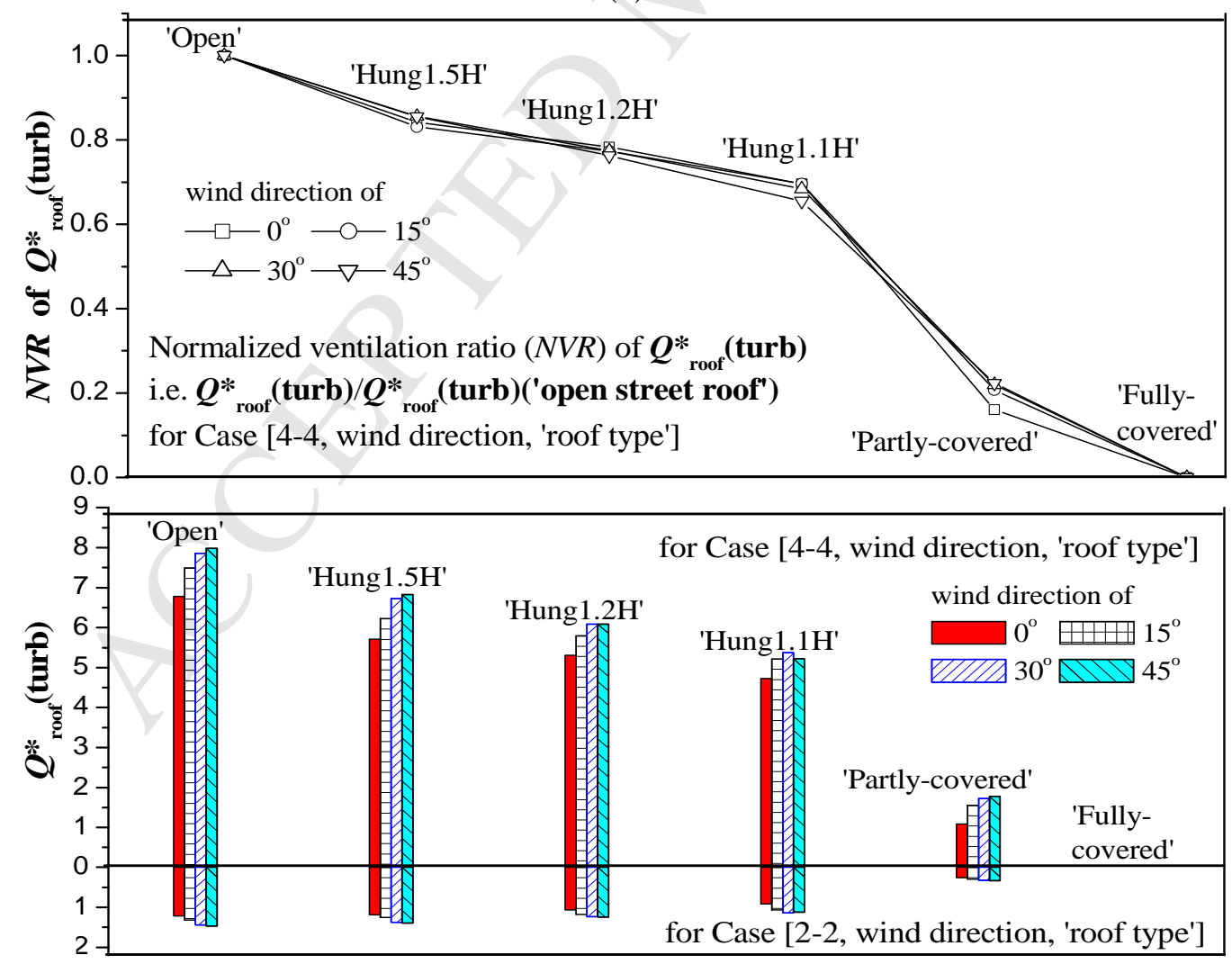

(b) 


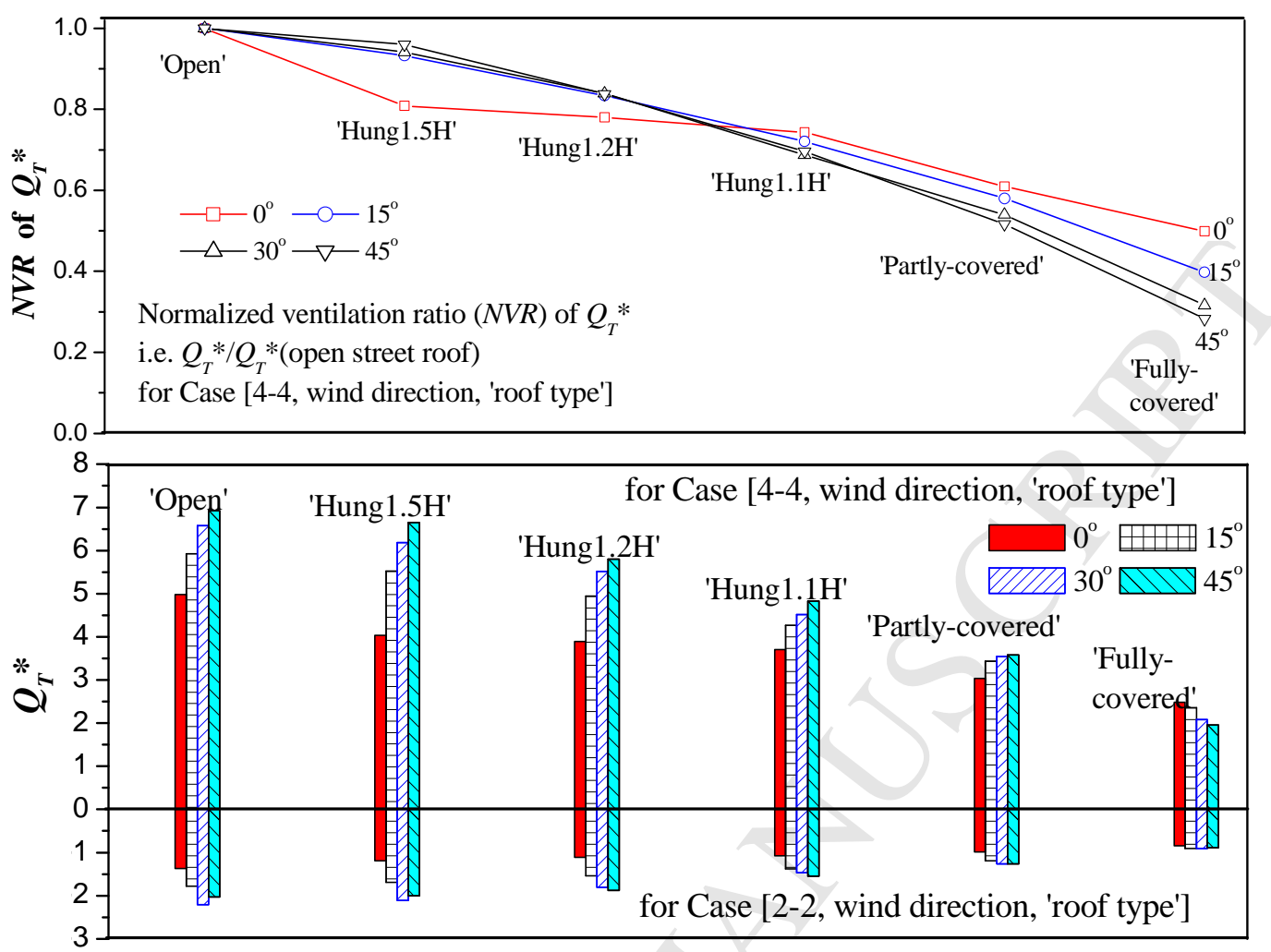

(c)
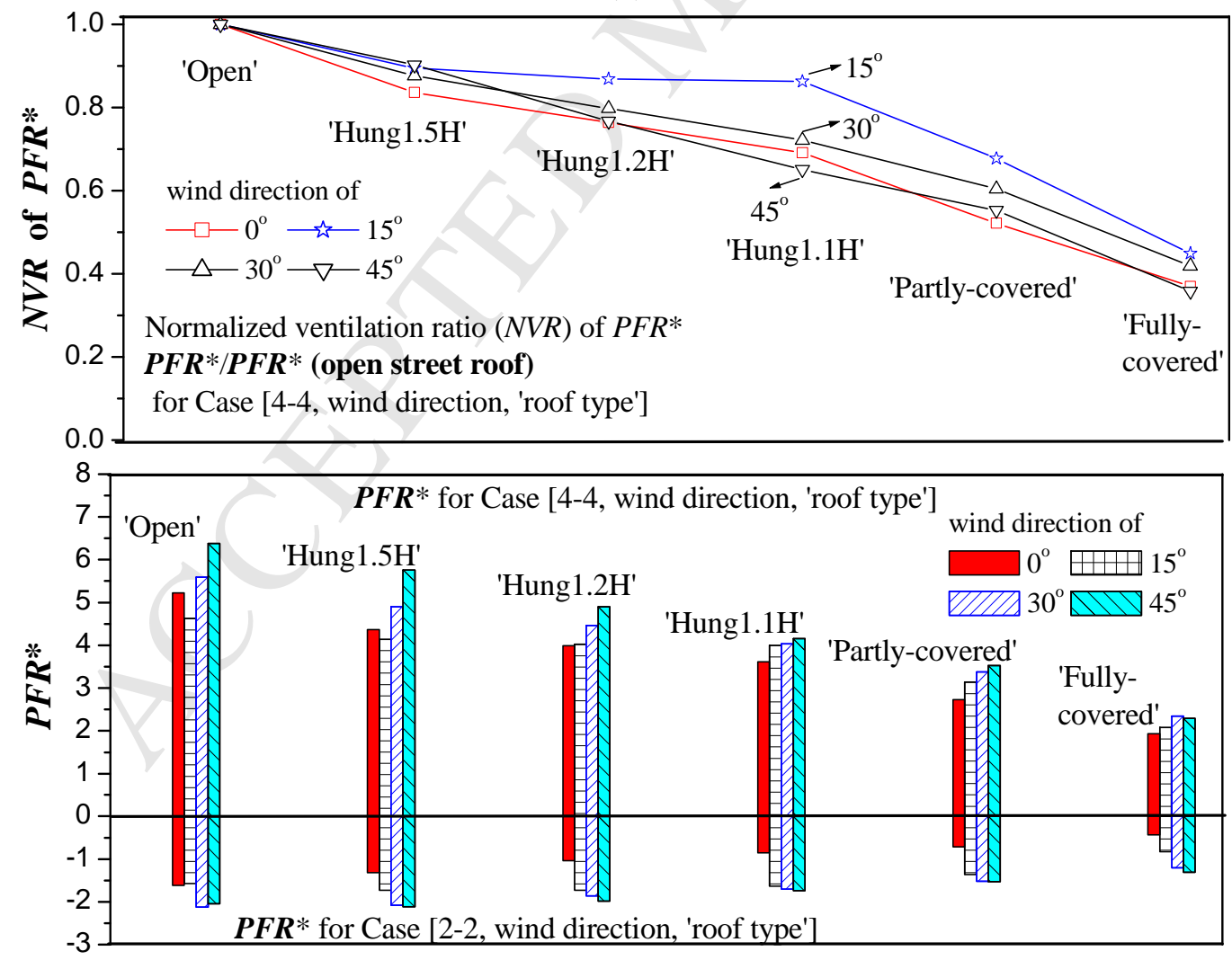

(d) 


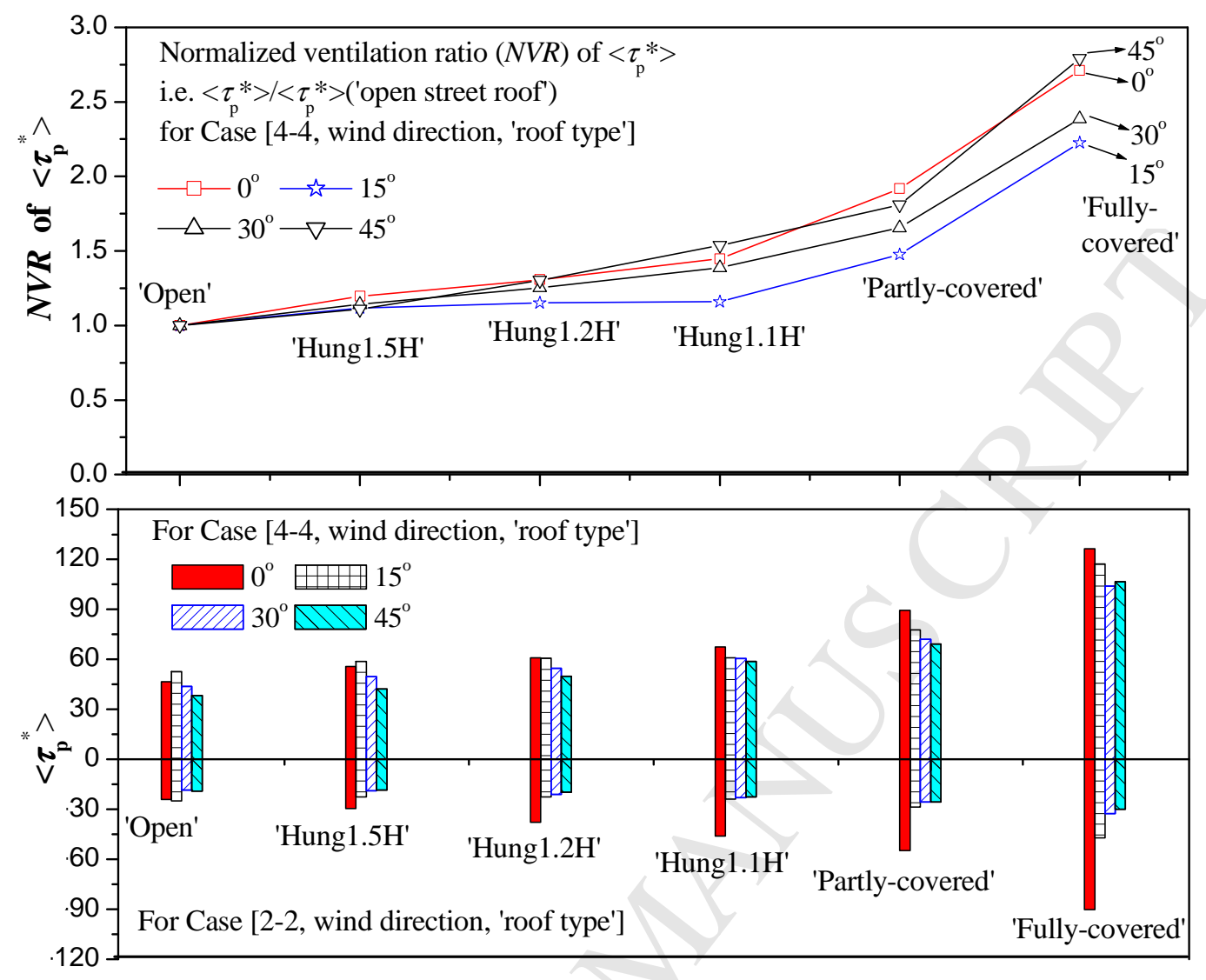

(e)

Fig. 13 Hang et al. 

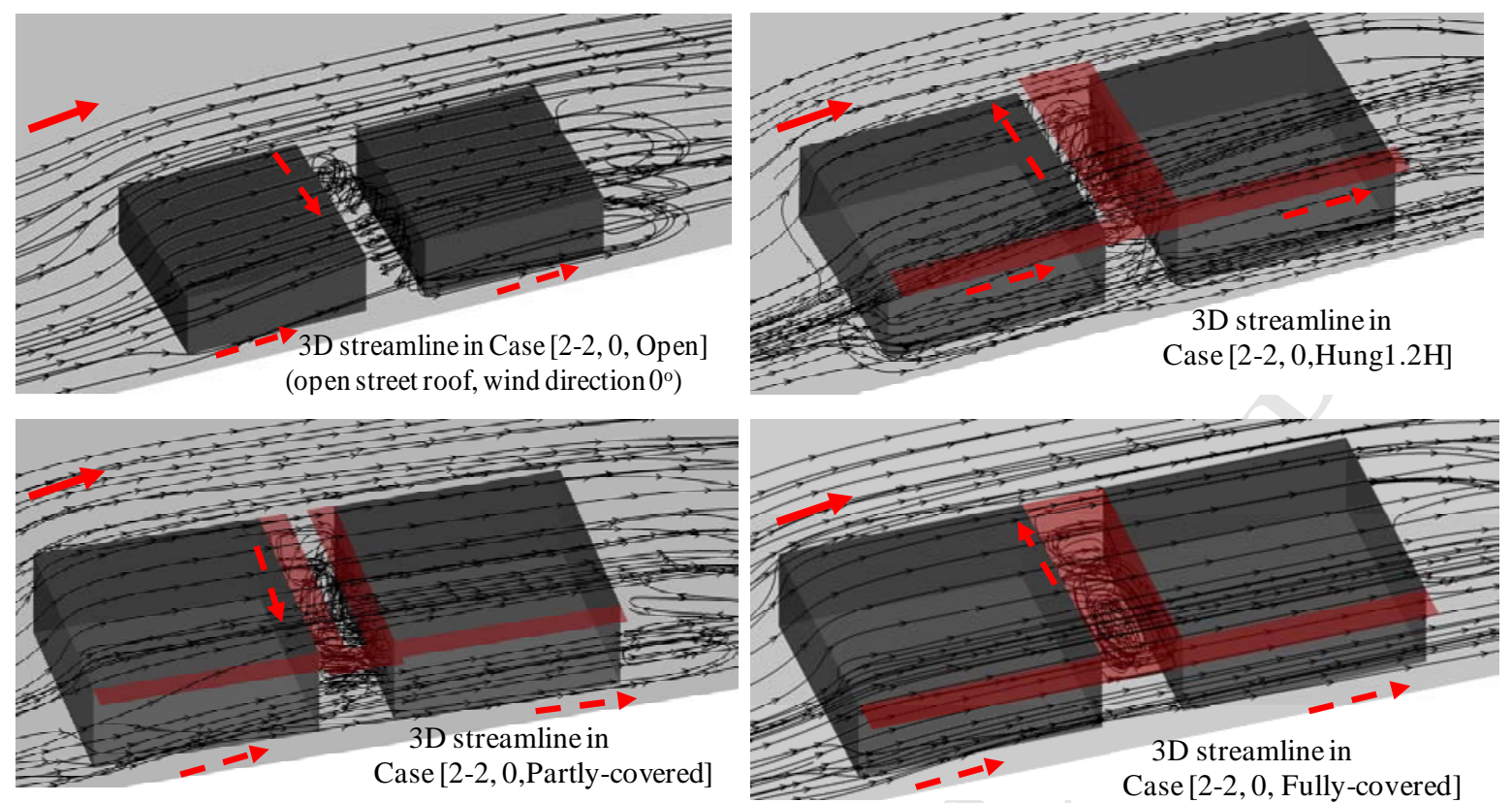

(a)

Normalized age of $\operatorname{air}\left(\tau_{p}^{*}=\tau_{p} \times 100 \mathrm{~s}\right)$ in $z=0.22 \mathrm{H}$
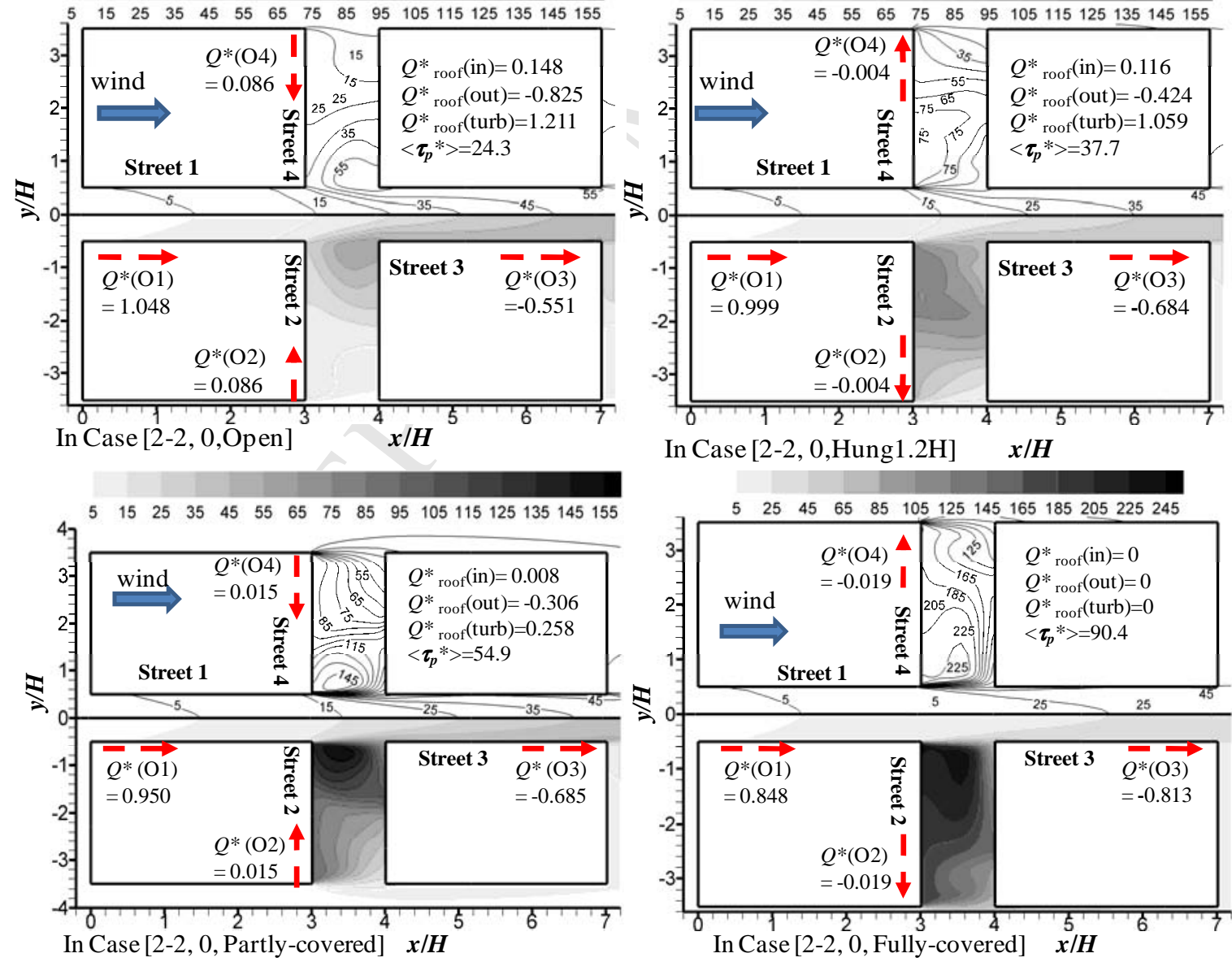

\section{In Case [2-2, 0, Hung1.2H] $\quad \boldsymbol{x} / \boldsymbol{H}$}

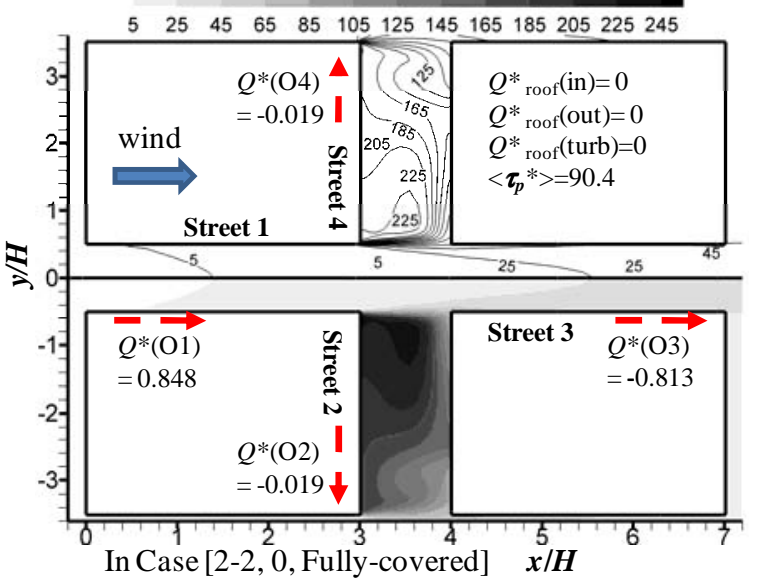

(b)

Fig. 6 Hang et al. 

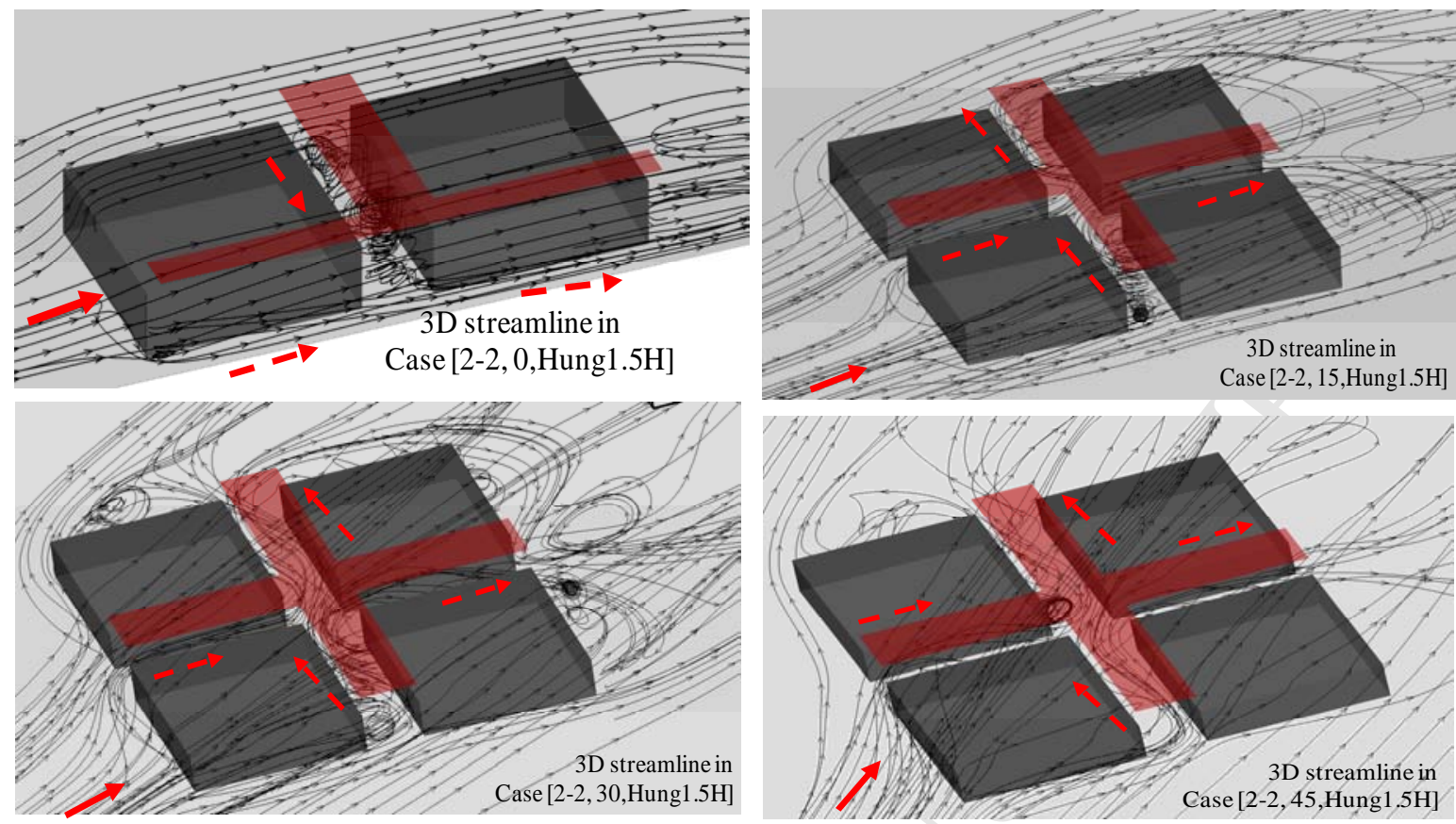

(a)

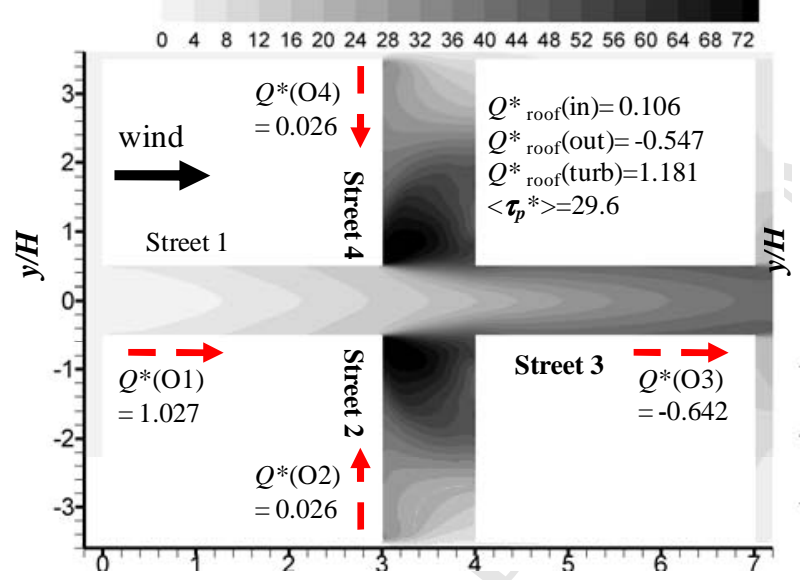

Normalized age of air $\left(\tau_{p}^{*}=\tau_{p} \times 100 \mathrm{~s}\right)$ in $z=0.22 \mathrm{H}$
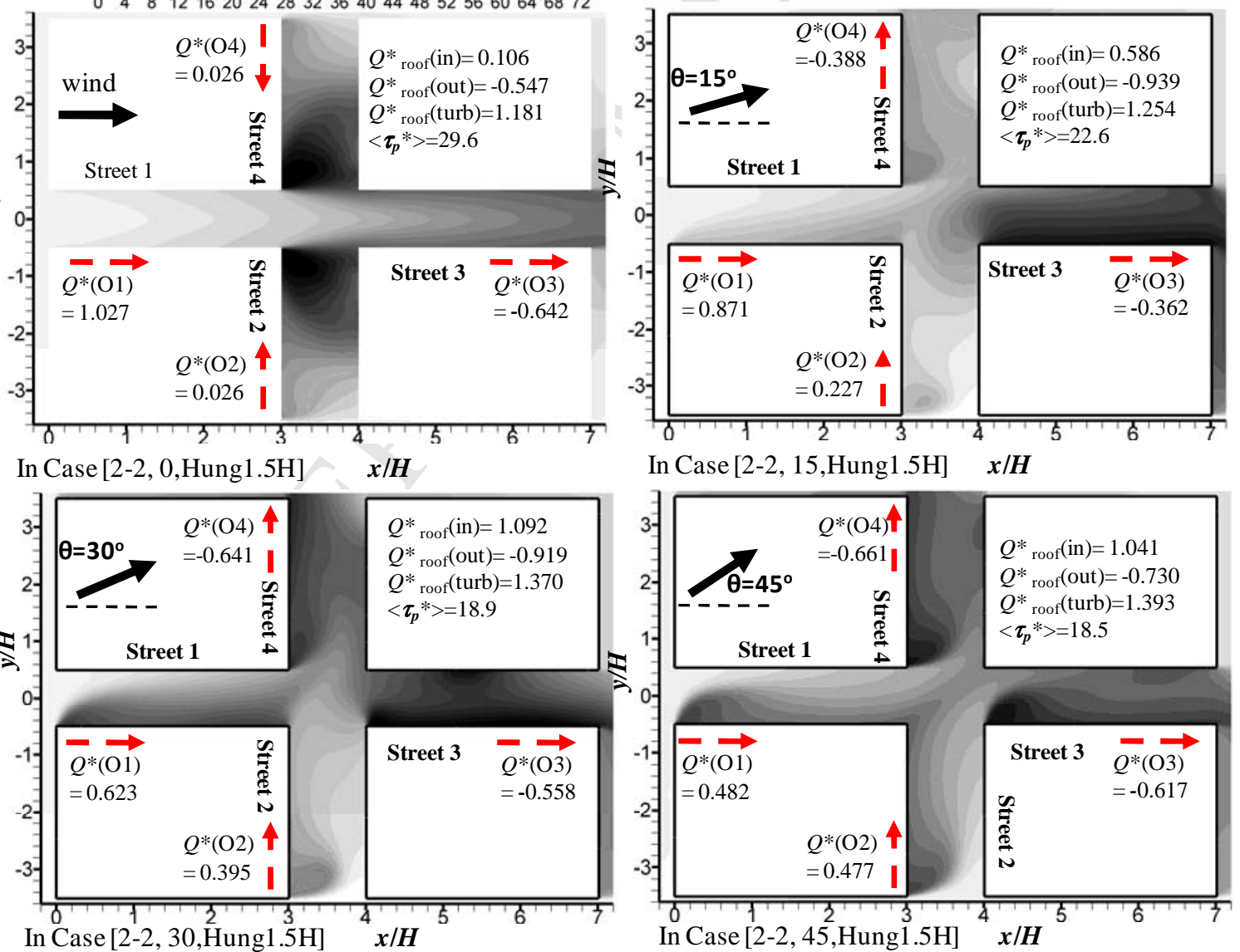

In Case [2-2, 15, Hung1.5H] $\boldsymbol{x} / \boldsymbol{H}$

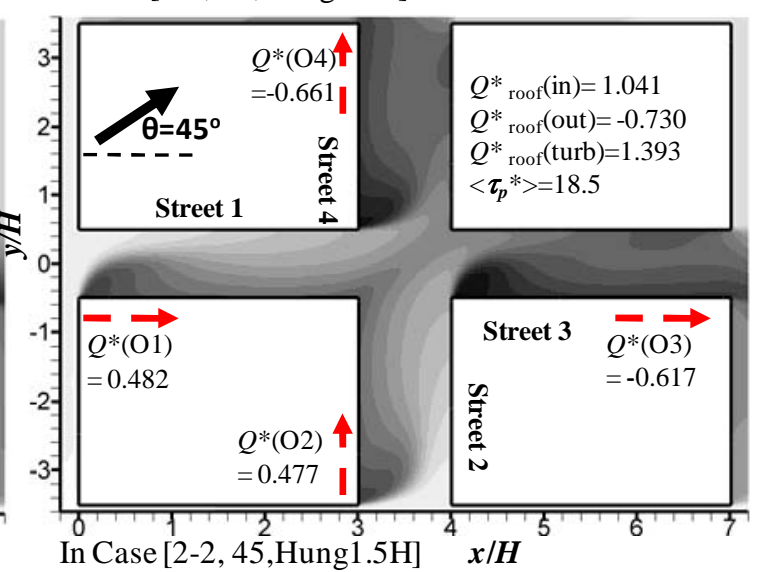

(b)

Fig. 7 Hang et al. 
Normalized age of $\operatorname{air}\left(\tau_{p}^{*}=\tau_{p} \times 100 \mathrm{~s}\right)$ in $z=0.22 \mathrm{H}$

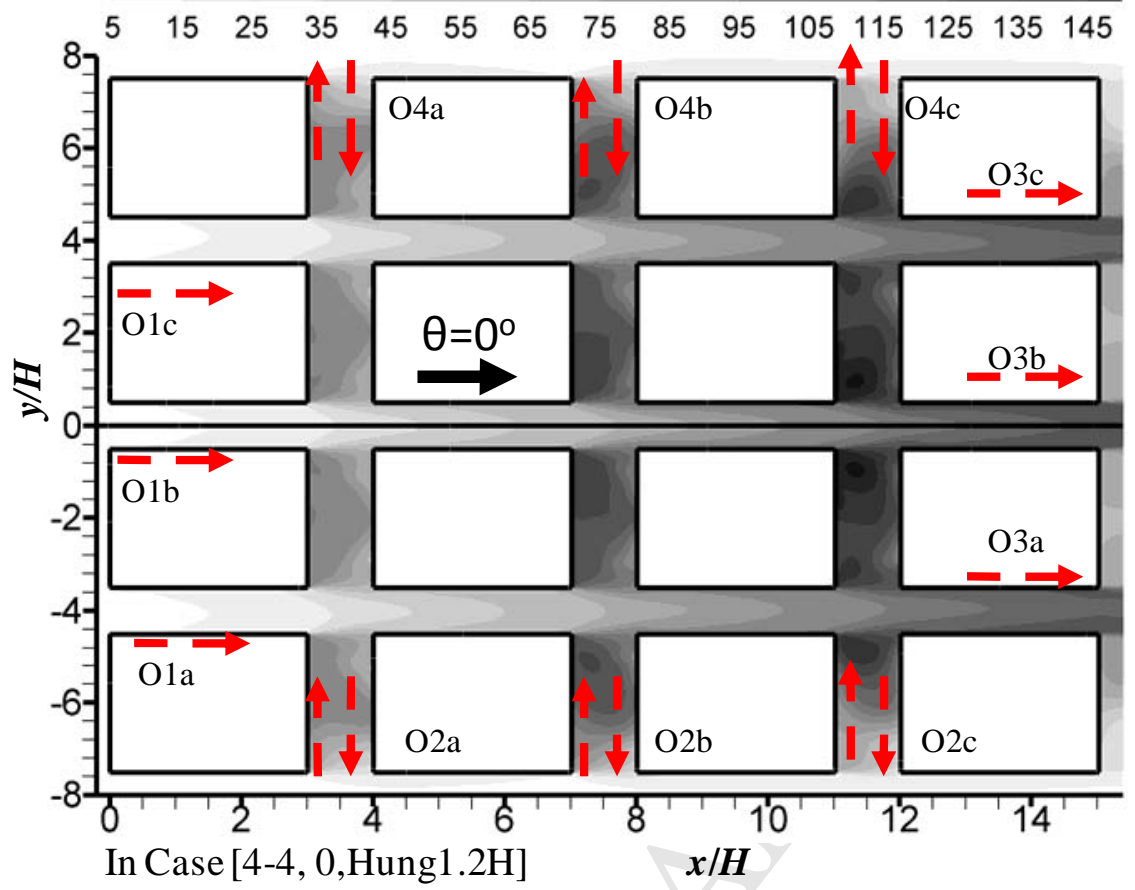

(a)

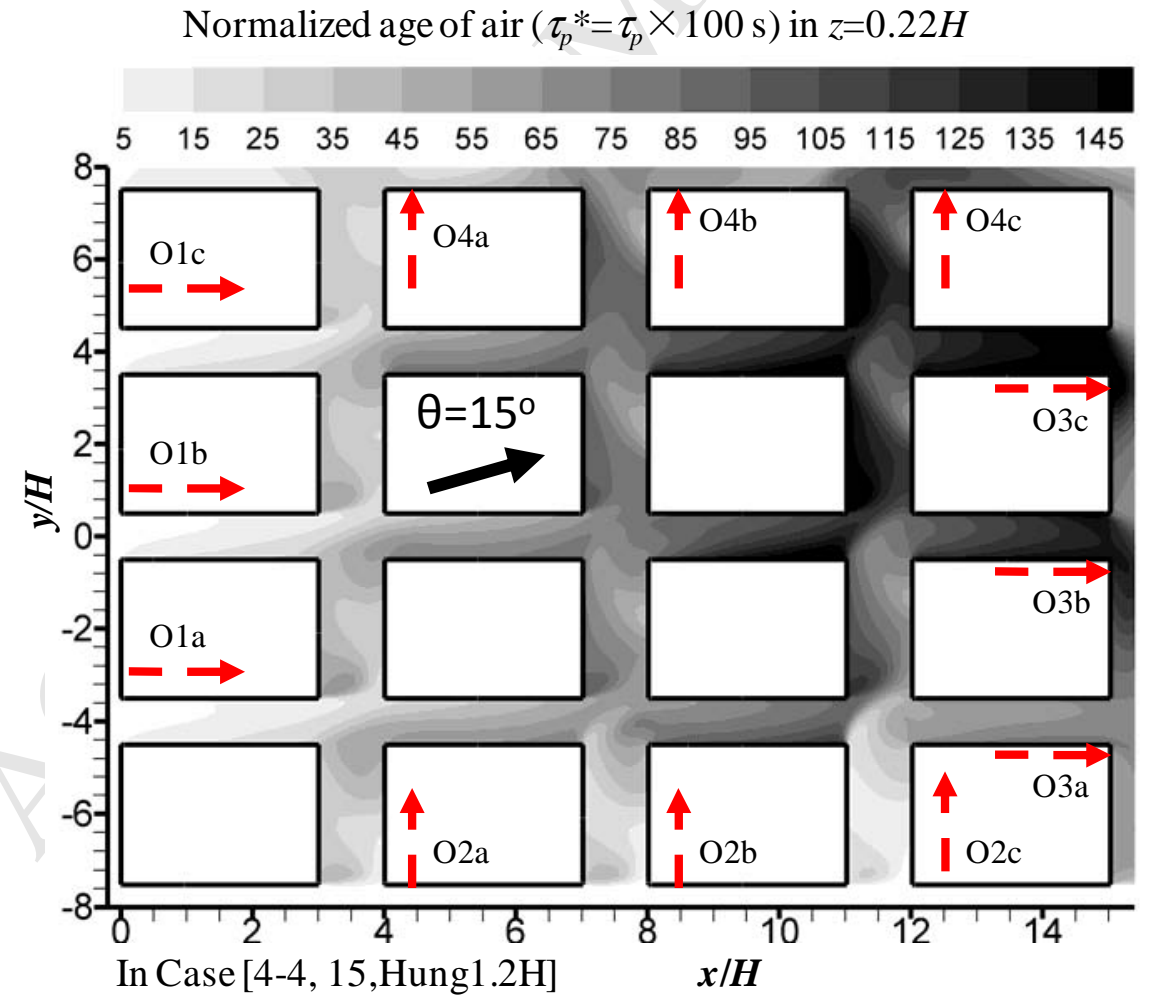

(b) 


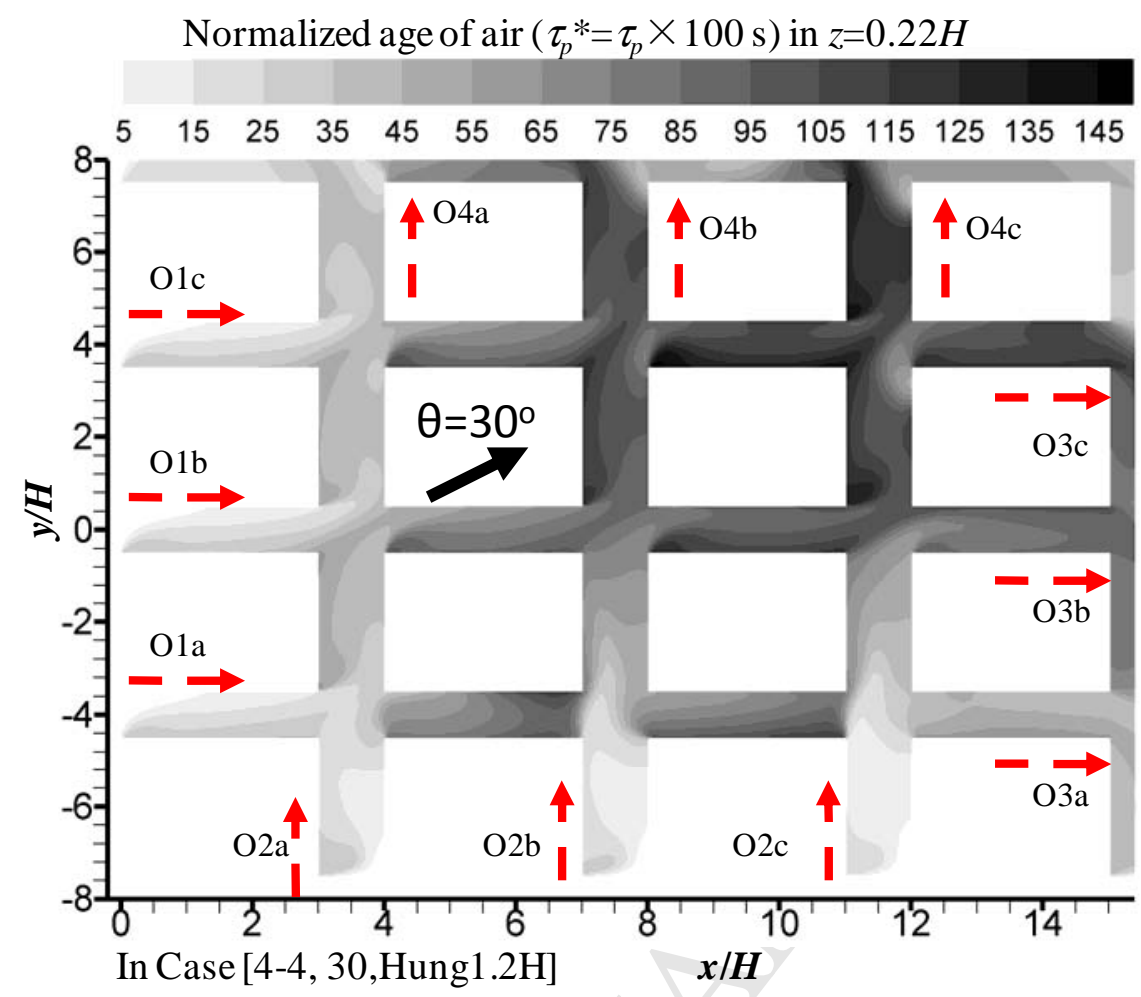

(c)

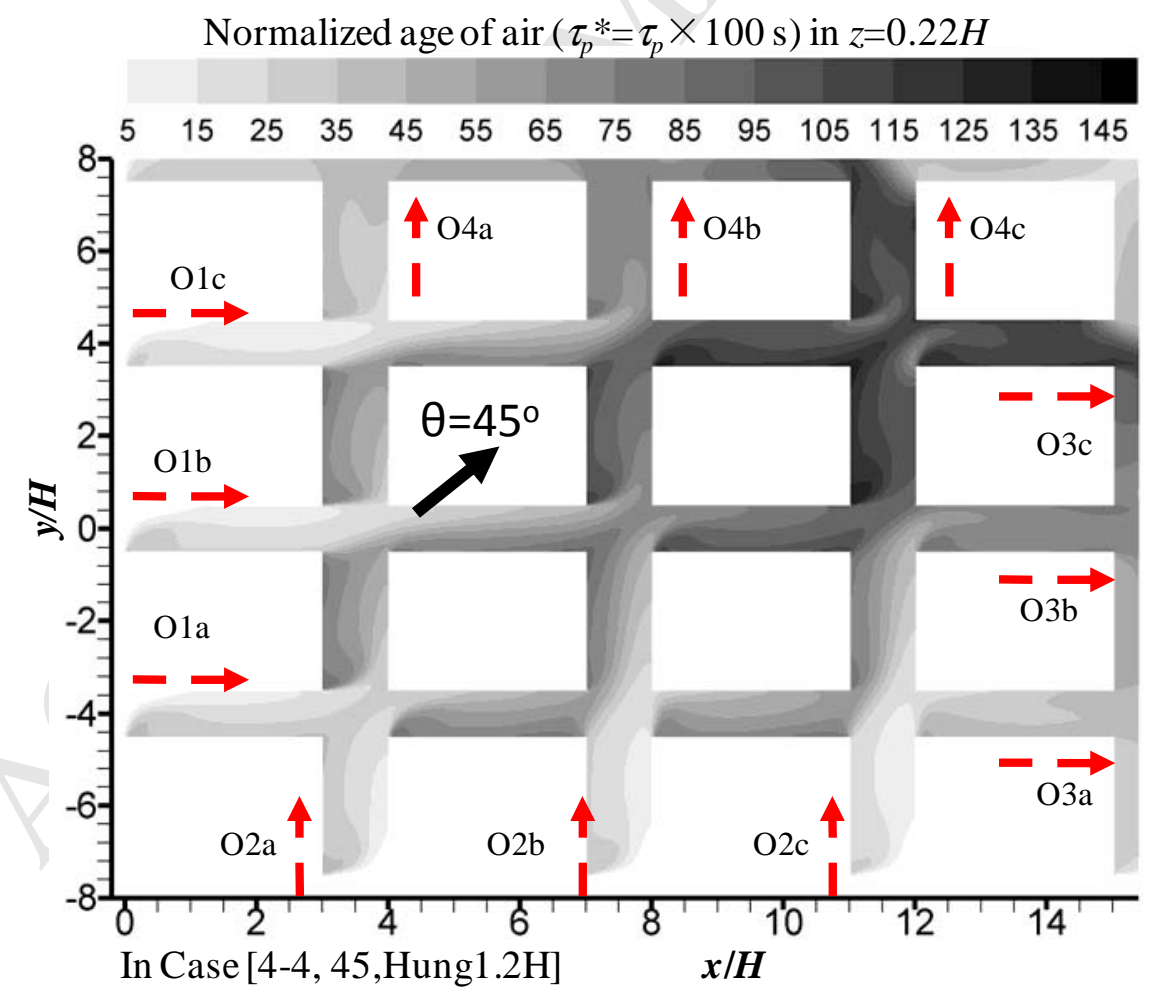

(d)

Fig. 10. Hang et al. 